\title{
The development, implementation and evaluation of a community health project
}

Citation for published version (APA):

van Assema, P. T. (1993). The development, implementation and evaluation of a community health project. [Doctoral Thesis, Maastricht University]. Datawyse / Universitaire Pers Maastricht. https://doi.org/10.26481/dis.19930101pa

Document status and date:

Published: 01/01/1993

DOI:

10.26481/dis.19930101pa

Document Version:

Publisher's PDF, also known as Version of record

\section{Please check the document version of this publication:}

- A submitted manuscript is the version of the article upon submission and before peer-review. There can be important differences between the submitted version and the official published version of record.

People interested in the research are advised to contact the author for the final version of the publication, or visit the DOI to the publisher's website.

- The final author version and the galley proof are versions of the publication after peer review.

- The final published version features the final layout of the paper including the volume, issue and page numbers.

Link to publication

\footnotetext{
General rights rights.

- You may freely distribute the URL identifying the publication in the public portal. please follow below link for the End User Agreement:

www.umlib.nl/taverne-license

Take down policy

If you believe that this document breaches copyright please contact us at:

repository@maastrichtuniversity.nl

providing details and we will investigate your claim.
}

Copyright and moral rights for the publications made accessible in the public portal are retained by the authors and/or other copyright owners and it is a condition of accessing publications that users recognise and abide by the legal requirements associated with these

- Users may download and print one copy of any publication from the public portal for the purpose of private study or research.

- You may not further distribute the material or use it for any profit-making activity or commercial gain

If the publication is distributed under the terms of Article $25 \mathrm{fa}$ of the Dutch Copyright Act, indicated by the "Taverne" license above, 

The development, implementation and evaluation of a community health project 


\section{Promotor:}

\section{Prof.dr. G.J. Kok}

\section{Co-promotores:}
Dr. M.P. Eriksen
Dr. H. de Vries

Beoordelingscommissie:
Prof.dr. F. ten Hoor (voorzitter)
Prof. L.W. Green (University of British Columbia, Vancouver, Canada)
Dr. E.J.J. de Leeuw
Dr. R.A. Knibbe
Dr.ir. N.G. Röling (Landbouwuniversiteit Wageningen)

The study described in this thesis and the publication of this thesis was financially supported by the Dutch Cancer Society. 


\section{Acknowledgements}

I would like to thank all people who contributed to the study that is described in this thesis: advisors (Gerjo Kok, Michael Eriksen, Hein de Vries), research assistants (Marcel Pieterse, Paul Geelen, Anneloes Ravelli, Ardi Quaedackers), other colleagues, and all the people in Bergeyk who contributed to the 'Healthy Bergeyk' project. Especially, I would like to express my gratitude to Mieke Steenbakkers and Diny Gabriëls-Stensen. Their unconditional devotion to the project was astounding.

Patricia van Assema

Maastricht 1993 



\section{Contents}

Chapter 1 Overview 11

Introduction 11

$\begin{array}{ll}\text { Cancer and behavior } & 13\end{array}$

$\begin{array}{ll}\text { Determinants of cancer-related risk behavior } & 14\end{array}$

Pilot study $\quad 16$

$\begin{array}{ll}\text { Survey } & 17\end{array}$

$\begin{array}{ll}\text { Implications for the intervention } & 18\end{array}$

Opinions and knowledge about the prevention possibilities $\begin{array}{ll}\text { of cancer } & 18\end{array}$

Implications for the intervention $\quad 19$

A questionnaire measuring fat: consumption 20

$\begin{array}{ll}\text { Validity and reproducibility } & 21\end{array}$

Intervention development and planning of the

implementation of the intervention $\quad 22$

Community organization principles $\quad 22$

Implications of the application of community

organization principles for the organization of

$\begin{array}{ll}\text { the project } & 29\end{array}$

Conceptual framework for the development of the intervention $\quad 30$

Intervention components $\quad 32$

Workbook 34

Health policy and health promotion $\quad 35$

Implementation of the intervention $\quad 37$

$\begin{array}{ll}\text { Bergeyk } & 37\end{array}$

Implementation $\quad 37$

Continuation of the project 41

Evaluation $\quad 41$

Effect evaluation $\quad 42$

Process evaluation $\quad 44$

General conclusions $\quad 46$

$\begin{array}{ll}\text { Methodological limitations } & 47\end{array}$

Implications for community projects in the Netherlands $\quad 48$ 
Chapter 2 The determinants of four cancer-related risk

behaviors

Introduction

Method

Instrument development

Data collection

Analyses

Results

Prevalence of risk behaviors, intentions and correlations between risk behaviors

Overall explained variance and the contribution of the determinants in explaining risk behavior

Attitude towards the risk behavior

Social influence

Self-efficacy

61

Differences between intenders and non-intenders

Discussion and implications for behavior change interventions

Smoking behavior

Alcohol consumption

Fat consumption

Solaria use

Final conclusions

Chapter 3 The reliability and validity of a Dutch questionnaire on fat consumption as a means to rank subjects according to individual fat intake

Introduction

Methods

Purpose, content and format of the short questionnaire

Reference instrument

Subjects and procedures

Statistical methods

Results

Discussion 
Chapter 4 Results of the Dutch community project

'Healthy Bergeyk'

Introduction

Theoretical background of the project, intervention

components, and organization of the project

Method

Design and sample

Questionnaire and measures

Analysis

Results

Behavioral results of the project

Project effects and exposure to the project

Determinants of program exposure

Discussion and conclusions

Chapter 5 The process evaluation of a Dutch community health project

Introduction

Theoretical background of the project, intervention components, and organization of the project

Method

Data collection

Data analysis

104

Results

Design level: What actually occurred at the design level of the project?

Design level: What was the opinion of the project group members about the project?

Output level: Which health activities were organized, how often, how many people participated, and what were the characteristics of the participants?

Output level: What was the level of satisfaction of the participants and the leaders with the activities, and what were the effects of the activities? 
How many inhabitants of the community were familiar with the project, and what was their opinion about the project?

Discussion and conclusions 112

Implications for the process evaluation 113

Implications for the project

References

Summary

Samenvatting

Annex 1

Curriculum vitae 


\section{Chapter 1}

\section{Overview}

\section{Introduction}

The incidence of cancer in the Netherlands is high (Coebergh, 1989): Dutch breast and lung cancer rates are, for instance, among the highest in the world (U.S. Department of Heaith and Human Services, 1985). Cancer is the second most frequent cause of death in the Netherlands and the leading cause of death in women between 30-60 years (Coebergh, 1989). The incidence of cancer will increase substantially in the next few decades, mainly due to changes in the size and age structure of the Dutch population (Scenario Commission Cancer, 1987). The consequences of cancer are serious for individuals and their social environment, and with respect to both mortality (about 35,000 a year) and morbidity (severely reduced quality of life, industrial disability, emotional problems, etc.). Costs to society are high as well, taking account of health care costs, sickness benefits, industrial disability benefits, etc. (Koopmanschap et al., 1991; Schrameijer \& Brunenberg, 1992).

Primary prevention of cancer, i.e. prevention of the onset of the disease, has become an important goal of Dutch health policy (Tweede Kamer, 1986; Ministerie van Welzijn, Volksgezondheid en Cultuur, 1989a, 1989b). In the last few decades it has become clear that primary prevention of cancer is possible by reducing risk behavior in the general population. Approximately $80 \%$ of all cancer deaths are thought to be related to life-style factors (Doll \& Peto, 1981; Doll, 1989).

This thesis describes the development, implementation and evaluation of a population-based cancer prevention intervention. The goal of the intervention was a reduction in the prevalence of four types of cancer-related risk behavior in the adult population: smoking, high fat consumption, excessive alcohol consumption and solarium use.

The development of an intervention that can promote behavioral changes requires a systematic approach, including a careful study of the health problem, 
the behaviors related to this health problem and the determinants of these risk behaviors, and, subsequently, the development, implementation and evaluation of the intervention (Green et: al., 1980; Kok \& De Vries, 1989). In the first phase of the research project presented in this thesis, a survey was conducted among a random sample of the Dutch population to obtain an overview of the opinions and knowledge of the population on cancer prevention and to assess the determinants of the four cancer-related risk behaviors. The four risk behaviors were selected on the basis of current knowledge about the relationship between cancer and behavior. The results of the survey yielded points of impact for the second phase of the research project, which involved the development of a community intervention. In the third phase of the research project the intervention was implemented in a small Dutch municipality and evaluated. In the effect evaluation the experimental community was compared with a control community on three occasions with respect to changes in risk behavior. Process evaluation was conducted to assess whether the intervention was implemented as planned. A separate study investigated the relative validity and reproducibility of a 25-item questionnaire designed to rank individuals according to dietary intake of fat. This instrument was specifically developed for measuring fat intake in the survey and in the effect evaluation of the community project.

Chapter 2 of this thesis reports the research into the determinants of the four cancer-related risk behaviors. In chapter 3 the questionnaire on fat consumption is presented and its relative validity regarding a 7-day diet record and its reproducibility are discussed. The results of the effect evaluation of the community project are presented in chapter 4 . Chapter 5 reports the design and results of the process evaluation of the project. This first chapter provides an overview of the entire research project. This introduction to the thesis is followed by a summary of the present knowledge concerning the relationship between cancer and individual risk behavior. Subsequently, a broad outline of the different phases of the research project is given and the main results are discussed. Finally, general conclusions of the research conducted are formulated and some methodological aspects and the implications of the project for community projects in the Netherlands are discussed. 


\section{Cancer and behavior}

Individual risk behaviors that are common among the general population, i.e. dietary habits, smoking, alcohol consumption and exposure to UV radiation, are thought to be responsible for the greater part of all cancer deaths (Doll \& Peto, 1981; Peto, 1985; Doll, 1989).

Dietary habits are thought to account for approximately $35 \%$ of all cancer deaths'. The strongest epidemiological evidence of the assumed relation between diet and cancer is the protective effect of a high consumption of (fresh) fruit and vegetables on cancers at different locations, especially cancers of the respiratory and digestive tracts (Block et al., 1992). Furthermore, there is suggestive evidence that a high fat intake, and concurrent high energy intake and high body weight, increases the risk of certain cancers, such as breast cancer and colon cancer (Dutch Nutrition Council, 1986a, 1991). High (satured) fat consumption is also related to coronary heart disease (Dutch Nutrition Council, 1982, 1989). In the Netherlands, the Dutch Nutrition Council has formulated dietary recommendations for cancer prevention (Dutch Nutrition Council, 1986a). These are in accordance with the general Dutch dietary recommendations for a healthy diet (Dutch Nutrition Council, 1986b). The Dutch Nutrition Council has given first priority to reduction of fat intake (Dutch Nutrition Council, 1991), as most health benefits are expected from this dietary recommendation. The Dutch National Food Consumption Survey 1987/1988 has shown that mean fat intake is as high as 40 per cent of total energy intake. More than $80 \%$ of the Dutch population eat too much fat (Hulshof \& Van Staveren, 1991; Hulshof, 1993).

Smoking is another very important risk behavior of cancer. Smoking is estimated to be responsible for $30 \%$ of all cancer deaths and is especially related to cancers of the respiratory system (Doll \& Peto, 1981). There is strong epidemiological evidence for the relation between smoking and cancer (U.S. Department of Health and Human Services, 1982). Smoking is also strongly related to the incidence of, for example, coronary diseases and several respiratory diseases (U.S. Department of Health and Human Services, 1983. 1984).

1 The estimated percentages of cancer deaths caused by the different risk behaviors are described by Doll and Peto for the U.S. and the U.K. However, they seem to relate more or less to all western countries, although the percentages may vary among the different countries due to differences in the prevalence of the various carcinogenic agents. 
Alcohol is causally related to cancers of the oral cavity, pharynx, larynx, oesophagus, liver, and maybe also to breast cancer (International Agency for Research on Cancer, 1988; Duffy \& Sharples, 1992). In some European countries alcohol combines with smoking (and possibly with some aspects of bad nutrition) to cause an additional $10 \%$ of all cancer deaths (Doll, 1989). However, the risk for a non-smoker who drinks alcohol moderately is very small and the consumption of two or three glasses of alcohol a day seems to be associated with a reduced risk for coronary thrombosis (Colsher \& Wallace, 1989; Doll, 1989). Extensive alcohol use is also related to, for example, social problems and travel accidents (Doll, 1989).

A fourth risk behavior is exposure of the (untanned) skin to extensive UV radiation. Exposure to this carcinogenic agent is responsible for just a small percentage of all cancer deaths, but a much higher percentage of all cancer cases, due to the importance of UV light in causing relatively non-fatal cancers (Doll \& Peto, 1981).

The Dutch government has decided that the primary prevention of cancer should be intensified. Government documents include several proposals for actions and governmental measures that should reduce the prevalence of cancer-related risk behavior. Explicitly it is mentioned that there are many possibilities for the execution of these actions and measures on the local level (Ministerie van Welzijn, Volksgezondheid en Cultuur, 1989a, 1989b).

\section{Determinants of cancer-related risk behavior}

Insight into behavioral determinants is a prerequisite for the development of an effective behavior change intervention. It provides points of impact for the intervention (Green et al., 1980; Kok \& De Vries, 1989).

In the first phase of the research project a telephone survey was conducted to analyze the determinants of four cancer-related risk behaviors in the adult Dutch population: smoking, high fat consumption, excessive alcohol consumption and solarium use (reported in detail in chapter 2 of this thesis). The study also addressed the question whether the four risk behaviors were interrelated. Strong correlations between the risk behaviors might make it interesting to develop an index or scale of the risk behaviors and to investigate the determinants of such a lifestyle index or scale. Cancer can be caused by a combination of risk factors. Therefore, influencing lifestyles is more effective than influencing only one of the risk behaviors (U.S. Department of Health and Human Services, 1986). A 
study into the determinants of a combination of risk factors might indicate points of impact for such a lifestyle intervention.

The four risk behaviors included in the study were chosen on the basis of the current knowledge about the relationship between cancer and behaviors. Specifically, high fat consumption was chosen as dietary risk behavior because of the priority given to this risk factor by the Dutch Nutrition Council. Exposure to UV radiation is caused both by exposure to the sun and exposure to artificial sunlight. These behaviors are quite different and may have different determinants. Because of the complexity of the study it was impossible to include both behaviors in the determinants study. Since solarium use ${ }^{2}$ seemed to become more popular, was perceived to be a more superfluous behavior and interventions focusing on this risk behavior might to be more possible it was chosen: it is also easier to measure.

The theoretical model that was used in the determinants study was the 'Attitude - Social influence - Efficacy model' (ASE model) (De Vries et al., 1988; Kok et al. "1991). Several theoretical models can be used for explaining human behavior, such as the Theory of Reasoned Behavior (Ajzen \& Fishbein, 1980), the Health Belief Model (Janz \& Becker, 1984), Social Learning Theory (Bandura, 1986) and the Theory of Planned Behavior (Ajzen \& Madden, 1986). The ASE model combines the most important psycho-social behavioral determinants. According to this model, behavior is determined by people's attitude toward the behavior, social influence and self-efficacy. An attitude represents a person's general feeling of (un)favorableness toward the behavior, and is determined by perceived positive and negative consequences of the behavior. Health is only one of the possible attitudinal considerations and is often of relative unimportance compared with considerations such as costs, (dis)like, status, etc. (Hochbaum, 1983). Social influence refers to the influence of others, both directly (expectations of important others) and indirectly (what others dol. Self-efficacy refers to a person's expectation regarding his capability to realize a (desired) behavior. Attitudes, social influence and self-efficacy predict the intention to perform the behavior which, in turn, predicts the behavior itself. External variables, such as demographic variables, influence behavior via the three determinants and the intention. Between intention and behavior there may be barriers or lack of skills. These barriers and skills only

2 This includes the use of tanning booths, sun lamps with UV radiation, tanning salons, etc. 
become important if the behavior is actually performed. Actual performance of the behavior leads to a feedback process that, in turn, influences the three determinants.

\section{Pilot study}

In order to develop questionnaires for a telephone survey, a pilot study was conducted. The main aim of this pilot study was the operationalization of the theoretical concepts attitude and self-efficacy. To measure attitudes, items have to be formulated about all possible salient advantages and disadvantages of the behavior (Ajzen \& Fishbein, 1980). For measuring self-efficacy, preferably different situations are defined in which it can be difficult not to perform the risk behavior (Bandura, 1986; Kok et al., 1991). A separate research question referred to the usefulness of the qualitative research method (i.e. focus group interviews) in this preliminary research stage. Therefore, the results of the focus group interviews were compared with another, quantitative, research method.

A focus group usually exists of 7-10 persons who are selected on the basis of certain common characteristics related to the subject of study. The general aim of focus group interviews is to gain insight in the ideas or feelings of persons about a problem or phenomenon. In a focus group interview the interaction between participants is central. This interaction is started by an experienced leader who puts forward a topic in which the researchers want to have more insight (Basch, 1987; Krueger, 1988; Morgan, 1988; Van Assema et al., 1992a).

In the pilot study four focus group interviews were conducted. Participants were selected by taking a random sample from a telephone directory. In the interviews the four risk behaviors were discussed in order, by means of a sequence of questions. In addition to the interviews, short written questionnaires were completed by 131 adults. These respondents were approached in three public community buildings. They were asked to tick off in lists of answer possibilities what they perceived to be the most important advantages and disadvantages of the four risk behaviors. Also, they were asked to tick off in which situations it was difficult for them not to perform the risk behaviors. The lists were developed on the basis of previous literature results and own ideas, but were not based on the results of the focus group interviews as these took place at the same time.

For each behavior, the pilot study yielded 8-11 items (depending on the risk behavior) covering the advantages and disadvantages of the risk behavior and 3 - 
4 questions (depending on the risk behavior) about different situations which could measure self-efficacy.

Both the interviews and the questionnaires brought to light advantages, disadvantages and situations that were not mentioned or ticked off in the other method. Therefore, it was concluded that focus group interviews are a very useful method in this research stage. The method, which is very open, seems to be especially useful for relatively new subjects where literature studies give little guidance in the early research phases. However, it seems preferable to use a two-step approach in which the focus group results are combined with previous literature findings and subsequently quantified by means of a structured questionnaire (Van Assema et al., 1992b).

\section{Survey}

Questionnaires for telephone interviews were developed including questions on risk behaviors and behavior determinants. Because many variables were to be measured, seven partially different questionnaires were developed. The research population for the survey was selected by taking a random sample from the Dutch telephone directories. Subsequently each telephone number was randomly assigned to one of the seven questionnaires. The total population for the study consisted of 1600 adults. The questionnaires were completed by performers as well as non-performers of the four risk behaviors.

For all four risk behaviors, subjects who performed the risk behavior were compared with subjects who did not with respect to attitudes, social influence and self-efficacy beliefs. Also, subjects who intended to change their risk behavior were compared with those who did not.

The results indicated that, apart from small correlations between smoking and heavy alcohol consumption and between high fat consumption and heavy alcohol consumption, there were no significant relationships between the four risk behaviors. Therefore, no attempts were undertaken to study the determinants of a combination of risk factors. Furthermore, the results showed that the four types of risk behavior are determined by several factors: the perceived behavior of the social environment, individual attitudes towards the risk behavior, and self-efficacy perceptions on changing the risk behavior. High fat consumption differs from the other risk behaviors, in that people generally are not aware of their high fat consumption. Comparison between those who intended to change their risk behavior and those who did not, showed that the different determinants may vary in importance for people at different 'stages of 
change' (Prochaska \& DiClemente, 1984). Based on the study findings, it was determined for each risk behavior which changes in determinants the intervention should emphasize. In addition, possible strategies to achieve these changes were devised (Van Assema et al., 1993).

\section{Implications for the intervention}

Despite the absence of correlations between the risk behaviors, it was concluded that the intervention should include more than one risk behavior. As already mentioned, influencing lifestyles is more effective than influencing only one of the risk factors (U.S. Department of Health and Human Services, 1986). Prevalence was not as high for all the four types of behavior, but the majority of the population seemed to perform at least one risk behavior. Therefore, a multirisk behavior intervention might attract and reach more people and because of this might be more effective in reducing the population risk. However, a multirisk behavior intervention has some disadvantages primarily related to complex program planning and implementation. Accordingly, it was decided that emphasis should be placed on the two major types of risk behavior, smoking and nutrition, with less attention being paid to the other two, less prevalent, types of risk behavior, whose contribution to cancer risk is not as great.

Furthermore, it was concluded that a comprehensive approach would be required to change the cancer-related risk behaviors in the general population, as the risk behaviors are determined by several factors and seem to be strongly held and socially accepted. Mass media activities as well as interpersonal methods, self-help programs, structural activities and a social network approach should be part of the intervention. Based on findings of other studies it was decided that such a comprehensive program would be best accomplished at the community level (Farquhar et al., 1984; Puska, 1984; Mittelmark et al., 1986; among others).

\section{Opinions and knowledge about the prevention possibilities of cancer}

Simultaneous with the determinants study, a study was conducted into the current opinions and knowledge of the Dutch population about the risk factors and prevention possibilities of cancer. Previous studies had shown that the public's knowledge about the causes and prevention possibilities is limited, often confused, and sometimes even wrong, and that Dutch research in this field was very limited (Knopf, 1976; Charlton, 1977; Luther et al., 1982; 
National Cancer Institute, 1983; Jackson \& Laking, 1985; Commission of the European Communities, 1987; Van Assema et al., 1987). Knowledge about the health risks of a behavior is mostly not a sufficient, but still a necessary condition for behavior change (Green et al., 1980). Therefore, insight in the present knowledge of the target population is relevant for the development of a cancer prevention program.

Knowledge about the health risks of a behavior is important for the motivation of a person to change behavior only, if there is a threat of the disease, i.e. the person thinks the disease is serious and perceives the own chance of developing the disease to be real, and if the person really believes the behavioral change will reduce the chance of developing the disease (Janz \& Becker, 1984).

The data for this study were gathered in the focus group interviews of the pilot study described earlier and by means of some additional questions in the telephone survey.

Both the survey and the focus group interviews revealed that most people were rather pessimistic about the possibilities of cancer prevention. Only $26 \%$ of the respondents thought there were possibilities to do something themselves to prevent cancer. Some people had faulty knowledge, but most respondents were able to mention some possibilities to prevent cancer, such as not smoking or healthy eating habits. However, most people perceived factors beyond their control, such as pollution and food additives, to be far more important than the factors they do have under control. Also, while cancer was perceived to be a serious disease, they regarded their own chances of developing cancer as small (Van Assema et al., 1990a).

\section{Implications for the intervention}

Based on the results of the study it was concluded that the intervention should improve people's insights into their own risks of developing cancer and at the same time into what they could do themselves to prevent it. Also the relative importance of controllable factors should be stressed in comparison to external factors. Furthermore, information should focus on misconceptions.

The intervention should be supported by actions from (local) government. People will be more inclined to change their ideas if government policy is consistent with these changes and provides legitimacy for them (Milio, 1986).

People might not be attracted by a cancer prevention project nor be willing to participate in it. Therefore, the intervention should preferably be presented as a general health improving project in order to gain the attention and participation 
of the target group in the intervention in the first place. A general health approach is also in line with the fact that the major risk factors of cancer (smoking and dietary habits) are also the major risk factors of coronary heart disease and some other health problems.

\section{A questionnaire measuring fat consumption}

In order to measure fat consumption (in the survey and later on in the effect evaluation of the cancer prevention project) a short questionnaire was developed. Chapter 3 of this thesis describes this questionnaire in detail. The development of a new questionnaire was necessary as the existing instruments (i.e., the 24-hour recall, the weighted or unweighted record, the dietary history method) are less suitable for large-scale food consumption research. They are expensive, time consuming and require trained dieticians to interview subjects or to check the food records (Bingham et al., 1988). Moreover, they produce very detailed information, while in studies on the effectiveness of community nutrition intervention programs, or in studies into the determinants of specific nutrition behaviors, it is not always necessary to measure all nutrients or to measure nutrient intake in a precise manner. In our study, only a ranking of subjects according to the intake of fat was required.

The fat consumption questionnaire consists of 25 items covering 12 (groups of) food products. The questionnaire was developed by selecting (groups of) food products which have the highest contribution to total fat intake in the Dutch population (Van den Brandt et al., 1991). Subjects were asked how frequently these 12 groups of food products were usually consumed during the last 6 months (e.g., "how many days a week do you usually drink milk?"). For some food products additional items on quantity (e.g., " how many glasses of milk on one day?") or kind of product (e.g. low fat or high fat milk) were included. For each of the 12 (groups of) food products a fat score, ranging from 1 point (lowest fat intake) to 5 points (highest fat intake), was determined. Subsequently, an individual total fat score was calculated by adding up the 12 food product fat scores for each subject. Consequently, this total fat score ranges from 12 to 60 points. The average time for telephone administration of the fat consumption questionnaire was 5 minutes. 


\section{Validity and reproducibility}

The quality of research measurements is determined by the validity and the reproducibility of the method used. The concept of validity refers to the absence of systematic (non-random) error while reproducibility is associated with random error or variability (Burema et al., 1988). The relative validity of the questionnaire on fat consumption was assessed in relation to a 7-day diet record, which is generally accepted as a relatively valid and reliable food consumption research instrument (Bingham et al., 1988). The reproducibility of the questionnaire was determined by a test-retest procedure. The validation and reproducibility study are reported in detail in chapter 3 of this thesis.

The validation study was conducted among a random sample of adults (age 18 years or older). These subjects received a letter with information on the purpose and procedures of the study. Subsequently they were approached by telephone and requested to participate. If so, the subjects were asked to complete the fat consumption questionnaire, or an appointment was made to complete the questionnaire another day. After the telephone interview, the subjects were visited twice at home by trained dieticians. The subjects were asked to keep diet records for seven subsequent days. During the first visit the diet records were handed out and the use of the pre-structured food records was explained. The purpose of the second visit was to collect and check the food records and to weigh the household measures used in the diet records. A total of 52 subjects participated in the validation study.

For the reproducibility study a random sample of 639 inhabitants of the control community in the effect evaluation of the project, were interviewed twice with a one-year time span between the interviews.

A Pearson correlation of 0.59 was observed between fat intake estimated by 7-day diet records and fat score derived from the fat consumption questionnaire. Gross misclassification, defined as disagreement between the two fat consumption assessments beyond an adjacent tertile, was $15.4 \%$. A Pearson correlation of 0.71 was calculated by a test-retest procedure. These results are of the same order or better than those reported in a few other comparable studies (Jain et al., 1980; Willett et al., 1985; Block et al., 1989; Kristal et al., 1990).

It was concluded that the Dutch questionnaire on fat consumption is a rapid, simple and inexpensive method that can be used effectively in nutrition education research to rank individuals according to their dietary fat intake (Van Assema et al., 1992c). 

intervention

In the second phase of the research project an intervention was developed for implementation in a community by a local project group. The target group of the intervention were all inhabitants of a community age 18 years or older. The intervention was presented as a general health program. The main goals of the intervention were a reduction in the percentage of smokers and a reduction in fat consumption. The intervention also focused on reduction of excessive alcohol consumption and solarium use, but less extensively.

The development of the intervention and the planning of the implementation of this intervention were based on two different theoretical approaches:

(1) A conceptual framework that combined two theoretical (health education) models, i.e. the Transtheoretical Model of Stages of Change and the Model of Behavioral Change.

(2) The empirical literature on community organization principles.

The conceptual model was used for the development of a package of local health activities aiming at behavioral change in the community. Community organization principles were mainly used to plan the implementation of this intervention in a community, i.e. to plan the overall organization of the project. However, community organization principles were also applied as much as possible in the local health activities that were part of the intervention.

This paragraph firstly discusses why and which community principles were applied in the project. Subsequently, the implications of the application of these principles for the overall organization of the project are presented. Secondly, the conceptual framework and the components of the intervention are presented. Thirdly, the workbook that was developed to help a local project group implement the intervention is discussed. Finally, some international developments regarding health policy and health promotion in the last thirty years as well as how the intervention fits in with these developments are briefly discussed.

\section{Community organization principles}

Traditionally, attempts have been made to encourage the general public to adopt healthier behavior mainly by means of mass media education interventions. In addition, some legal measures have been taken, such as 
alcohol and tobacco excise and food value labeling. From effect studies it appears that these interventions, have disappointingly little effect, resulting in hardly any behavior change, while they reach only a small segment of the target population (McGuire, 1984; Liedekerken et al., 1988).

Community projects, however, seem to have more potential in this respect, as was found in successful interventions in the late 1970s and early 1980s aimed at reducing the risk of coronary heart diseases. (Maccoby et al., 1977; Farquhar et al., 1984; Puska, 1984). As used in this thesis, community projects ${ }^{3}$ are projects in a geographical area (a city, a neighborhood, a municipality) that apply 'community organization' principles. Community organization can be defined as the process by which community groups are helped to identify common problems or goals, mobilize resources, and in other ways develop and implement strategies for reaching the goals they have set. A key concept in community organization is 'empowerment', i.e. an enabling process through which individuals take control over their lives and their environment (Minkler, 1990). Most community health projects cannot be said to be applying community organization, but they borrow some community organization principles and methods. Although community organization is definitely not a new strategy, the application of community organization in the (Dutch) health education field is relatively new.

A brief description of community organization principles that are applied in community health projects is provided in the next subsections. Although the principles will be discussed one by one, there is considerable overlap between them.

\section{- Participation}

The participation of inhabitants in the planning and implementation of the project is a major premise of community health projects. Participation can have advantages on both the individual and the community level. On an individual level, people involved in community efforts may experience increased social support, which may contribute to a sense of control which may in turn have positive health benefits (Cohen \& Syme, 1985). On a community level, participation of community members is important to fit the project to local needs, habits, possibilities and barriers, which can be assessed

3 In the Netherlands community projects are also defined as local initiatives, local projects or social network approaches 
in co-operation with the inhabitants (Orlandi et al., 1990; see also the sections 'social network approach' and 'link up with the current situation'). Participation provides the opportunity for community ownership of the project (Green \& Kreuter, 1991) and facilitates not only the use (see also the section 'Link up with the current situation), but also the enlargement of existing capacities in the community, which will make the people capable of solving their own (health) problems (Chavis et al., 1983). Community ownership and control will facilitate long-term continuation of the project by the community itself, which is often a major goal of community projects.

Beside the advantages of community participation, it should also be stressed that participation is not easy to accomplish (Bracht \& Gleason, 1990).

Green (1986, p. 212) notes that the principle of participation has not been systematically codified in health education with a cohesive set of constructs, definitions and propositions'. Possible definitions will not be discussed, but for practical purposes three dimensions in the concept of participation will be distinguished:

(1) The extent of participation. Arnstein (1969) used the metaphor of a ladder to distinguish the different degrees of participation. The foot of the ladder represents total lack of participation, while the top represents complete participation (Figure 1).

(2) The phase of participation. The extent of participation can vary between the different planning phases of the project. Inhabitants may only be consulted in the problem definition of the project, but there might be partnership in the implementation of the activities.

(3) The number of people that participate. It is possible that the group of inhabitants may be small, but have a high degree of participation, whereas a large group of people may be involved but with only a small degree of participation.

\section{- Social network approach}

The social network approach refers to the explicit use of the community's interpersonal communication channels. By using interpersonal communication alongside a mass media approach more people in the community can be reached (1) and projects can be more successful in achieving behavioral change and maintenance (2).

(1) The 'diffusion of innovation' theory of Rogers (1983) states that a new idea will not be adopted by everyone at the same time and in the same 


\section{Citizen control \\ Delegated power \\ Partnership \\ Placation \\ Consultation \\ Informing \\ Therapy \\ Manipulation}

Figure 1. Ladder of citizen participation (Arnstein, 1969)

way. The theory distinguishes 'innovators', 'early adopters', 'early majority', 'late majority' and finally 'laggards'. Innovators are cosmopolite and are actively searching for new information and ideas, using mass media as their main source of information. Early adopters are respected members of the social network, often functioning as opinion leaders or as 'social models'. As such they have a great influence on the adoption of new ideas by the other members of the network. The early majority is the larger number of members adopting a new idea shortly after the early adopters. The late majority, often consisting of members with a lower socio-economic status, are often more difficult to reach. They receive their information mainly from people in their direct social environment. The laggards, finally, are socially isolated members of a network, who are the most difficult group to reach.

By using mass media to spread information, probably only the upper segment of a social network will be reached. To reach all members, including those from the lower socio-economic groups, the message should also be spread by members of the network itself (Preston et al., 1988; Weenig, 1991). Diffusion from network members to other network members will be easier when the information fits closely to the current beliefs, values and experiences of the population (see also the section 'participation'). Furthermore, a prerequisite for diffusion is a close-knit network in which the members communicate a lot with each other (Weenig, 1991).

(2) The social environment has great influence on individual behavior change and behavior maintenance (see also the section 'environmental strategy'). Social influence has been studied from different theoretical points of view: 
- Network members act as models for each other; they learn from the behavioral consequences they observe in each other (Bandura, 1986). This is especially valid as they can identify themselves better with the model.

. When people have doubts concerning their own attitude or behavior, they compare themselves with other persons whom they consider to be in certain relevant aspects their equals (Festinger, 1954),

People exert social pressure on each other to perform the same behavior.

The effect of this social pressure depends on the availability of punishment facilities (i.e. exclusion) (Moscovici, 1985).

- Information diffused by a source familiar to the target population is more credible and therefore more effective (McGuire, 1985).

People can support each other's behavior change; the network can function as a source of social support (Suls, 1982).

A project with a social network approach uses the influence people have on each other's behavior. A prerequisite for this is a certain amount of social involvement is the network (Weenig, 1991). Of similar importance is that social influence can be counterproductive for an intervention as well when the present group norm disagrees with the intended behavior change. In such situations confidence needs to be gained carefully, starting with the opinion leaders (Weenig, 1991).

Projects with a social network approach sometimes make use of paraprofessionals, who can be defined as members of the target population, trained as educators. Particularly with the lower income and education groups the use of paraprofessionals has proved to be effective (De Walle-Sevenster et al., 1986). For outsiders these populations are hard to contact because of their distrust of strangers and their sensitiveness to differences in socioeconomic status, language etc. (De Walle-Sevenster et al., 1986). This distrust is reduced when the information is provided by someone accepted as a social model (Preston et al., 1988). Aside from these advantages, there are a few disadvantages in using paraprofessionals. The training of paraprofessionals may be time-consuming and expensive and will not always be possible. In such situations the alternative is to engage professionals from within or outside the community to carry out the educating tasks. However to find acceptance in the community, members of the community can be mobilized in organizational tasks. 
Because of the social network approach, community projects have become popular among health educators for reaching people with lower socioeconomic status.

\section{- Environmental strategy}

People's behavior is largely determined by both the social and the physical environment they live in. It is very difficult for an individual to change his behavior, when obstructing factors in his social or physical environment remain unchanged (Bracht, 1990; see also the section 'social network approach'). Furthermore, environmental factors such as air pollution can also be directly related (i.e. not via behavior) to health problems (Simons-Morton ot al., 1988). Creating an environment that is positive towards the desired behavior and supports this behavior, is a strategy that is used in community interventions. For that, multiple strategies (i.e. educational, provisional and regulatory) designed to influence both environmental forces and behavioral patterns at several levels of the community are used (Green \& Kreuter, 1991).

\section{- Intersectoral approach}

Gray (1985) defines intersectoral co-operation as the bringing together of resources, such as information or money, by two or more stakeholders, for the purpose of solving problems that cannot be solved by individual stakeholders. By stakeholders Gray means those individuals, groups and organizations that are directly influenced by the actions of others within the domain. Domain means the set of actors that become connected by a common problem or interest. In other words, an intersectoral approach aims at involving many sectors from different societal, governmental and private spheres in a co-ordinated effort. The importance of an intersectoral approach to health problems has been underlined many times (De Leeuw, 1989). There may be problems that do not need an intersectoral approach, but many health problems are determined by multiple factors (Milio, 1986; see also the section 'environmental approach') and different sectors in the community may have the power to influence these factors. Each sector is a source of facilities, money, expertise, volunteers, etc. which can help to achieve program goals. Through intersectoral co-operation the resources can be channeled and coordinated. Also, structural changes that are supported by different community sectors may be achieved more easily. Furthermore, by means of intersectoral co-operation more people in the community can be reached. Each sector 
represents a different group of people, and therefore involvement of a sector means having an entry to the people they represent. Intersectoral co-operation can also improve local structures. New communication lines can arise and diffusion between sectors can be improved (see also the section 'social network approach'). Finally, educational messages of different organizations can be attuned to each other.

In intersectoral co-operation the win-win principle is important. Sectors will only co-operate with each other if there is something to win for all of them.

There is not much theory available on the development and institutionalization of intersectoral co-operation. However, Gray (1985) has developed a framework for it, which distinguishes three phases in the development of intersectoral co-operation, i.e. problem-setting, directionsetting and structuring. The framework emphasizes that the development of intersectoral co-operation is not easy. Several prerequisites have to be met and many barriers can arise (Hueben \& De Leeuw, 1991).

\section{- Multi-media and multi-method strategr}

Community projects make use of various mass media channels and various educational strategies. The advantages of such an approach can be illustrated from several points of view:

A combination of methods will have a synergetic effect (Liedekerken et al., 1988; Bracht \& Kingsbury, 1990).

A combination of educational methods and the use of various mass media channels will increase the proportion of the target population reached. People make use of different sources of information, some primarily using mass media and others primarily using their friends and relatives (see also the section 'social network approach'). Furthermore, mass media channels differ in the number and groups of people they reach (Damoiseaux, 1991).

The process of behavior change consists of several stages: in the first stage the message has to attract attention and has to be comprehensible, then the determinants of the intended behavior have to be changed (attitude, social influence, self-efficacy) and, finally, the intended behavior change has to be accomplished and maintained (McGuire, 1985). Mass media are particularly suitable for attracting the attention of the target population lagenda-setting function), while a more personal approach will be necessary to bring about changes in determinants and behavior (Green et al., 1980; McGuire, 1985). 
Therefore, to go through the process of behavior change, different activities are required, which must take place in a logical order.

People learn in different ways and differ in their preference for educational methods (Green et al., 1980). For example, while some people prefer to quit smoking by means of a self-help manual, others may choose to attend group sessions. Consequently, offering various methods will increase the participation and success rate.

\section{Link up with the current situation}

Community projects link up as much use as possible with the current situation in a community. Interventions correspond closely to pre-existing initiatives, and support them. The projects fit to local needs, habits, possibilities and barriers (see also the section 'participation'). Available resources are used as much as possible (see also the section 'intersectoral co-operation). Existing networks are used (see also the section 'social network approach') or improved (see also the section 'intersectoral co-operation'). Besides advantages related to cost and time, linking up with the current situation will facilitate institutionalization of the project (Lefebvre, 1990).

\section{Implications of the application of community organization principles for the} organization of the project

Rather recently, Bracht \& Kingsbury (1990) have published about a five stage community organizing model. This model describes five stages in the organization of a local health project through which community organization principles can be given concrete form: community analysis, design-initiation, implementation, maintenance-consolidation, and dissemination-reassessment. Bracht \& Kingsbury published their model after the start of the project described in this thesis. Because the community organizing process as proposed by Bracht \& Kingsbury corresponded with the process planned by the researchers involved in the cancer prevention project, this model has been adapted as the general model for the organization of the project (see also the section 'Implementation of the intervention').

The model proposes that in the first stage of a community project an analysis is made of the community's needs, resources, social structure and values. Community members and organizations are involved in this analysis. Subsequently, the main aim of the design and initiation stage should be the establishment of a formal structure for community involvement, for instance a 
local project group in which people and organizations from the community are represented. In this stage, mission and goais need to be defined, and roles and responsibilities of all those involved need to be clarified. In the implementation stage effectively operating programs that can accomplish the mission have to be initiated. Sequential workplans have to be developed. Activities preferably use available resources and existing institutions, and they are adapted to local constraints and values. Subsequently, during the maintenance-consolidation stage those involved gain experience with the activities. The project develops a solid foundation in the community and the activities are gaining acceptance. Activities are being more fully incorporated into the established structures of the community. The last stage is the dissemination-reassessment stage. Although activities are modified, expanded or abandoned continuously during the project, at some point the project group formally assesses what has been learned and determines future directions.

\section{Conceptual framework for the development of the intervention}

Based on the results of our research into the determinants of the four risk behaviors a conceptual framework for the intervention was developed that combines the Stages of Change Model with a Model of Behavioral Change.

The Transtheoretical Model of Stages of Change (Prochaska \& DiClemente, 1984) operates on the assumption that people do not change behavior all at once, but continuously through stages. The model proposes that people may be at four different stages of change: precontemplation, contemplation, action, and maintenance. Precontemplators are subjects who have not considered changing their behavior in the desired way. Contemplators have considered this action but have not made a commitment and are not taking action yet. Actors are those subjects who have recently made an overt effort to change their behavior, and maintainers have continued their behavior change over an extended period of time $e^{4}$.

The Model of Behavioral Change (McGuire, 1985; Kok \& De Vries, 1989) suggests the phases that lead to a continued change in behavior as a result of health communication: attention to and comprehension of the message,

4 In later publications Prochaska and DiClemente have added a preparation stage to the model. People in this stage do intend to change their behavior in the near future and are actually making plans to do so (Prochaska \& DiClemente, 1992) 


\section{Attention and comprehension}

\section{Change in attitude}

\section{Change in social influence}

Change in self-efficacy

Behavior change

Behavior maintenance

Figure 2. Conceptual framework

changes in the determinants of behavior (attitudes, social influence and self. efficacy), a change in behavior, and maintenance of the behavior change.

In the framework the behavioral change phases are set against the different stages of change (Figure 2). The intervention can shift people from one stage ta another by passing through the behavioral change phases. However, the behavioral change phases are not equally important for people at different stages of change (Prochaska \& DiClemente, 1992; Van Assema et al., 1993). For example, precontemplators especially need an attitude change, while contemplators especially need a change in self-efficacy. Therefore, some of the combinations in the framework are relatively more important than others and should get more attention in the intervention.

The conceptual framework was generic for all four types of risk behavior. However, an additional 'awareness' phase was added to the Model of Behavioral Change in relation to changing fat consumption. Our survey showed that most Dutch people were not aware of how high or low in fat their diets are. In other words, many people do not even know that they eat too much fat, i.e. that they perform the risk behavior. In this aspect, fat consumption differs from the other risk behaviors, where performance of the behavior is obvious, i.e. smoking cigarettes, drinking alcohol, using a solarium. 
The framework ${ }^{5}$ served as a checklist for the developers of the intervention to ensure that the intervention included activities for subjects in each stage of change and to cover whatever phase of behavioral change these people are in. It helped to orchestrate the multiple activity strategies and to determine the time sequence of the activities.

\section{Intervention components}

By means of the conceptual framework and with the community principles and the results of the survey in mind, thirty-two health education and health promotion activities were carefully selected or developed. The activities were divided into five intervention components: a mass media component, a group and self-help program component, an information center component, a social network component, and a structural component aiming at changes in the physical environment. An overview of project activities, organized by intervention component, is given in Figure 3.

Already existing and tested activities were used as much as possible. For instance, the smoking cessation courses that were selected for the intervention had already been organized by the Life and Health Foundation (Stichting Leven en Gezondheid) ${ }^{6}$ for many years throughout the Netherlands.

If no suitable activities were available, they were either developed and pretested or guidelines for the development of a new activity were given. For example, one of the activities that was specifically developed for the project was the self-help fat reduction program (component B) (Van Assema et al., 1990b; Steenbakkers et al., 1992). This program consists of 16 pages and can be hung in the kitchen or other suitable places. The program consists of four steps. Each step focuses at a different group of food products: butter and sauces (step 1), diary products (step 2), meat, meat products, fish and eggs (step 3) and food eaten between the main meals (step 4). At each step suggestions are given how the amount of fat consumed by eating these products can be reduced. Tables are included which indicate how many grams of fat a portion of a product contains. In these tables users can see how much

5 Examples of more or less comparable intervention development matrixes/schemes are for instance described by Brink et al. (1988) and Preston et al. (1988).

6 The smoking cessation activities of the Live and Health Foundation are now organized by the Smoking and Health Foundation (Stichting Volksgezondheid en Roken) 


\section{Component A: mass media activities}

messages about the project group and the project activities in general poster with the logo of the project pens with the name of the project messages about structural changes in the community messages about the advantages and disadvantages of smoking messages for non-smokers

reports of interviews with community members that stopped smoking messages about the project's smoking cessation activities messages about nutrition to raise awareness and attitude change messages about social influence and eating habits reports of interviews with community members about nutrition recipes

messages about the project's fat reduction activities messages about the advantages and disadvantages of exposure to. UV radiation messages about the availability of pamphlets about UV radiation

- messages about alcohol consumption in general and the project's alcohol reduction activities

\section{Component B: group and self-help activities}

- self-help stop smoking manual

- stop smoking group course

- self-help fat reduction program

- living room nutrition sessions

- sumbathing pamphlets

\section{Component $\mathrm{C}$ : information center}

- enrollment in activities and requests for materials

- call-backs to requesters of materials

- information about the project's activities and health information

\section{Component $D$ : social network activities}

- organizing meetings for key figures

- regular (informal) contacts with key figures

\section{Component E: structural activities}

- smoking restrictions in organizations and associations

- nutrition information in shops

- nutrition information in restaurants and cafetarias

- information for nutrition preparers

- use instructions on solaria

- alcohol restrictions in organizations and associations

Figure 3. Overview of activities by program component 
fat they usually eat and how much fat they can cut out by eating another product. Users are advised to take one week for each step. Each time users follow one of the suggestions, they can indicate this by putting a cross in a box against the specific advice. At the end of the program users can do a test. During one day they can record everything they eat in a scheme. Using the tables in the program they can count how many grams of fat they have eaten during this day. Products that are not mentioned in the program can be looked up in a food product guide that is supplementary to the program. This self-help fat reduction program was developed by means of the pretest route proposed. by Damoiseaux (1991). Drafts of the program were discussed with both educational and subject experts and adjusted in the light of their comments. The program was also discussed with subjects of the target population to evaluate the acceptability, understandability and attractiveness of the program.

Other activities were not developed in detail, but specific guidelines for the development of these activities were given. An example of such an activity is the nutrition living room sessions (component B) (Van Assema et al., 1992d). This activity was based on the 'Tupperware' concept; inhabitants could apply for a nutrition session by a dietician in their own home and invite about 8 other people (family, friends, neighbors). The host or hostess is offered a small present. Guidelines for recruiting participants as well as for the content and education methods of the evening were formulated.

\section{Workbook}

To help a project group with representatives from several local organizations implement the intervention, a workbook was developed in which the thirty-two activities were described (Van Assema \& Steenbakkers, 1990). In addition to this the workbook included background information on the relationship between health and behavior. the determinants of behavior and how behavioral change can be achieved. The workbook also included guidelines for the local project group. The project group was recommended to proceed through three steps.

(1) The first step was to organize themselves as a group. The workbook gave instructions for making a meeting schedule, developing a recognizable logo and ordering note-paper and envelopes with this logo. Also, to facilitate the intersectoral co-operation, instructions were given to make regulations to record agreements about for instance the decision-making process, goals, roles and responsibilities. 
(2) The second step was to choose activities. The project group was encouraged to organize activities from each program component. However, to increase involvement and ownership they were also free to develop their own activities. For each of the thirty-two activities in the workbook, the target, target group and importance of the activity were described. A time schedule for the implementation of the activity was also provided. Forms were included that could help the group to make balanced decisions.

(3) The third step was to prepare and implement the activities. The workbook included general recommendations as well as so-called work schedules for the systematic set-up of the different activities. Examples of materials, such as possible press releases, were also part of the workbook. The project group was recommended to split up in small workgroups, which would each be responsible for the preparation and implementation of certain activities. Also, they were recommended to link up with existing activities in the community.

\section{Health policy and health promotion}

In the early 1970 s the vision emerged that a policy to promote health should not only be focused on the quality and quantity of health care services, but especially also on other factors that influence health, such as individual lifestyles, biological factors, and physical and social environments. Since then, it has appeared from empirical research that these other factors indeed have a larger impact on health than the health care system alone (De Leeuw, 1989). The Canadian Lalonde report was the first document in which such a policy was advocated (Lalonde, 1974).

In 1977 the World Health Assembly decided that the main social target of governments and the World Health Organization (WHO) in the coming decades should be the attainment by all citizens of the world by the year 2000 of a level of health that would permit them to lead a socially and economically productive life (HFA2000). In the Netherlands, HFA2000 led to the publication of two health policy documents, namely the 'Nota 2000' and the 'OntwerpKerndocument Gezondheidsbeleid'.

In line with the new vision on health policy, the European regional office of the WHO initiated a health promotion program to attain HFA2000. Health promotion was defined as 'the process of enabling individuals and communities to increase control over the determinants of health, and thereby to improve their health'. This European definition of health promotion clearly differs from its North 
American definition, i.e 'health promotion is any combination of health education and related organizational, economic, and environmental supports for behavior conductive to health in individuals, groups or communities (Green \& Lewis, 1986):

The development of healthy public policy (i.e. advocating policies to advance health or hinder policies with detrimental effects on health) became an important prerequisite of the WHO health promotion program, as policies are believed to influence health to the largest extent possible (De Leeuw, 1989). Other characteristics that can be attached to the concept of health promotion are that:

it is integral, i.e. covers the health problem with various policy interventions which should be attuned to each other;

- it is intersectoral;

$=$ it is comprehensive;

- it is participatory;

- it mobilizes resources for health, i.e. enables and empowers individuals, groups, communities and organizations to improve health and health determinants (De Leeuw, 1989).

In 1986 the WHO Healthy Cities project was initiated. In this project the principles of the health promotion concept are given concrete form at the local level. The goal of the project is to improve the health in cities by supporting them in the development of activities and processes that are health improving (De Leeuw, 1991).

The cancer prevention intervention described in this thesis is clearly in line with the concept of health promotion. Several concepts that are characteristic for the WHO health promotion program and the Healthy Cities project were also applied in the cancer prevention project, such as intersectoral co-operation and participation. Nevertheless, a major difference between the Healthy Cities project and the cancer prevention project was that individual lifestyle change was at the core of the cancer prevention intervention, while building healthy public policy is the starting point of the Healthy Cities project. In other words, the cancer prevention project leans somewhat more to the North American definition of health promotion by starting the project from a health education point of view instead of a policy point of view. 


\section{Implementation of the intervention}

\section{Bergeyk}

To evaluate the program, it was implemented in the municipality of Bergeyk. Bergeyk was selected at random from six. municipalities in the Netherlands each with the following characteristics:

1) about 10,000 inhabitants

2) urbanization degree $B 2$, indicating an urbanized countryside municipality with at least 5,000 inhabitants in the main village (CBS, 1987)

3) within 100 kilometers of the University of Limburg.

The decision to implement the project in an urbanized countryside municipality was taken, because $55 \%$ of the Dutch population live in such a municipality. This increases the generalizability of the project's results and the possibilities for replication of the project throughout the country. Furthermore, the decision to implement the project in a small community with most inhabitants concentrated in one main village was also based on the notion that the project was an experiment. A major goal of the researchers was also to gain experience with this kind of project. Therefore, it was decided not to test it in the most difficult circumstances.

Bergeyk is situated in the province of Noord-Brabant along the border with Belgium. The municipality consists of three villages: 't Hof, 't Loo and Weebosch. Bergeyk has a slightly more than 10,000 inhabitants, of whom 8,200 live in 't Hof. Bergeyk is traditionally an agrarian community. However, in recent decades there has been an extensive growth in the industrial, trade and service sector.

\section{Implementation}

The implementation of the intervention is described in detail in chapter 5 of this thesis. Figure 4 gives a time schedule of the implementation of the project. Due to the limited time available, the project was initially started and financed for one year. However, the initiators sought to encourage the project group to continue the project.

On the financial side, the project's budget was limited. The financial input in the project was intentionally kept to a minimum as financial restrictions should not be a barrier in case of large-scale implementation of the project later on. The main costs of the project were related to the appointment of a part-time local co-ordinator. 
October 1989

November 1989

January 1990

February 1990

March 1990

March - August 1990

June 1990

September 1990 - February 1991

November 1990

January 1991

September 1991
Field orientation

Report of field orientation send to community members Appointment local co-ordinator for 13 months

Recruitment of project group members

First official meeting of the project group

Preparation period

Start of the small workgroups

Activity period

Establishment workgroup 'continuation'

Grant proposals to province and municipality

Continuation of the project

Figure 4. Time schedule project implementation

The project started in 1989 with a community analysis conducted by university staff. Written materials on the community were collected, a score of key figures from different sectors in the community was interviewed and short street interviews were conducted. The major goals of this analysis phase were to analyze local structures, resources and barriers, to introduce the project in the community, to achieve early community involvement, and to answer some important implementation questions such as which community sectors should be involved in the further implementation of the project.

The results indicated that the need to do something in the community to prevent cancer and coronary heart diseases was widely acknowledged. In the street interviews cancer, smoking and bad nutrition were spontaneously mentioned as the main health problems in the community. There did not seem to be another (health) problem that was perceived to be more important by the inhabitants. Most key figures showed their interest in the project and some of them expressed their willingness to contribute to the project. Eleven sectors were mentioned that should be involved in the further implementation of the project. It was indicated that the project could link up with the (limited) disease prevention efforts that were already undertaken in the community. A report with the results of the community analysis was sent to all key figures in the community (Van Assema, 1989).

In January 1990, a part-time local co-ordinator who lived in the community was hired. Her main tasks were to co-ordinate the project, to stimulate and support the project group members and to prepare and chair the meetings. The local co-ordinator had a background in social-cultural work, was enthusiastic 
and energetic and knew the community. The local co-ordinator invited all the sectors mentioned during the community analysis to participate in a project group. All sectors agreed, resulting in a project group with eleven representatives from local government, the women's association, the health sector, the National Cross Association?, an environmental organization, the cultural sector, the association for the elderly, the organization for industry and shops, and three neighborhood associations. In March 1990, a meeting was organized for project group members, local co-ordinator, university staff, mayor and aldermen, and press. During this meeting the project group was offered the workbook and a small budget by the university staff. This meeting marked the official start of the project. The project group took about three months to. organize themselves, make agreements about for instance the decision-making process, goals, roles and responsibilities, and decide about the activities. They decided to call the project. 'Healthy Bergeyk'. The project group chose to organize most of the activities in the workbook and some own activities. Then, four small workgroups were formed. One of the small workgroups took responsibility for the planned mass media activities. Another workgroup sef itself the task of establishing a local information center where inhabitants could enroll in activities, request materials and get information about the project. The other two groups took responsibility for group and structural activities respectively. The local co-ordinator participated in all workgroups. The whole project group also continued to meet regularly, especially to keep each other informed about the progress and results of the activities.

Health activities were organized in Bergeyk from September 1990 through February 1991. An overview of established activities, organized according to risk behavior, is given in Table 1 .

Except for the smoking cessation course and the cooking course, all activities were free of charge for participants. The costs for the separate activities were either moderate or low.

The project group co-operated with other people and organizations in the community in organizing the activities. For example, they worked with a group of five dietitians who voluntarily helped the project group with nutrition activities. Sixteen other community members were recruited to work as volunteers in

7 The National Cross Association is a large Dutch association with a mission to provide medical aids, community care and general prevention. 


\section{Smoking}

newspaper article

small group course

self-help manual

questionnaire on smoking policies

letter to workplaces and associations

\section{Nugrition}

newspaper article

cooking course

living room session

lecture

self=help fat reduction program

newspaper advertisement

with healthy recipes

sanciwich 'Healthy Bergeyk'

advice to workplace cafetarias

recipes to cafetarias and restaurants

\section{Alcohol}

newspaper article

questionnaire on alcohol policies

letter to workplaces and associations

letter to local government

letter to cafes and discotheques

\section{Solarium}

newspaper article

\section{General}

newspaper article

exhibition

information market 
the project's information center. The project group also gained the involvement of the police and food shop owners.

Continuation of the project was discussed in the project group in November 1990. A workgroup was formed to study the possibilities for continuation. The workgroup advised the project group to try to get grants from provincial and local government for continuing the project and the appointment of the local coordinator for another experimental period of two years. After these two years the project should have to become a structural part of local health policy.

\section{Continuation of the project}

After a few months" break. (March 1991-August 1991) the project has been continued by the project group with a grant from locall and provincial government ${ }^{8}$. At the restart of the project in September 1991, the design of the project. was changed based on the experiences gained diuring the first experimental year of the project. The project group has become the board of an official 'Healthy Bergeyk' Foundation. All sectors, except local government, are still represented in this board. Local government feared conflict of interests, because they partly subsidize the Foundation. In the new structure, the board defines the policy of the Foundation. Other community members are recruited for task groups which prepare and organize activities in the community. The project focuses not only on the four risk behaviors, but also on other risk behavior and health problems. The university is represented on the project advisory committee now, as are two regional health organizations. The advisory committee has regular meetings with the new local co-ordinator.

\section{Evaluation}

A health promotion project can be evaluated at one or more of three levels: process, impact, and outcome (Glanz et al., 1990). Impact data can provide information about whether an intervention has changed (determinants of) health behavior. Process data can help to answer the question why the intervention

8 At the end of the research period of the 'Healthy Bergeyk' project, a policy study was conducted by De Bruijn (1993) based on the Agenda-Building Theory of Cobb and Elder (1983). The purpose of the study was to predict whether a formal preventive health policy would be developed in Bergeyk as a continuation of the 'Healthy Bergeyk' project. Perceptions about the project of key figures in Bergeyk were studied. The study found that, although it could be assessed that the familiarity of the project was high and support for the projeci less high, no conclusions could be made about the continuation of the project. 
was effective or why not. Outcome evaluation assesses the distant or ultimate effect of a program and provides answers to bottom-line questions about changes in morbidity, mortality and quality of life.

In the evaluation of the 'Healthy Bergeyk' project both impact data and process data were collected. Due to the short time period of the research, measurement of reductions in cancer incidence was not possible and therefore could not serve as an effect indicator. Impact data were collected in the effect evaluation, process data in the process evaluation.

\section{Effect evaluation}

The effect evaluation of the 'Healthy Bergeyk' project is reported in detail in chapter 4 of this thesis. The effect of the project on the four cancer-related risk behaviors was studied by means of a pretest-posttest control group design, with two posttests (Cook \& Campbell, 1979). This design was chosen as it rules out many threats to internal validity. As described earlier, the experimental community was selected at random from six Dutch municipalities; three were situated in the province of Limburg, the other three in the province of NoordBrabant. Bergeyk is situated in the province of Noord-Brabant. Subsequently, the control community was selected at random from the three municipalities in the other province, to ensure that mass media channels (regional newspapers, etc.) were as different for the communities as possible. The control community received no new intervention.

A cohort research sample was selected by taking a random sample of 1000 adults (age 18 and over) from the computerized population registers of both the experimental and control communities. The subjects received a letter before all measurements to inform them about the study, but not about the experimental condition they were in. Subjects were then interviewed by telephone on three occasions. The baseline survey was in February 1990 (T1). Follow-up interviews were conducted in February 1991 (T2) and September 1991 (T3).

The survey included questions on the four risk behaviors, but also measured demographic variables, attitudes, social influence and self-efficacy towards the four risk behaviors and intention to change the risk behaviors. Also, involvement with the community and some general variables, like perceived chance of getting cancer, were measured. In the experimental group, at T2, exposure to the project was assessed, using familiarity with the project and discussion about the project with other people as indicators. 
The results indicated a significant reduction in fat intake in the experimental community compared to the control community. This effect could be overestimated because of a floor effect in the control group, where the baseline mean fat intake was significantly lower than in the experimental community. However, a dose-response effect between project exposure and reduction in fat intake that was found in the experimental community, strengthened the likeliness that the reduction in fat intake was caused by the project. Also, a floor effect in the control community is not obvious, as mean fat intake is as high as 40 per cent of total energy intake in the Netherlands (Hulshof \& Van Staveren, 1991). At least a $12.5 \%$ reduction in fat intake is recommended compared to current intake (from 40 to $30-35$ per cent of total energy intake) (Dutch Nutrition Council, 1986b, 1991) and this is not an unfeasible goal (Kistemaker, 1991). In our study, the mean fat intake in the experimental community decreased by 1.2 points. This means a $4.3 \%$ reduction compared to baseline fat intake.

No significant group differences were found for smoking, although resuits were in the expected direction. In addition to this, there was a trend towards a greater percentage of smokers who stopped between baseline and second posttest being people who knew the project.

Consistent with the higher priority given to the other risk behaviors, no significant effects were found for alcohol consumption and solarium use. However, it should be mentioned that from a study of Lemmens et al. (1992). in which several types of survey methods on alcohol consumption were compared, it can be derived that our instrument for measuring alcohol consumption might not have been a very reliable one and therefore not suitable for measuring changes in alcohol consumption.

It is difficult to compare the behavioral effects of the 'Healthy Bergeyk' project with those observed in other studies. In the Netherlands no results of comparable projects are as yet available. Comparison with foreign communitybased prevention projects is difficult as the target populations for these projects were much larger and the projects lasted much longer. Also, effect measurements differed, especially for fat intake.

In addition to studying the behavioral effects of the project, special attention was given in the effect evaluation to the determinants of program exposure. Attention for the project is the first phase in the behavioral change model and a prerequisite for further change. Results indicated that people exposed to the project were more involved with their community, and more likely to be female. 
married and with middle or higher education. Baseline risk behavior did not influence project exposure.

\section{Process evaluation}

The process evaluation of the 'Healthy Bergeyk' project is reported in detail in chapter 5 of this thesis. The main objectives of the process evaluation were to assess what was done and how this was evaluated by participants and leaders of activities, project group members and the community in general, in order not only to assess whether the project implemented as planned, but also to give rapid feedback to those involved in the planning and organization of the project.

Data collection took place throughout the implementation period of the project (March 1990 through February 1991). Data were gathered using a mix of data collection methods: minutes of meetings, registration forms, prestructured telephone interviews, written questionnaires, and semi-structured interviews. Community members were involved in the data collection.

The results indicated that the project group achieved many health activities in their community in a short time period. Most of the activities focused on fat consumption. Several activities focused on smoking cessation, while just a few activities were directed at the reduction of alcohol consumption and the use of solaria (Figure 5). The project group had problems organizing structural activities. These activities were perceived to be difficult to achieve. Shops, restaurants, cafetarias and workplaces were expected to be unwilling to participate. They were also afraid that shops, restaurants and cafetarias might take their own advantage of the activities. The project group did not want to be viewed as people that poke one's nose into everything. They did not want to force other people to a specific behavior. In their opinion, people and organizations should ask for these activities themselves.

The number of inhabitants that participated in group activities or requested self-help materials was not large. In some cases this was due to enrollment limits of the activities. It seemed that if the implementation period had been longer, participation rates would have been higher. The group activities and selfhelp materials seem to have reached especially women with a low level of education and specific parts of the community. However, as many participants indicated they had talked about the activity with other people, there might have been a spin off effect. In general, participants in group or self-help activities were positive about the activity and the activities seem to have been quite effective in achieving their goals. 
Familiarity with the project in the community was high. Directly after the implementation period $82.4 \%$ of the 665 respondents who completed the first posttest of the effect evaluation were familiar with the project: $42.4 \%$ could mention the name of the project and $40 \%$ could not mention the name, but recognized the name after the interviewer mentioned it. Mass media seemed to have been an important source of information. Also, almost $37 \%$ of all respondents indicated they had discussed the project with someone else. The general opinion in the community about the project was positive and supportive of a continuation of the project.

The main positive elements of the project concerned the workbook and the intersectoral co-operation. The workbook was positively evaluated by the project group members and used a lot. Due to the workbook a rapid start to the project was possible. As the project group decided to organize the greater part of the workbook activities, a package of activities was organized that was based on health education theory and methods. The intersectoral composition of the project group was positively evaluated by all participants. According to the project group members, communication between the sectors has been improved due to the co-operation and more was achieved than if they would not have worked together.

A negative aspect of the project was the short implementation period. There was a lot of time pressure on the project and the project group members were overburdened. The project group members indicated that better information about time investments should have been given at the beginning of the project. One of the most negative consequences of the time pressure was that there was no time to carry over knowledge and skills to the community. The local coordinator spent a lot of time on practical jobs to make sure that intended health activities could take place, instead of creating conditions for the continuation of the project. This resulted in a lack of expertise in those involved in the project and therefore the university had to interfere in the project in order to ensure that the group would organize effective activities. This was not appreciated by the project group and did not improve ownership of the project. For this reason, and also because the discussion about continuing the project started too late, the continuation of the project did not proceed easily. The aim to continue the project without the local co-ordinator after the one-year period was not realized.

Another problem was that the risk behaviors the project should focus on had already been defined by the university and could not be changed due to grant conditions. 


\section{General conclusions}

The research project described in this thesis tried to develop a well-planned, low-budget cancer prevention intervention that was based on sound theory. At the same time consideration was also given to practical implementation questions. Our first overall conclusions is that with the limitations of the project in mind the results of the community project are encouraging. Although the project was only partially successful in reaching its behavioral objectives, the project led to effective, appreciated and integrated health promotive activities in the community at short notice and achieved high community awareness and support. A relevant reduction in fat intake was found one year after the first meeting of the project group. This reduction in fat intake was sustained at least for another half-year. Besides this, changes in the percentage of smokers were in the desired direction.

The workbook was a key element in the project and served to integrate health education theory and methods with the community organizing process. The workbook was a tool that enabled the university staff to leave the implementation of a well-planned intervention for the greater part to the community, thereby creating the opportunities for community participation and involvement. Through the workbook the physical presence of the university staff in the community could be reduced to a minimum.

The project appears to have drawn effectively on some community organization principles, especially intersectoral co-operation. However, it was difficult to combine quality and effectiveness of health education and health promotion activities with high community ownership of the project and longterm project continuation. Participation opportunities were perceived to be limited, especially in defining the problems the project would focus on. More community control might have improved community involvement and ownership and might have increased the probability of long-term continuation of the project which, in turn, might have improved effectiveness. On the other hand, more community control might also have led to the organization of less effective activities in the community which would have reduced the project's effectiveness. In spite of the limited community participation an intersectoral network for health promotion which functioned well was created in the community which continued the project after the experimental period. More insight into whether there was actual intersectoral co-operation and into the determinants of the successful co-operation might have been obtained if, in the 
development and evaluation of the project, the theoretical insights into the process of intersectoral co-operation, for instance the work of Gray (1985), had been used more explicitly.

Another limitation of the project was the short implementation period, due to the fact that the research had to be finished within a certain time period. If the implementation period had been longer, the number of people participating in local health activities might have been higher and therefore the behavioral effects might have been better.

In the interpretation of the project's results it should also be kept in mind that the multiple risk factor approach might have reduced the potential effect on one risk behavior. For example, smokers might have chosen to reduce their fat intake instead of quitting smoking (see also Schwartz, 1987).

The project was not intended as a project: to reach people with lower socioeconomic status. However, awareness and participation rates in this group might give an indication of the success of the community organization approach. The findings showed that project awareness was positively related to level of education. However, the process evaluation showed higher participation rates for lower educated people. This was, however, especially connected to the high participation of women in a specific age group, whose levell of education might not be the best indicator of their socio-economic status.

\section{Methodological limitations}

In this section, the main methodological shortcomings of the research project are discussed.

In the effect study no physical measurements, such as cholesterol or $\mathrm{CO}$, were taken beyond self-reported behavior, which can be seen as a limitation of the study. Physical measurements can enhance the validity of the self-reports.

Another limitation of the effect study was the nonfeasibility of a multiple communities design. Therefore, individuals were taken as the unit of analysis. This means that though the communities were randomized, the individuals within the communities were not and results might be biased due to factors that differ between the experimental and community group. However, several demographic variables were measured and the influence of those variables that differed significantly between the groups was checked.

In the effect study, in addition to seeking significant differences in behavioral change between the experimental and control community, evidence for a dose- 
response relationship was sought by partitioning the experimental sample by level of exposure. The dose-response relationship as found between exposure and change in fat consumption was used to strengthen the possibility that the behavioral change in the experimental community compared to the control community was caused by the project. However, it should be kept in mind that such a result does not address the rival hypothesis of self-selection, i.e. those who selectively attend to a message could be those who spontaneously change (Flay \& Cook, 1981).

A proper evaluation study of a complex project should not be limited to the assessment of its final outcomes. Any real insight into the projects effectiveness can only be obtained when there is also a good process evaluation. The study findings show that due to the process evaluation the project was documented extensively and that successful and less successful elements of the project were assessed. The evaluation also produced enough information to explain the (lack of) behavioral effects of the project. The data of the process evaluation were used to give fast feedback to the staff as well as the involved community members. However, some of the results of the process evaluation should be interpreted carefully. High satisfaction was found in project group members and participants of activities. However, satisfaction is a difficult concept to measure. High levels of satisfaction are found in most programs (Pirie, 1990).

Furthermore, lack of pretests can been seen as one of the limitations in the evaluation of the group and self-help materials in the process evaluation. Pretests would have created better possibilities to assess changes in (determinants of) risk behaviors as a result of the activities.

One of the disadvantages of the involvement of community members in the data collection was that interviews were not always conducted properly. In retrospect it would have been better to involve them in the questionnaire development also. Their involvement would probably also have given them more insight in the importance of some of the questions in the interviews and of the process evaluation in general.

\section{Implications for community projects in the Netherlands}

The 'Healthy Bergeyk' project has been an unique project, in the sense that at the start of the project in 1989 similar projects (i.e. health projects integrating 
leave possibilities to adapt the activity to the locai situation and needs of the population. For the development of the scenario's research studies should be stimulated. For many risk behaviors, local health activities are not evaluated or not even developed yet. Therefore, more research is needed on the development and evaluation of local health activities. In behalf of this, information exchange and co-operation between field workers and researchers should be improved, because research studies should be tuned to local needs and new activities should be tested in a field setting.

It is also recommended that the possibilities for community participation in the project should be as large as possible, without going at the cost of the effectiveness of the intervention and the workability of the project. In addition to project group members other community members should be involved also, for instance by asking them to participate in task groups that are responsible for the organization of a specific activity. Furthermore, all persons involved in the project should be informed immediately and explicitly about the expected time investment and the goals for long-term continuation of the project. Also, preferably, the community is not only involved in the selection of activities, but also in the selection of the health problems and health behaviors the project will focus on. Selection of health problems and risk behaviors should be based on both the results of epidemiological research and the needs in the community. Guidelines for selection should be included in the workbook. However, at this moment, it is extremely difficult to get a grant for a project aiming at community participation in problem definition, because the specific health objectives of the project cannot be defined in advance. Therefore, we think new procedures of grant making are necessary in the Netherlands for community participation in problem definition to be possible in projects.

Finally, it takes time for community projects to get going. In the beginning of the project the role of the local co-ordinator is essential. The local co-ordinator should have the skills to motivate people, to co-ordinate the project and to help people to work together. In the beginning of the project, the local co-ordinator is the face of the project, the powerful center. Later on, the co-ordinator should make him or herself superfluous by carrying over tasks and expertise. Finally, the project will have a solid foundation in the community and activities will be incorporated into the existing structures of the community. However, this might take some years. Therefore, the appointment of the local co-ordinator should be longer than the one-year appointment of the co-ordinator in the 'Healthy Bergeyk' project. Also, sufficient time and effort should be devoted to the 
selection of a co-ordinator. A good co-ordinator is a first prerequisite for the success of a local project. 



\title{
Chapter 2
}

\section{The determinants of four cancer-related risk behaviors ${ }^{1}$}

\begin{abstract}
This paper reports research into the determinants of four cancer-related risk behaviors: smoking, excessive alcohol consumption, high fat consumption and use of solaria. The results indicate that the four types of risk behavior are determined by several factors: the perceived behavior of the social environment, individual's attitudes: towards the risk behavior, and self-efficacy perceptions on changing the risk behavior. High fat consumption differs from the other risk behaviors, in that people tend not to be aware of their high fat consumption. No significant relationships were found among the risk behaviors apart from small correlations between smoking and heavy alcohol consumption and between high fat consumption and heavy alcohol consumption. The implications of these results for the development of behavior change programs are discussed.
\end{abstract}

\section{Introduction}

Primary prevention of cancer has become an important goal of health care policy in most countries, including the Netherlands, where breast and lung cancer rates are among the highest in the world (U.S. Department of Health and Human Services, 1985). Cancer prevalence can be greatly reduced by changes in individual behaviors such as smoking, excessive alcohol consumption, high fat consumption and excessive exposure to UV radiation (Doll \& Peto, 1981; Doll, 1989). The development of interventions that can realize these behavioral changes requires a systematic approach, including the assessment of the psycho-social determinants of the risk behaviors (Kok \& De Vries, 1989).

1 Will be published as: Van Assema, P., Pieterse, M., Kok, G., Eriksen, E., \& De Vries, H. (1993). The determinants of four cancer-related risk behaviours. Health Education Research, 8. 
Several theoretical models can be used for explaining human behavior, such as the Theory of Reasoned Behavior (Ajzen \& Fishbein, 1980), the Health Belief Model (Janz \& Becker, 1984), Social Learning Theory (Bandura, 1986) and the Theory of Planned Behavior (Ajzen \& Madden, 1986). The 'Attitude - Social influence - Efficacy model' (ASE model) (De Vries et al., 1988; Kok et al., 1991) combines the most important psycho-social behavioral determinants. According to this model, behavior is determined by people's attitude towards the behavior, social influence and self-efficacy. An attitude represents a person's general feeling of (un)favorableness towards the behavior, and is determined by perceived positive and negative consequences of the behavior. Health is only one of the possible attitudinal considerations and is often a relatively unimportant one compared with considerations such as costs, (dis)like, status, etc. (Hochbaum, 1983). Social influence refers to the influence of others, both directly (expectations of important others) and indirectly (what others do). Selfefficacy refers to a person's expectation regarding his capability to realize a (desired) behavior. Attitudes, social influence and self-efficacy predict the intention to perform the behavior which, in turn, predicts the behavior itself. External variables, such as demographic variables, influence behavior via the three determinants and the intention. Between intention and behavior there may be barriers or lack of skills. These barriers and skills only become important if the behavior is actually performed. Actual performance of the behavior leads to a feedback process that, in turn, influences the three determinants.

The main purpose of the present study was to analyze the determinants of four cancer-related risk behaviors (smoking, excessive alcohol consumption, high fat consumption and use of solaria) in the adult Dutch population. Attitudes, social influence and self-efficacy beliefs for all four behaviors were compared between those who performed the risk behavior and those who did not, as well as between those who intended to change their risk behavior and those who did not. Furthermore, the study focused on the question whether the risk behaviors were interrelated and, if so, whether they had common determinants. The study was not intended as a risk factor prevalence study. The implications for behavioral change interventions are discussed and suggestions for intervention strategies are provided. 


\section{Method}

\section{Instrument development}

In order to develop questionnaires for telephone interviews, a pilot study was conducted using focus group interviews. The main aim of this pilot study was the operationalization of the theoretical concepts: attitude, social influence and self-efficacy. For each behavior, the focus group interviews resulted in the following questionnaire items:

(1) Between 8 and 11 items (depending on the risk behavior) on the advantages and disadvantages of the risk behavior; the sum of the scores of these beliefs produced a score for indirect attitude.

(2) Two questions on whether the risk behavior is good/bad or pleasant/unpleasant; the sum of the scores of the two questions produced a score for direct attitude.

(3) One question to measure perceived behavior of the social environment.

(4) Two consecutive questions to measure subjective norms indirectly; the sum of all the scores on the second question produced a score for subjective norm.

(5) Three to four questions (depending on the risk behavior) about different situations to measure self-efficacy; the sum of the scores for the different situations produced a score for self-efficacy.

(6) One question to the performers of a risk behavior about anticipated barriers if they were to change the risk behavior.

Some examples on how these questions on behavioral determinants were presented to subjects and how responses were rated can be found in Annex 1 .

Smoking behavior was measured by asking subjects whether they smoked cigarettes. Respondents were classified as a risk performer if they answered yes to this question. Smokers were also asked to indicate the number of times they had tried to quit.

Alcohol consumption was measured by asking the respondents to indicate the number of times they drank six or more glasses on a single day in the last 6 months. Also, weekly consumption was estimated by asking about the alcohol consumption on two recent weekdays and the most recent three weekend days. Respondents were classified as a risk performer if they consumed six glasses of alcohol at least once a week or had a weekly consumption of at least 22 glasses. In the Netherlands, glasses of alcohol usually contain $1.25 \mathrm{cl}$ alcohol, independent of whether it is beer, wine or spirits. 
Fat consumption was measured by a 25-item questionnaire covering 12 (groups) of food products. For each of the 12 (groups of) food products a fat score - ranging from 1 point (lowest fat intake) to 5 points (highest fat intake) was determined. An individual total fat score was calculated by adding up the 12 food product fat scores. Consequently, this total fat score ranged from 12 to 60 points (Van Assema et al., 1992c). Respondents who scored in the upper tertile of this questionnaire were classified as risk performers. In addition, selfreports of fat consumption were obtained by asking the respondents whether they thought they were (relatively) fat or (relatively) lean eaters.

Exposure to UV radiation was measured by questioning the frequency of solarium use in the past year. Respondents were classified as a risk performer if they used a solarium at least once during the last year.

Finally, the questionnaires contained questions about age, gender, education, perceived health status and intentions to change risk behavior.

Because many variables were to be measured, not all variables could be included in one questionnaire. Therefore, seven partially different questionnaires wore developod in such a way that in separate subsamples determinants could be related to risk behaviors, risk behaviors could be related to each other and determinants could be related to each other. Four separate questionnaires focussed on the separate risk behaviors, assessing all determinants for this behavior; three questionnaires focussed on all four risk behaviors but only assessed one determinant: either attitudes, social influences or self-efficacy.

\section{Data collection}

The research population was selected by taking a random sample from the Dutch telephone directories. Subsequently each telephone number in this sample was randomly assigned to one of the seven questionnaires. The total population for the study consisted of 1600 adults. The questionnaire on smoking was completed by 100 smokers and 100 non-smokers, the questionnaire on alcohol consumption by 100 relatively low alcohol consumers and 100 relatively high alcohol consumers (i.e. at least once a week six or more glasses on a single day or a weekly consumption of at least 22 glasses), and the questionnaire on solaria by 100 users and 100 non-users of solaria. Preselection for these three questionnaires took place by asking respondents about risk behavior prior to the interview. For instance, as soon as 100 nonsmokers had been reached, only smokers were interviewed. The other four questionnaires were each completed by 250 subjects, without preselection. An 


\begin{tabular}{llll}
\hline Questionnaire 1 & Questionnaire 2 & Questionnaire 3 & Questionnaire 4 \\
$\mathrm{N}=200$ & $\mathrm{~N}=200$ & $\mathrm{~N}=200$ & $\mathrm{~N}=250$ \\
Preselection & Preselection & Preselection & \\
\hline
\end{tabular}

\section{Smoking behavior}

\section{Alcohol consumption}

\section{Solarium use}

\begin{tabular}{|c|c|c|c|}
\hline & & & Fat consumption \\
\hline Attitude & Attitude & Attitude & Attitude \\
\hline Social influence & Social influence & Social influence & Social influence \\
\hline Self-efficacy & Self-efficacy & Self-efficacy & Self efficacy \\
\hline Questionnaire 5 & Questionnaire 6 & Questionnaire 7 & \\
\hline $\mathrm{N}=250$ & $N=250$ & $N=250$ & \\
\hline Smoking behavior & Smoking behavior & Smoking behavior & \\
\hline Alcohol consumption & Alcohol consumption & Alcohol consumption & \\
\hline Solarium use & Solarium use & Solarium use & \\
\hline $\begin{array}{l}\text { Fat consumption } \\
\text { Attitude }\end{array}$ & Fat consumption & Fat consumption & \\
\hline
\end{tabular}

Social influence

\section{Self efficacy}

Figure 1. Overview of questionnaires and samples

overview of questionnaires and samples is given in Figure 1. The telephone interviews were conducted by 15 trained female students using personal computers having program which allowed immediate data input. The average time for telephone administration of the questionnaires was 20 minutes.

\section{Analyses}

The overall explained variance by the determinants for each of the risk behaviors was determined by multiple regression analysis, using the results of the four questionnaires focusing on the behaviors separately.

Statistical differences between those who performed the risk behavior and those who did not, and between those who intended to change their risk behavior and those who did not, were determined by univariate analysis of variance - also using the results of the four questionnaires focusing on the behaviors separately. People scoring in the upper tertile of the fat consumption questionnaire were compared with people scoring in the lower tertile. The 
influence of external variables, such as age, gender and education was studied using analysis of covariance with the external variables as covariates. If analysis of variance showed significant results, while analysis of covariance did not, it was studied which covariate was responsible. Subsequently, a two way or three-way analysis of variance was conducted with the significant covariate(s) as independent variabie(s) next to risk behavior. The results of these subanalyses will only be mentioned if significant.

The results of the three questionnaires focusing on all four risk behaviors $(N=750)$ were used for risk factor prevalence rates and correlations between the risk behaviors.

\section{Results}

Prevalence of risk behaviors, intentions and correlations between risk behaviors

Of the respondents, $32.3 \%$ reported that they smoked cigarettes. Of the smokers, $27 \%$ intended to stop smoking, while $21 \%$ intended to smoke a (bit) less. Almost $65 \%$ of the smokers indicated that they had tried to stop smoking at least once; of these $30 \%$ said they had tried three times or more. Of the respondents, $11.3 \%$ appeared to be heavy drinkers, consuming at least once a week six or more glasses on a single day during the last 6 months or at least 22 glasses in the week before the interview. Slightly more than $30 \%$ of the heavy drinkers intended to drink less; of these half intended to drink reduce alcohol intake substantially. As mentioned above, persons who scored in the upper tertile of the fat consumption questionnaire were defined as being high fat consumers. Only $15.5 \%$ of the high fat consumers expressed an intention to eat less fat. In the self-reports of fat consumption less than $20 \%$ of the respondents believed that they ate too much fat. Self-reports of low or high fat consumption correlated moderately with the fat consumption questionnaire $\{r=0.35, p<0.001)$. Of the respondents, $16.5 \%$ used a solarium at least once during the last year; of these about $30 \%$ wanted to reduce $(18 \%)$ or stop using it $(10 \%)$. Users of a solarium also exposed themselves more to natural UV radiation during vacation, work and leisure time.

As may be seen from Table 1, two-thirds of the respondents performed at least one risk behavior, while approximately $25 \%$ engaged in two or more risk behaviors. Table 2 shows that only smoking and heavy alcohol consumption, and high fat consumption and heavy alcohol consumption were moderately 


\begin{tabular}{ccc}
\hline $\begin{array}{c}\text { No. of } \\
\text { risk } \\
\text { behaviors }\end{array}$ & $\begin{array}{c}\text { Per cent } \\
\text { valid } \\
(\mathrm{N}=732)\end{array}$ & $\begin{array}{c}\text { Per cent } \\
\text { cumulative }\end{array}$ \\
\hline 4 & 0.4 & 0.4 \\
3 & 5.2 & 5.6 \\
2 & 18.6 & 24.2 \\
1 & 41.0 & 65.2 \\
0 & 34.8 & 100.0 \\
\hline
\end{tabular}

Table 2. Correlations between risk behaviors

\begin{tabular}{lccc}
\hline & Smoking & Alçohol & Fat \\
\hline Alcohol & $0.23 \cdots$ & & \\
Fat & 0.03 & $0.10^{\prime \prime}$ & \\
Solarium & 0.05 & 0.01 & 0.01 \\
\hline
\end{tabular}

$" p<0.01, \cdots p<0.001$

correlated. No other significant relationships were found between the risk behaviors.

Overall explained variance and the contribution of the determinants in expleining risk behavior

Table 3 shows that the overall explained variance varied from $20 \%$ for fat consumption to $69 \%$ for smoking behavior. Attitude made the largest contribution in explaining the risk behavior, except for smoking behavior, where self-efficacy provided the largest contribution.

\section{Attitude towards the risk behavior}

Table 4 shows that for all the four behaviors, risk performers held less negative attitudes towards the risk behavior than people not at risk; they thought the particular behavior was not as unpleasant and not as bad as non-risk people thought it was.

More specifically, Table 5 shows that differences in attitude between smokers and non-smokers were related to beliefs that smoking tastes good, is 
Table 3. Correlations of determinants with the risk behaviors and overall explained variance by the determinants for each of the four risk behavior

\begin{tabular}{lcccc}
\hline & Smoking & Alcohol & Fat & Solarium \\
\hline Direct attitude & 0.61 & 0.48 & 0.41 & 0.49 \\
Indirect attitude & 0.71 & 0.69 & 0.31 & 0.48 \\
Behavior social environment & 0.30 & 0.49 & 0.28 & 0.30 \\
Indirect subjective norm & -0.14 & 0.07 & 0.05 & 0.02 \\
Self-efficacy & 0.77 & 0.58 & 0.21 & 0.28 \\
Overall explained variance & $69 \%$ & $59 \%$ & $20 \%$ & $31 \%$ \\
\hline
\end{tabular}

sociable, is good for the nerves, smells good, causes shortness of breath and some other (less distinctive) beliefs.

Heavy drinkers had a stronger belief that heavy alcohol consumption tastes good, being intoxicated is pleasant and that they could tolerate a lot of alcohol. Also, they believed that heavy drinking is a way of feeling relaxed, makes it easier to interact with other people and helps to work out problems. The belief that heavy alcohol drinking is related to cancer risk was not strongly held by the respondents.

Attitudinal differences between high and low fat consumers were primarily related to beliefs that a high fat food pattern makes you fat, high fat food tastes good and is gratifying. The belief that a high fat consumption is related to cancer was not strongly held among those with either low or high fat consumption. Analysis of covariance showed that differences between high and low fat consumers on beliefs concerning skin problems and tolerance could be attributed to differences between men and women. The beliefs that a fat food pattern creates skin problems and is not as easy to tolerate were more strongly held by women than men.

Use of solarium appeared to be primarily associated with relaxation and feeling good. Users more than non-users liked the warmth on their skin and reported that solarium use gave them a relaxed feeling. Furthermore, users believed more strongly that the use of a solarium protects them from sunburn in the real sun and that it is good for their bones and muscles. Non-users were more convinced that using a solarium is unnatural. Moreover, users, as opposed to non-users, thought that the use of a solarium made them look more beautiful and healthy. Not as distinctive, but still significant, were differences between users and non- 


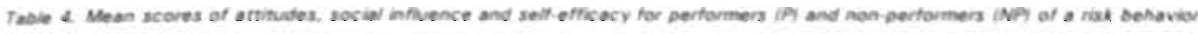

\begin{tabular}{|c|c|c|c|c|c|c|c|c|c|}
\hline & \multicolumn{3}{|c|}{ Smoking $(\mathrm{N}-200)$} & \multicolumn{2}{|c|}{ Alcohol $(\mathrm{N}=200 \mathrm{i}$} & \multicolumn{2}{|c|}{ Fat $(\mathrm{N}=178)$} & \multicolumn{2}{|c|}{ Solanum i $=2001$} \\
\hline & & NP & $P$ & NP & $P$ & Ne & $\mathbf{P}$ & NP: & $p$ \\
\hline Risk behav is good $(-2)$ or bad $(-2)$ & 111 & -1.82 & $1.50 \cdots$ & 1.91 & $1.32 \cdots$ & 170 & 0990 & 1.34 & $0.200=0$ \\
\hline Risk behav a pleasant $(-2)$ of unpleasant $(-2)$ I & $|2|$ & 1.00 & $131 \cdots$ & 155 & $0.20 \cdots$ & 0.78 & $0.35 \cdots$ & 0.94 & $064 \cdots$ \\
\hline Derect attitude $[1]+\mid 2]$ & & -2.82 & $0.19 \cdots$ & -3.47 & $-153 \cdots$ & 2.48 & $0.64 \cdots$ & -2.28 & $0.40 \cdots$ \\
\hline indirecr artitude $(\cdot 2) \cdot 2)^{\circ}$ & & -0.80 & $003 \cdots$ & 0.58 & $0.23 \cdots$ & -0.56 & $023 \cdots$ & 0.39 & $0,12 \cdots$ \\
\hline Behavior social environment $(+2) \cdot 2)^{6}$ & & -0.67 & $0.22 \cdots$ & 1.22 & $0.16=2$ & 057 & $0.26 \cdots$ & 1.31 & $055 \cdots$ \\
\hline Indirect subjective norm $(+2) \cdot 2)^{\circ}$ & & $0 \mathrm{BO}$ & $1.23^{\circ}$ & 0.70 & 0.56 & 0.61 & 0.54 & 0.37 & 0.33 \\
\hline Selt-efticacy $t+2 \%-2)^{4}$ & & -1.77 & $0.67 \cdots$ & 1.57 & $0.35 \cdots$ & 0.58 & $0.16 \cdots$ & -1.32 & $0.66 \cdots$ \\
\hline
\end{tabular}

${ }_{p}<0.05, \cdots p<0.01, \cdots p<0.001$

- 2. posivive artitude towards the nak behavior; -2 . negative artitude towards the rak behavor

". 2. many peopie in the social envronment who perform the rak behuvior, 2 , few people in the social environment who pertorm the nisk behavior.

1. 2. postive subjective norm towards the risk behavior, -2. negative subjective norm towards the risk behavior

4. 2. low self-efficacy towards the nsk behavor, -2 , high self-efficacy towards the nak behavor.

For those variables measured with a different number of items indirect artitude and seif efficacvl a mean score over all ifems is given in order to make results between risk behavion comparable

users in beliefs about increased cancer risk, getting sunburnt or an increased vitamin status from solarium use.

\section{Social influence}

Table 4 shows that people who performed a specific risk behavior had more people in their environment who performed the same risk behavior compared with those who did not.

Apart from smoking, there was no significant difference in subjective norm between performers and non-performers of the risk behaviors (Table 4). Most respondents stated that they were not affected by other people's opinion on the risk behavior. Further analysis of the items used to measure the subjective norm, showed that the difference in subjective norm between smokers and nonsmokers was mainly due to smokers stating significantly more often than nonsmokers that they gave in to non-smokers and perceived increased negative opinion on smoking from them $(p<0.01)$.

\section{Self-efficacy}

Those at risk had lower self-efficacy in relation to avoiding the risk behavior in specific situations (Table 4). However, analysis of covariance showed that the difference in self-efficacy between people with a high and a low fat consumption was caused by older people (age 60 and older) having higher selfefficacy expectations than younger people (under the age of 60 ). 
Table 5. Mean scores of beliefs $(+2 /-2)$ for performers (P) and non-performers: (NP) of a risk behavior

\begin{tabular}{|c|c|c|}
\hline Beliefs & NP & $P$ \\
\hline \multicolumn{3}{|l|}{ Smoking $(N=200)$} \\
\hline trouble to other people & -1.63 & $-1.28 * * *$ \\
\hline increases the risk of coronary heart disease & -1.55 & $-1.33^{*}$ \\
\hline increases the risk of cancer & -1.65 & $-1.21 * *$ \\
\hline tastes good/bad & -1.04 & $3.54 * *$ \\
\hline causes shortness of breath & -1.48 & $-0.89 * \cdots$ \\
\hline sociableiunsociable & -0.36 & $1.44 * *$ \\
\hline smells good/bad & $=1.51$ & $-0.26 * *$ \\
\hline good for nerves & 0.44 & $1.11 * *$ \\
\hline relieves boredom & 0.32 & $0.71 * *$ \\
\hline keeps weight down & 0.45 & 0.48 \\
\hline \multicolumn{3}{|l|}{ Alcohol $(\mathbf{N}=200)$} \\
\hline tastes good/bad & 1.26 & $1.29 * * *$ \\
\hline easy/difficult to tolerate & -1.11 & $1.40 * *$ \\
\hline increases the risk of coronary heart disease & -1.23 & $0.95^{*}$ \\
\hline pleasant/unpleasant to be intoxicated & -1.05 & $-0.15 * *$ \\
\hline easier to interact with other people & 0.22 & $0.56^{* *}$ \\
\hline feeling bad not being able to drive a car & -0.60 & -0.60 \\
\hline relaxing & 0.38 & $0.74 *$ \\
\hline increases the risk of cancer & -0.67 & 0.53 \\
\hline helps to work off problems & 0.07 & $0.31 * *$ \\
\hline \multicolumn{3}{|l|}{ Fat $(N=178)$} \\
\hline increases the risk of coronary heart disease & -1.74 & -1.63 \\
\hline makes you fat & -1.61 & $-1.13 * *$ \\
\hline gives skin problems & .1 .09 & $-0.79 *$ \\
\hline increase the risk of cancer & -0.63 & .0 .64 \\
\hline tastes good/bad & 0.17 & $0.81 *$ \\
\hline easy/difficult to tolerate & 0.12 & $0.85 *$ \\
\hline sociable/unsociable & 0.17 & 0.42 \\
\hline gratifying & 0.10 & $0.31 *$ \\
\hline \multicolumn{3}{|l|}{ Solarium $(N=200)$} \\
\hline unnatural & -1.78 & $-1.28 * * *$ \\
\hline dries up the skin & -1.33 & -1.11 \\
\hline running the risk of getting sunburnt & -1.13 & $.0 .89 *$ \\
\hline increases the risk of cancer & -1.12 & $-0.80 *$ \\
\hline feeling relaxed/tense & 0.46 & $1.32 *$ \\
\hline prevents burning in the real sun & 0.53 & $1.03 * * *$ \\
\hline pleasant/unpleasant heat on the skin & 0.13 & $1.24 * *$ \\
\hline good for bones and nerves & 0.27 & $0.63 *$ \\
\hline look more/less healthy & 0.15 & $0.59 * *$ \\
\hline look more/less beautiful & -0.21 & $0.44 *$ \\
\hline produces vitamins & 0.03 & $0.12^{*}$ \\
\hline
\end{tabular}

$" p<0.05, \cdots p<0.01, \cdots * p<0.001$ 
Table 6. Mean scores of self-efficacy $(+2-2)$ in specific situations for performers $(P)$ and nonperformers (NP) of a risk behavior

\begin{tabular}{|c|c|c|}
\hline Situations: & NP & $\mathrm{P}$ \\
\hline \multicolumn{3}{|l|}{ Smoking $(N=200)$} \\
\hline after dinner & -1.80 & $0.44 \cdots$ \\
\hline when you are at a party or in a bar or restaurant & -1.72 & $0.78 \cdots$ \\
\hline when you are in pleasant company & -1.80 & $0.80 \cdots$ \\
\hline \multicolumn{3}{|l|}{ Alcohol $(\mathrm{N}=200)$} \\
\hline when you are home in the evening & -1.85 & $-0.80 \cdots$ \\
\hline when you feel depressed & 1.58 & $-1.06 \cdots$ \\
\hline when other people offer you glasses of alcohol & -1.66 & $0.46 \cdots$ \\
\hline when you are at a party or in a bar or restaurant & -1.17 & $0.93 \cdots$ \\
\hline \multicolumn{3}{|l|}{ Fat $(N=178)$} \\
\hline when you are alone at home. & -1.48 & -1.18 \\
\hline when you see other people eat & -1.46 & $-0.99^{*}$ \\
\hline when you are hungry & -1.23 & 0.87 \\
\hline during the weekend & -1.16 & $-0.60^{*}$ \\
\hline \multicolumn{3}{|l|}{ Solarium $(N=200)$} \\
\hline when other people have a tan & -1.62 & $-1.07 \cdots$ \\
\hline when you think you do not look fit & -1.29 & $-0.65 \cdots$ \\
\hline when a solarium is readily available & .1 .05 & $-0.30 * *$ \\
\hline
\end{tabular}

*p<0.05, * $p<0.01, * * p<0.001$

More specifically. Table 6 shows that smokers seemed to find it especially difficult not to smoke in social situations. If they were to give up smoking, smokers would primarily expect problems like gaining weight, not being able to deal with stress, not knowing how to 'pose', becoming bad-tempered and not being able to resist a cigarette.

As was the case with smokers, social situations seemed to be most difficult for heavy drinkers. However, it was also less easy for them than for light drinkers not to drink at home or if they felt depressed. Heavy drinkers expected problems, such as not being able to resist aicohol or not being able to deal with stress and becoming bad tempered if they had to limit their drinking. Those who ate high fat diets primarily expected not being able to resist fatty products should try to eat less. The difference in self-efficacy between high and low fat scorers, in situations in which they see other people eat and during the 
Table 7. Mean acores of artitudes, social influence and self-efficacy for those who intend to change a risk behavior ilf and those who do not (NII)

\begin{tabular}{|c|c|c|c|c|c|c|c|c|c|}
\hline & \multicolumn{3}{|c|}{ Smoking $(\mathbb{N}=96 !$} & \multicolumn{2}{|c|}{ Alcohol $(\mathbb{N}=99)$} & \multicolumn{2}{|c|}{ Fat $\mathbb{N}=78:$} & \multicolumn{2}{|c|}{ Solarium $(\mathbb{N}=100)$} \\
\hline & & N!(58) & !138! & Nit69) & $(130)$ & Ni(63) & 11151 & NII72) & $(128)$ \\
\hline Aisk behav is good $(+2)$ or bad $(-2)$ & 111 & .1 .36 & $-1.82^{\circ}$ & -1.22 & -1.57 & -0.90 & -1.33 & 0.01 & $-0.75 \cdot$ \\
\hline Risk behav is pleasant $(+2)$ or unpleasant $(-2)$ & $\{2\}$ & $\uparrow .74$ & $0.82 \cdots$ & -0.25 & .0 .10 & 0.33 & 0.40 & 0.75 & 0.36 \\
\hline Direct attitude: $[1]+|2|$ & & 0.38 & $-1.00 * \cdots$ & -1.46 & -1.67 & .0 .57 & 0.93 & 0.76 & -0.39 \\
\hline Indirect attitude $(+2) \cdot 2)^{*}$ & & 0.17 & $-0.13 \cdots$ & 0.26 & 0.14 & 0.20 & -0.34 & 0.18 & $0.05 i$ \\
\hline Behavior social environment $(+2)-2)^{*}$ & & 0.41 & 0.03 & 001 & 0.37 & 0.97 & $0.53^{*}$ & -0.57 & -0.39 \\
\hline Indirect subjective nom $(+2)-2)^{\circ}$ & & -1.12 & .1 .47 & .0 .52 & .0 .63 & .0 .40 & $.1 \quad 13$ & -0.34 & -0.32 \\
\hline Self-officacy $(+2 i-2)^{4}$ & & 0.57 & 0.90 & -0.54 & $0.09 *$ & .0 .20 & 0.00 & -0.71 & -0.58 \\
\hline
\end{tabular}

"p<0.05. $\cdots p<0.01, \cdots p<0.001$

-+2 , positive attitude towards the risk. behavior; -2 , negative attitude towards the risic behavior.

+ + 2. many people in the social environment wha perform the risk behavior; -2 , few people in the social environment who perfom the risk. behavios

- +2 , positive subjective norm towards the risk behavior; -2 , negative subjective norm towards the risk behavior.

+2 . low self-efficacy towards the risk behavior; -2 , high self-efficacy towards the risk behaviot.

For those variables measured with a different number of items (indirect attitude and self-efficacy) an mean score over ali items is given in order to make results between risk behaviors comparable

weekend, could be attributed to older respondents (age 60 and over) having higher self-efficacy expectations in these situations than younger respondents (under the age of 60).

As far as the use of solaria was concerned, users found it more difficult than non-users not to use a solarium in situations in which they thought they did not look fit and when a solarium was readily available. An analysis of covariance showed that the difference in self-efficacy expectation in situations in which others have a tan was caused by male subjects and subjects aged 35 and over having higher self-efficacy than the other subjects.

\section{Differences between intenders and non-intenders}

Smokers who intended to stop smoking had a less positive attitude towards smoking than non-intenders (Table 7). More in depth analysis showed that they recorded a higher negative score on beliefs such as risk of cancer as a smoker $(p<0.01)$, smell $(p<0.01)$, sociability $(p<0.05)$ and smoking as a way of warding off boredom $(p<0.05)$.

Table 7 shows that those who intended to drink less alcohol had lower selfefficacy. It appeared from more in depth analysis that it was especially more difficult for intenders than for non-intenders not to drink if they did not feel on top form $(p<0.001)$. Similarly, those who intended to drink less were more likely to believe that heavy drinking helped them when they were having problems $(p<0.001)$. Intenders were also more likely to believe that heavy 
drinking was related to cancer $(p<0.05)$. Finally, intenders did not seem to be in such good health and could not tolerate heavy drinking as well as the nonintenders $(p<0.01)$.

Those who intended to consume less fat were more aware of risk performers in their environment, but did not differ in attitude from non-intenders. Only the belief that a fat food pattern gives skin problems appeared to differentiate 'intenders' from 'non-intenders': those intending to eat less fat reacted more negatively $(p<0.05)$. Furthermore, intenders seemed to be more aware of the fact that they might have difficulty in resisting fatty products $(p<0.01)$.

Those who intended to use the solarium less in the future were more likely than non-intenders to think that using a solarium is bad (Table 7).

\section{Discussion and implications for behavior change interventions}

Apart from small correlations between smoking and heavy alcohol consumption. and between high fat consumption and heavy alcohol consumption, no significant relationships have been found between the four risk behaviors in this study. This finding supports evidence from other studies conducted on correlations between health behaviors (Harris \& Guten, 1979; Mechanic \& Cleary, 1980; Calnan, 1985; Calnan \& Rutter, 1986). Strong correlations between the risk behaviors would have made it interesting to develop an index or scale of the risk behaviors and to investigate the determinants of such a lifestyle index or scale. Despite the absence of correlations, cancer can be caused by a combination of risk factors. Therefore, influencing lifestyles is more effective than influencing only one of the risk factors (U.S. Department of Health and Human Services, 1986). A study into the determinants of a combination of risk factors could have indicated points of impact for a lifestyle intervention. However, because of the lack of any strong or consistent pattern of inter-relationships between the risk behaviors in our study, no such attempts were undertaken. Therefore, in discussing the implications of the study findings for behavior change programs, we will primarily deal with each risk factor separately, although some comparisons between risk behaviors will be made.

In interpreting the results of this study, it should be born in mind that the overall explained variance by the model was quite limited, especially for fat consumption and solaria use. 


\section{Smoking behavior}

Smokers and non-smokers differ in attitude towards smoking, the number of smokers in their environment and self-efficacy. Only a small difference in subjective norm has been found between smokers and non smokers. The other three risk behaviors show even fewer differences in subjective norms between performers and non-performers. These findings can be confounded by artifacts within the measurement procedure. As a response to the question about pressure from significant others in respect of a specific risk behavior, most respondents stated that they are not affected by other people's opinion on the risk behavior at all. This is not surprising as social pressure often seems to be underestimated (Suls \& Miller, 1977): People may tend to think that their behavior mirrors their own attitude.

Most smokers appear to be 'precontemplaters', meaning that they do not intend to change their risk behavior (Prochaska \& DiClemente, 1984; DiClemente et al., 1985). These precontemplaters have more positive attitudes towards smoking than those who do intend to quit (contemplaters). By comparison to the precontemplaters it is not attitude, but the presence of many other smokers in their environment and their low self-efficacy - especially in social situations - which seem to be the main determinants of the smoking behavior of contemplaters. Many smokers report previous attempts to quit.

On the one hand, these findings imply that smoking interventions should place a greater emphasis on changing attitudes to shift the many precontemplaters to the phase of contemplation and action. On the other hand, for those smokers already in the phase of contemplation, the intervention should focus on improving self-efficacy (Den Boer et al., 1991). As self-efficacy proved to be especially problematic in social situations, changes in social acceptability and an increase in social resistance skills should be important intervention goals. Considerable effort should also be devoted to remotivating former quitters and training to maintain non-smoking behavior. Finally, as the risk behavior seems so strongly held and consistent with existing norms, smokers in all stages of change need incentives from their social and physical environment.

Giving information about pros and cons of smoking and not smoking, for example in mass media messages, is a possible way of achieving attitude change (McGuire, 1985; Flay, 1987). Our results indicate that, in particular, the social unacceptability of smoking, but also cancer risk and smell are items that should be stressed in such messages. Interpersonal methods and self-help programs are appropriate methods for improving skills (McGuire, 1985; 
Vartiainen et al., 1986; Schwartz, 1987). Another possible way of increasing self-efficacy is to use community members who have managed to stop smoking as social models in the program (Bandura, 1986). Structural provisions, such as non-smoking sections in buildings, can contribute to make smoking less socially acceptable for both precontemplaters and contemplaters, as can mass media messages that inform people who do not smoke about the role they can play in making smoking less socially acceptable, e.g. by asking smokers not to smoke in their house or at their worksite (Vartiainen et al., 1986). To remotivate former quitters, educational messages could stress the fact that there is a new stop smoking program which has proved successful. It is also important that these messages examine the expected problems the respondents indicated in our study when quitting, like weight gain and not being able to deal with stress: In order to maintain the non-smoking behavior people will especially need social support, feedback and incentives. Mass media can inform people who do not smoke how they can support quitters and give them appropriate feedback. Social support and feedback can also be given by telephone information and support lines and stop smoking courses should have follow-up sessions and stimulate mutual contact between participants (Schwartz, 1987). To increase the number of incentives for smokers from their social and physical environment, interventions should diffuse information via existing social networks and should include structural measures such as the establishment of smoke-free worksites and non-smoking sections in restaurants (Vartiainen et al., 1986).

\section{Alcohol consumption}

As far as alcohol consumption is concerned, risk takers have less negative attitudes towards drinking, more risk takers in their environment and lower selfefficacy - especially at parties, in bars and in restaurants. Compared with the other risk takers, heavy alcohol drinkers are the only ones who think the risk behavior is unpleasant, although not as unpleasant as people who do not drink as much think it is. Also, by comparison with the other risk behaviors, more salient beliefs about alcohol consumption are related to coping, such as 'helps to work off problems'. Those drinkers who intend to change their risk behavior have poorer health conditions and are more likely to believe heavy drinking is related to cancer. However, they are more aware of the importance of drinking alcoholic beverages when they have problems and how difficult it is not to drink. 
These results indicate that, like smoking interventions, alcohol interventions should focus on changing attitudes, but should also offer alternative ways for relaxation and coping with problems, increase resistance skills, and make the risk behavior less socially acceptable. As self-efficacy is especially problematic at parties, in bars and in restaurants, environmental changes should also be included in the intervention.

To change attitudes special emphasis could be placed in program messages on the relationship between heavy alcohol drinking and cancer risk. Alternative ways for relaxation and working off problems could, for instance, be offered using mass media and interpersonal methods. Interpersonal methods and selfhelp programs could be used to improve resistance skills. Environmental changes could be realized by improving the supply of alcohol-free drinks or low alcohol beers and wines at parties, in bars and in restaurants. To make excessive alcohol consumption less socially acceptable, organizations could be stimulated to make their receptions alcohol-free.

\section{Fat consumption}

Nutrition seems to be different from the other types of risk behavior, in that it also appears to be a knowledge/skill problem. While smoking is clearly known to be a risk, respondents do not appear to be aware of their nutritional risk behavior. Self-reports of low or high fat consumption do not correlate well with scores on the fat consumption questionnaire. Also, the small percentage of high fat consumers who intend to change their nutritional habits indicates that people might not be aware of their unhealthy eating habits.

These results show that increasing knowledge and skills to judge personal nutritional habits should take first priority in behavior change programs and considerable effort should be given to directing attention to the low-fat message. As soon as awareness is attained, changes in beliefs and social acceptability and increase in self-efficacy towards lower fat consumption should become a priority of programs.

To make people aware of their risk behavior, program messages could stress that 8 out of every 10 persons eat too much fat. Moreover, interpersonal methods and self-help programs could teach people to calculate their daily fat intake and to read food labels (Glanz, 1985). To direct attention to the low-fat message, changes in the physical environment, such as the availability and appropriate labelling of low-fat meals and snacks could be used (Albright et al., 1990; Anderson \& Haas, 1990; Samuels, 1990). Self-efficacy could be 
improved by the availability of recipes of low-fat meals and nutrition information in food-shops, restaurants and cafetarias (Glanz \& Seewald-Klein, 1986; Samuels, 1990). Skills could be improved in courses by comparing products, reading food labels and learning how to deal with social pressure.

\section{Solaria use}

Users of solaria have less negative attitudes towards the risk behavior than nonusers. Users relate use especially to relaxation, feeling and looking good. Like smoking, those users who intend to change have more negative attitudes than non-intenders. For these 'contemplaters' many users in their environment and low self-efficacy seem to be the main determinants of their solarium use.

Attitude change and self-efficacy improvement should be given priority in programs aiming at reducing exposure to UV radiation. Interventions should focus particularly on changing attitudes to shift the precontemplaters to the phase of contemplation and action. Alternatives, like relaxation techniques should be provided.

Ta change attitudes, program messages can stress some of the negative consequences of solaria use, e.g. cancer risk and eye damage. Also, messages can emphasize the fact that UV radiation is not essential for some of the perceived advantages of solaria, such as being good for bones or feeling relaxed.

\section{Final conclusions}

In general, the results of this study indicate that a comprehensive approach is required to change cancer-related risk behaviors in the general population, as risk behaviors are determined by several factors and seem to be strongly held and socially accepted. A multi-component and multi-level intervention will be required to bring about the necessary changes in behavioral determinants. Mass media activities as well as interpersonal methods, self-help programs, structural activities and a social network approach should be part of interventions. Such comprehensive programs seem to be best accomplished at the community level (Farquhar et al., 1984; Puska, 1984; Mittelmark et al., 1986; among others). 



\title{
Chapter 3
}

\section{The reliability and validity of a Dutch questionnaire on fat consumption as a means to rank subjects according to individual fat intake'.}

\begin{abstract}
In this paper a short, 25-item, telephone-administered questionnaire, designed to rank individuals according to their dietary intake of fat, is presented. Based on two studies of 52 and 639 men and women, respectively, its relative validity regarding a 7-day diet record and its reproducibility are discussed. A Pearson correlation of 0.59 was observed between fat intake estimated by 7-day diet records and fat score derived from the short questionnaire. Gross misclassification, defined as disagreement between the two fat consumption assessments beyond an adjacent tertile, was $15.4 \%$. A Pearson correlation of 0.71 was calculated by a test-retest procedure. It is concluded that the Dutch short questionnaire on fat consumption is a rapid, simple and inexpensive method that can very well be used in nutrition education research to rank individuals according to their dietary fat intake.
\end{abstract}

\section{Introduction}

Healthy nutrition plays an important role in the reduction of risk of chronic illness, such as coronary heart disease and cancer. During the last few decades there has been a growing interest in nutrition education in community-wide health promotion interventions (Glanz \& Mullis, 1988). To evaluate the effects of these programs on dietary behaviors, it is necessary to measure dietary

1 Published as: Van Assema, P., Brug, J., Kok, G., \& Brants, H. (1992). The reliability and validity of a Dutch questionnaire on fat consumption as a means to rank subjects according to individual fat intake. European Journal of Cancer Prevention, 1, 375-380. 
intake, preferably habitual dietary intake, on an individual level. However, measurement of the dietary intake of individuals is difficult. Several reviews have been written about the reliability and validity of the most common methods: the 24-hour recall, the weighted or unweighted record or the dietary history method (Block, 1982; Bingham et al., 1988; Medlin \& Skinner, 1988). However, these instruments are less suitable for large-scale food consumption research. The methods are expensive, time consuming and require trained dieticians to interview subjects or to check the food records (Bingham et al., 1988). Moreover, the methods produce very detailed information, while in studies on the effectiveness of community nutrition intervention programs, or in studies into the determinants of specific nutrition behaviors, it is not always necessary to measure all nutrients or to measure nutrient intake in a precise manner. Often, only a ranking of subjects according to the intake of a specific nutrient (or food product) is required.

In this paper a short, 25-item, telephone-administered questionnaire on fat consumption, designed to rank individuals according to their fat intake, is presented. The relative validity of this questionnaire in relation to a 7-day diet record is discussed. The reproducibility of the questionnaire is assessed by means of a test-retest procedure.

\section{Methods}

\section{Purpose, content and format of the short questionnaire}

In 1988 the questionnaire on fat consumption was developed as part of a larger telephone-administered interview in which subjects were questioned about a number of cancer-related risk factors. The telephone questionnaire is conducted using personal computers, the computer program allowing immediate data input. Interviewers can be trained to work on the personal computer and conduct the interview in less than 30 minutes. The average time for telephone administration of the fat consumption questionnaire is 5 minutes. The questionnaire was developed to study the determinants of cancer risk factors and to evaluate a community based health promotion program, the so-called 'Healthy Bergeyk' project (Steenbakkers et al., 1991). The fat consumption questionnaire consists of 25 items covering 12 (groups of) food products (Table 1). The questionnaire was developed by selecting (groups of) food products which have the highest contribution to total fat intake in the Dutch population (Van den Brandt et al., 1991). Subjects were asked how frequently these 12 groups of food products 
were usually consumed during the last 6 months (e.g., "how many days a week do you usually drink milk?") and for some food products additional items on quantity (e.g., "how many glasses of milk on one day") or kind of product (e.g. low fat or high fat milk) were included. For each of the 12 (groups of) food products a fat score, ranging from 1 point (lowest fat intake) to 5 points (highest fat intake), was determined. Furthermore, an individual totall fat score was calculated by adding up the 12 food product fat scores for each subject. Consequently, this total fat score ranges from 12 to 60 points. The scoring system is described in detail in Table 2.

\section{Reference instrument}

In food consumption research there is no method available to measure true dietary intake. Therefore only the relative validity of a new method to stucly food consumption can be assessed, that is, in relation to an existing and generally accepted method (Burema et al., 1988). As the reference instrument to validate the questionnaire on fat consumption, a 7-day diet record was used. This method does not depend on memory, is generally accepted as a relatively valid and reliable food consumption research instrument and has been used before in validation studies (Willett et al,, 1985; Cameron \& Van Staveren, 1988; Block et al., 1989; Flegal \& Larkin, 1990; Kristal et al., 1990). Since the day-to-day variation of intakes of many nutrients is substantial, the record period must be extended from several days to several weeks, depending on the nutrient concerned, to derive the habitual intake from diet records (Marr \& Heady, 1986; Nelson et al., 1989). For fat intake, estimates of 6 to 12 days have been made as a period sufficient to assess habitual intake (Marr \& Heady, 1986; Nelson et al., 1989).

In this study the method of estimated diet records was used (Bingham et al., 1988). This means that subjects were trained to write down everything they eat or drink in a diary specially designed for this purpose, in household measures (glasses of milk, spoons of sugar, cups of tea, etc.). The household measures used were quantified by trained dieticians, by volume or by weighing duplicate portions. This was done after the record period, when the diet records were collected and checked at the subjects' homes. Fat-containing food products from the diet records were encoded by the dieticians using the $1989 / 1990$ Dutch Food Composition Table (NEVO, 1989). From these data, mean individual fat intake (in grams) was calculated using the Becel Nutrition Program for personal computer (Becel, 1989). 
1. Milk

2. Yoghurt

3. Pudding/porridge

Bread
4. Cheese
5. Meat products

6. Butter

7. Meat

8. Gravy

\section{Fried snacks}

10. Snacks

11. Cake, pastry

12. Cookies
1. How many days a week do you usually drink milk?

2. How many glasses of milk do you usually drink on one day?

3. What kind of milk do you usually drink: full fat, half fat or low fat?

4. How many days a week do you usually eat yoghurt or fruit yoghurt?

5. How many bowls of yoghurt do you usually eat on one day?

6. What kind of yoghurt do you usually eat: full fat, half fat or low fat?

7. How many days a week do you usually eat pudding or porridge?

8. How many bowls of pudding/porridge do you usually eat on one day?

9. How many slices of bread (rolls, crackers or biscuits) do you usually eat on one day?

10. How many of these slices do you eat with cheese?

11. How many of these slices do you eat with meat products?

12. Can you mention two or three kinds of meat products you usually eat?

13. What do you use for your bread: margarine, low-fat margarine or butter?

14. Which brand do you usually use? Is this a package or a tub?

15. How often do you eat sausage (smoked, roasted, fresh) with your hot meal?

16. How often do you eat minced meat (mixed: half pork, half beef)?

17. How often do you eat lard meat?

18. How many days a week do you use gravy with your hot meal?

19. How many spoonfuls do you usually take with one meal?

20. What kind of spoon do you use: a table spoon ( $15 \mathrm{ml}$ ), a small gravy spoon (25 $\mathrm{ml}$ ) or a large gravy spoon $(35 \mathrm{ml})$ ?

21. In addition to your hot meal, how often do you eat snacks like french fries?

22. How often do you eat snacks like nuts, potato chips, pieces of cheese or sausage?

23. How often do you eat pastry, cake or large cookies?

24. How many days a week do you usually eat cookies?

25. How many cookies do you usually eat on one day?

\footnotetext{
- Bread is incorporated in the questionnaire as an introduction on the questions on cheese, meat products and butter on bread. For bread itself no fat score is calculated.
} 


\section{Subjects and procedures}

A random sample of adults (age 18 years or older) was drawn from the population of Maastricht, a medium-sized town in the Netherlands. These subjects received a letter with information on the purpose and procedures of the study and subsequently were approached by telephone and asked if they would be. willing to participate. If so, the subjects were asked to complete the short questionnaire during this first telephone call or an appointment was made to complete the telephone interview another day. A total of 52 subjects 129 women and 23 men, aged 21-68), agreed to take part in the validation study (51\% response). After the telephone interview, the subjects were visited twice at home by trained dieticians. The subjects were asked to keep diet records for seven subsequent days, starting between one week and one month after the telephone interview was completed. During the first visit the diet records were handed out and the use of the pre-structured food records was explained. The purpose of the second visit was to collect and check the food records and to weigh the household measures used in the diet records.

Additionally, 639 subjects ( 333 women and 306 men, aged 18-93), a random sample from inhabitants of Swalmen, the control community in the evaluation of the health promotion project 'Healthy Bergeyk', were interviewed twice with a one-year time span between the interviews. The data collected were analyzed in order to check the reproducibility of the questionnaire on fat consumption.

\section{Statistical methods}

In order to assess the relative validity of the food frequency questionnaire. Pearson product-moment correlation coefficient was used as the statistic to measure agreement between the individual total fat scores and the individual fat consumption in grams derived from the 7-day records (Burema et al., 1988).

Furthermore, to evaluate the ability of the questionnaire to classify individuals correctly into broad categories of fat intake, subjects were classified into two and three categories of fat intake separately by each method. Unweighted kappa statistics were calculated to assess the degree of agreement in classification by the two methods. Also, gross misclassification, defined as disagreement between the two fat consumption assessments beyond an adjacent tertile, was calculated (Burema et al., 1988).

In order to assess the reproducibility of the questionnaire, a Pearson correlation coefficient between the fat scores derived from the test-retest 
Score

$\begin{array}{lllll}5 & 4 & 3 & 2 & 1\end{array}$

1. Milk

1. Full-falt

$\geq 8 \quad 7.5$

4-3

2. Half-fat or varying

$\geq 15 \quad 14-10$

9.6

0

3. Low-tat

Frequency: ncr. of glasses per week

2. Yoghurt

\begin{tabular}{|c|c|c|c|c|}
\hline 1. Full-fat & $\geq 7$ & $6-5$ & $4 \cdot 3$ & $2 \cdot 1$ \\
\hline 2. Half-fat or varying & $\geq 14$ & $13-10$ & $9-6$ & 5.2 \\
\hline $\begin{array}{l}\text { 3. Low-fat } \\
\text { equency: no. of bowis }\end{array}$ & • & $\cdot$ & - & - \\
\hline $\begin{array}{l}\text { Pudding/porridge } \\
\text { equency: no. of bowls }\end{array}$ & $\geq 5$ & 4 & 3 & 2 \\
\hline Cheese & $\geq 4$ & 3 & 2 & 1 \\
\hline
\end{tabular}

Frequency: no. of slices per day with cheese

5. Meat product

\begin{tabular}{|c|c|c|c|c|c|}
\hline 1. Fat & $\geq 5$ & $4 \cdot 3$ & 2 & 1 & 0 \\
\hline 2. Varying & - & $\geq 4$ & 3 & 2 & $i-0$ \\
\hline 3. Lean & - & . & $\geq 6$ & $5-3$ & $2-0$ \\
\hline
\end{tabular}

Frequency: no. of slices of bread per day with meat products

6. Butter

$\begin{array}{lccccc}\text { 1. } 80 \% \text { fat } & 2: 7 & 6-5 & 4-3 & 2-1 & 0 \\ \text { 2. Verying } & 2.9 & 8-7 & 6.4 & 3-2 & 1-0 \\ \text { 3. } 40 \% \text { fat } & - & \geq 9 & 8.6 & 5-2 & 1-0\end{array}$

Frequency: no. of slices of bread per day with butter

7. Meat

Fatty kinds

$\geq 4$

$3 \cdot<4$

$2 \cdot<3$

$1 \cdot<2$

$<1$

Frequency: no. of days per week

8. Gravy

$\begin{array}{lccccc}35 \mathrm{ml} \text { spoon } & 27 & 6-5 & 4.3 & 2 & 1-0 \\ 25 \mathrm{ml} \text { spoon } & \geq 10 & 9.8 & 7.5 & 4-3 & 2-0 \\ 15 \mathrm{ml} \text { spoon } & \geq 20 & 19.16 & 15.10 & 9-6 & 5.0\end{array}$

Frequency: no. of spoons per week

9. Fried snacks

$\geq 3$

2

1

$0>,<1$

0

Frequency: no. of times per weok

10. Snacks

$\geq 4$

3

2

1

0

Frequency: no. of times per week

$\geq 4$

Frequency: no. of times per week

3

2

1

$<1$

12. Cookies

$\geq 22$

21-15

$14 \cdot 10$

$9 \cdot 5$

4-0

Frequency: no. of cookies per week

The scoring system of the fat consumption questionnaire was determined by a nutritionist by applying two global starting points:

Within a food product the scores should be higher in proportion to the increased intake of grams of fat.

- Between food products a corresponding score should refer as far as possible to corresponding arnounts of fat. 
procedure was calculated, as well as gross misclassification between test and retest. All statistical tests were performed using the SPSS- $X$ statistical computer package (SPSS Inc., 1988).

\section{Results}

Mean fat score was 26.7 points, 24.9 among women and 29.0 among men, as assessed by the questionnaire. Mean fat intake was. $96 \mathrm{~g}, 82 \mathrm{~g}$ among women and $11.4 \mathrm{~g}$ among men, as assessed by means of the 7-day diet record. Neither variable showed major departures from normal distribution.

Pearson correlation between the fat score based on the fat consumption questionnaire and the dietary intake of fat assessed by means of the 7-day diet record was 0.59 . Cohen's kappa was 0.42 with two categories and 0.25 with three categories. Gross misclassification between the two methods was $15.4 \%$. In the reproducibility study, mean fat score was 27.0 points 125.7 among women and 28.5 among men) in the first measurement and 26.8 points (25.1 among women and 28.7 among men) in the retest. Pearson correlation between the results of the two interviews was 0.71 . The percentage of subjects classified in opposite extreme fat consumption tertiles between the test and the retest was 3.9 .

\section{Discussion}

The quality of research measurements is determined by the validity and the reproducibility of the method used. The concept of validity refers to the absence of systematic (non-random) error while reproducibility is associated with random error or variability. In this study the relative validity of the questionnaire on fat consumption was assessed in relation to a 7-day diet record. The reproducibility of the questionnaire was determined by a test-retest procedure.

A Pearson correlation of 0.59 for total fat consumption between the fat consumption questionnaire and the 7-day diet record, as found in our study, is of the same order as those reported in the few other comparable studies. Kristal et al. (1990) reported a correlation of 0.52 for total fat intake between a 46 . item telephone-administered dietary questionnaire and the mean of two 4-day diet records. Block et al. (1989) found a correlation of 0.58 between a 13-item questionnaire on total fat intake and the mean of three 4 -day diet records. 
The kappa statistic of 0.42 on two categories can be interpreted as indicating moderate agreement between measures, according to criteria suggested by Fleiss (1981). The kappa statistic is of the same order as that found by Kristal et al. (1990) for the 46-item telephone-administered questionnaire. The kappa statistic of 0.25 on three categories must be considered to represent poor agreement, but the gross misclassification was $15.4 \%$, compared to $18.8 \%$ as found by Kristal et al. (1990).

The reproducibility of the questionnaire as assessed by means of the Pearson correlation between the fat score based on the first measurement and that derived from the retest was also satisfactory. Kristal et al. (1990) reported exactly the same correlation $(0.71)$ between test and retest results on total fat consumption of a 46-item questionnaire. Test-retest correlations of 0.69 and 0.57 on total fat consumption were reported by Jain et al. (1980) and Willett et al. (1985) for much larger questionnaires.

Results in validation studies might be biased because whichever measurement is conducted first could influence the subsequent measurement. To minimize this offect it was decided in this study to let the subjects complete the short telephone interview first, as it can be assumed that the influence of the short questionnaire on the 7-day record is less than vice versa. It is impossible in food consumption studies to conduct multiple measurements of one person at the same time. In reproducibility studies for food consumption methods, repeated measurements on the same subject will therefore relate to different days or periods. This means that the within-person variation is not only due to the variation caused by the food consumption method but also to the different time period. Therefore, it is important that the repeated measurement is done at a time (period) as similar as possible to the first measurement. In this study both measurements were done in the same months of subsequent years and in the evenings of work days. In this way variation caused by seasonal changes in dietary habits was kept to a minimum.

In the Netherlands, as in many other countries, dietary recommendations on fat consumption are made in reference to total energy intake, i.e. to reduce total fat intake from $40 \%$ to $30-35 \%$ of total energy intake (Dutch Nutrition Council, 1986). The fat consumption scores derived from our questionnaire are based on absolute fat intake in grams. Assessing total energy intake was not possible without an unacceptable extension of the questionnaire. However, in the Dutch National Food Consumption Survey of 1987-1988 (Hulshof \& Van Staveren, 1991) a correlation of 0.57 between absolute fat intake and fat intake as a 
percentage of energy intake was observed among adults. Therefore, we consider a questionnaire based on absolute fat intake to be a useful instrument, also in assessing the effects of nutrition programs aiming at the reduction of the energy percentage of fat.

In conclusion, the fat consumption questionnaire presented here is a rapid, simple and inexpensive method for use in nutrition education research, where ranking of subjects according to dietary fat intake is requested. Moreover, the fat consumption questionnaire might also be used as a nutrition intervention tool to provide inexpensive behavioral feedback on dietary intake of fat. 



\title{
Chapter 4
}

\section{Results of the Dutch community project 'Healthy Bergeyk'}

\begin{abstract}
This article reports on the results of a community health project that was implemented in the Dutch municipality of Bergeyk. The major goal was to reduce four cancer-related risk behaviors: smoking, high fat consumption. excessive alcohol consumption, and use of solaria. A control community received no new intervention. Data were collected from both communities among cohort research samples on three occasions using telephone interviews. The results indicate a significant reduction in fat intake in the experimental community. No other significant behavioral effects were found. Further analysis among respondents in the experimental condition showed that those personally exposed to the project as indicated by familiarity with and discussion about the project, had a greater decrease in fat consumption between baseline survey and second posttest than those who were not. Also, the percentage of smokers who quit between baseline survey and second posttest was greater among those who knew about the project than among those who did not. Finally, discriminant analysis was used to further examine the determinants of project exposure. Community involvement, marital status, education, and gender were related to project exposure.
\end{abstract}

\section{Introduction}

The incidence of cancer is high in the Netherlands. Dutch breast and lung cancer rates are among the highest in the world (U.S. Department of Hiealth and

1 Submitted for publication as: Van Assema, P., Steenbakkers, M., Kok, G., Eriksen, M., \& De Vries, H.. Results of the Dutch community project 'Healthy Bergeyk'. 
Human Services, 1985). Therefore, primary prevention of cancer has become an important goal of Dutch health policy. The incidence of cancer can be greatly reduced or postponed to a later age by changes in individual risk behaviors, such as smoking, high fat consumption, excessive alcohol consumption, and excessive exposure to UV radiation (Doll \& Peto, 1981; Doll, 1989). As these individual risk behaviors are common among the general population, populationbased interventions are most promising for cancer prevention. The health promotion literature reflects an increasing recognition that the success of population-based interventions not only depends on the use of tested behavioral strategies for life-style interventions. It also depends, for a large part, on the effective application of community organization principles (Bracht, 1990), such as a social network approach (i.e.. spreading information from network members to other network members), participation of the target group, intersectoral co-operation, and aiming at individuals as well as the environment they live in.

The 'Healthy Bergeyk' project began in 1990. The major goal of the project was a reduction in the prevalence of cancer-related risk behaviors, especially smoking and high fat consumption, in adults (age 18 and over). Project development and implementation were based on community organization principles as well as health education theory and methods.

This article describes the project, its theoretical background, and its behavioral results. It also describes the dose-response relationship between project exposure and project effects, and the determinants of project exposure.

\section{Theoretical background of the project, intervention components and, organization of the project}

For the development of the intervention, a conceptual model was used that combines the Stages of Change Model with a Model of Behavioral Change. The Transtheoretical Model of Stages of Change (Prochaska \& DiClemente, 1984) proposes that people may be at different stages of change: precontemplation, contemplation, action, and maintenance. Precontemplators are subjects who have not considered changing their behavior in the desired way. Contemplators have considered this action but have not made a commitment and are not taking action yet. Actors are those subjects who are actually changing their behavior, and maintainers have continued their behavior change over an 
extended period of time. The Model of Behavioral Change (McGuire, 1985; Kok \& De Vries, 1989) suggests the phases that lead to a continued change in behavior as a result of health communication: attention to and comprehension of the message, changes in the determinants of behavior (attitudes, social influence and self-efficacy), a change in behavior, and maintenance of the behavior change. The behavioral change phases may vary in importance for people at different stages of change. For example, precontemplators especially need an attitude change, while contemplators especially need a change in selfefficacy (Van Assema et al., 1993; Prochaska \& DiClemente, 1992).

Based on this conceptual framework, thirty-two local health activities were carefully selected or developed, in order to have interventions for subjects in each stage of change and to cover whatever phase of behavioral change these persons are in. The activities were divided into five intervention components: a mass media component, a group and self-help program component, an information center component, a social network component, and a structural component. Community organization principles were applied as much as possible in the selection and development of the activities.

The conceptual framework was generic for all four types of risk behavior. However, an additional awareness phase was added to the Model of Behavioral Change in relation to changing fat consumption, because most Dutch people are not even aware of how high or low in fat their diets are (Van Assema et al., 1993). In other words, many people do not even know that they eat toc fat, i.e. that they perform the risk behavior. In this aspect $t_{x}$ fat consumption differs from the other risk behaviors, where performance of the behavior is obvious, e.g. smoking cigarettes.

Community organization principles were not only applied in the development of the intervention, but also used to plan the implementation of the intervention in the community. The community principles were given concrete form by organizing the project similar to the five-stage community organizing model of Bracht \& Kingsbury (1990); community analysis, design-initiation, implementation, maintenance-consolidation, and dissemination-reassessment. The project started with a community analysis (stage 1 ) conducted by university staff. Written materiais on the community were collected, key figures in the community were interviewed and short street interviews were conducted. The major goals of this analysis phase were to introduce the project in the community, to achieve early community involvement and to answer some important implementation questions such as which community sectors should 
be involved in the further implementation of the project. A report with the results of the community analysis was sent to all key figures in the community. Next, a part-time local co-ordinator who lived in the community was hired. The local co-ordinator invited all the sectors mentioned during the community analysis to participate in a project group. All sectors agreed, resulting in a project group with eleven representatives from local government, the women's association, the health sector, the National Cross Association, an environmental organization, the cultural sector, the association for the elderly, the organization for industry and shops, and three neighborhood associations (stage 2: designinitiation).

In the spring of 1990 the project group started its meetings. In order to ensure effective and integrated health promotion activities as a result of the community organizing process, the project group was offered a workbook and a small budget by the research team. The workbook described the five intervention components. The project group was encouraged to organize activities from each intervention component. However, they were also free to develop their own activities. The project group took six months to organize themselves and to choose and prepare health activities with support from the local co-ordinator and using guidelines in the workbook. During the next six months the project group implemented several health activities in the community (stage 3: implementation). An overview of activities, organized by risk behavior, is given in Table 1 (Van Assema et al., submitted). In addition to the activities in Table 1, there have been activities, such as newspaper articles, exhibitions, an information market, posters and pamphlets, to gain attention for the project in general. Also, a project information center was started. This center, where sixteen trained volunteers worked, had a key role in the organization of the activities and the dissemination of materials.

The project group co-operated with other people and organizations in the community in organizing the activities. For example they worked with a group of five dietitians who voluntarily helped the project group with nutrition activities.

The project was initially started and financed for one year. However, planning for continuation of the project started from the beginning. Details about the planning for and actual process of continuation (stage 4 and 5) are described elsowhere (Van Assema et al., submitted). After a few months' break (March 1991-August 1991) the project has been continued by the project group with a 
Tabie 1. Overview of project activities by nisk behavior

\begin{tabular}{|c|c|c|c|c|}
\hline & SMOKING & NUTRITION & ALCOHOL & SOLARIUM \\
\hline Newspaper articles & several articles & several articles & several articles & several articles \\
\hline $\begin{array}{l}\text { Small group } \\
\text { activities }\end{array}$ & $\begin{array}{l}\text { stop smoking group } \\
\text { courses. }\end{array}$ & cooking course & & \\
\hline & & $\begin{array}{l}\text { group sessions at } \\
\text { inhabitants' houses }\end{array}$ & & \\
\hline Lectures & & $\begin{array}{l}\text { lectures for } \\
\text { associations }\end{array}$ & & \\
\hline Self-help manuals & $\begin{array}{l}\text { stop smoking } \\
\text { self-help manual }\end{array}$ & $\begin{array}{l}\text { step by step less } \\
\text { fat manual }\end{array}$ & & \\
\hline Letters & $\begin{array}{l}\text { letter with } \\
\text { suggestions for } \\
\text { smoking policies to } \\
\text { workplaces and } \\
\text { associations }\end{array}$ & & $\begin{array}{l}\text { letter with } \\
\text { suggestions for } \\
\text { alcohol policies to } \\
\text { workplaces and } \\
\text { associations } \\
\text { letter to local } \\
\text { government to start } \\
\text { alcohol policies } \\
\text { letter to cafes and } \\
\text { discctheques. about } \\
\text { availability of } \\
\text { alcohol-free drinks }\end{array}$ & \\
\hline Other activities & $\begin{array}{l}\text { questionnaire on } \\
\text { smoking policies in } \\
\text { workplaces and } \\
\text { associations }\end{array}$ & $\begin{array}{l}\text { bi-weekly } \\
\text { advertisements in } \\
\text { newspaper with } \\
\text { healthy recipes }\end{array}$ & $\begin{array}{l}\text { questionnaire on } \\
\text { alcohol policies in } \\
\text { workplaces and } \\
\text { associations }\end{array}$ & \\
\hline & $\begin{array}{l}\text { sandwich 'Healthy } \\
\text { Bergeyk' sold by } \\
\text { cafetarias }\end{array}$ & & & \\
\hline & $\begin{array}{l}\text { nutrition advice to } \\
\text { workplace } \\
\text { cafetarias }\end{array}$ & & & \\
\hline & $\begin{array}{l}\text { recipes for } \\
\text { healthy sandwiches } \\
\text { sent to cafetarias } \\
\text { and restaurants }\end{array}$ & & & \\
\hline
\end{tabular}


grant from local and provincial government. The researchers are represented on the project advisory committee now.

\section{Method}

\section{Design and sample}

The effectiveness of the project was studied by means of a pretest-posttest control group design, with two posttests (Cook \& Campbell, 1979). The municipality of Bergeyk and the control community were selected at random from six municipalities in the Netherlands with the following characteristics:

1) about 10,000 inhabitants

2) urbanization degree $B 2$, indicating an urbanized countryside municipality with at least 5,000 inhabitants in the main village

3) within 100 kilometers of the University of Limburg

Three municipalities were situated in the province of Limburg, the other three in the province of Noord-Brabant. The experimental community was selected at random from the six communities. After that, the control community was selected at random from the three municipalities in the other province, to ensure that mass media channels (regional newspapers, etc.) were as different for the communities as possible. The control community received no new intervention.

A cohort research sample was selected by taking a random sample of 1000 adults (age 18 and over) from the computerized population registers of both the experimental and control communities. The subjects received a letter before all measurements to inform them about the study, but not about the experimental condition they were in. This letter was undersigned by the mayor and secretary of the municipality. Subjects were then interviewed by telephone on three occasions. The interviews were conducted by trained students using personal computers having a software program which allowed immediate data input. The average time for each interview was 20 minutes.

\section{Questionnaire and measures}

The baseline survey was in February 1990 (T1), and the project implementation took place from March 1990 to February 1991. Follow-up interviews were conducted in February 1991 (T2) and September 1991 (T3). Process evaluation occurred throughout the implementation period and included careful registration records and participants' evaluation for all program elements, as well as 
documentation and evaluation of the process of intersectoral collaboration in the project. group (Van Assema et al., submitted).

Smoking behavior was measured by asking the subjects whether they smoked cigarettes. Also, smokers were asked to indicate the mean number of cigarettes a day in the: previous week. Alcohol consumption was measured by asking respondents to indicate the number of times they drank six or more glasses on a single day' during the last six months. Also, weekly' consumption was estimated by asking about the afcohol consumption on the previous Tuesday and Saturday. The sum of glasses consumed on both days was multiplied by 3.5 . Fat consumption was measured by a newly developed 25-item questionnaire covering twelve (groups) of food products. The questionnaire yields a fat score for each of the twelve (groups of) food products, ranging from 1 (lowest fat intake) to 5 points (highest fat intake). Individual total fat scoresi are calculated by adding up the twelve food product fat scores, resulting in total fat scores that range from 12 to 60 points. A separate study of the relative validity and reproducibility of the questionnaire showed that the questionnaire is a suitable instrument for ranking subjects according to dietary tat intake (Van Assemar et al., 1992c). Exposure to UV radiation was measured by asking about the frequency of solarium use in the past year.

The questionnaire also measured demographic variables, attitudes, social influence and self-efficacy towards the four risk behaviors and intention to change the risk behaviors. Also, involvement with the community and some general variables, like perceived chance of getting cancer, were measured. In the experimental group, at T2, exposure to the project was assessed, using familiarity with the project and discussion about the project with other people as indicators.

\section{Analysis}

For analyzing the behavioral effects of the program, the Mantel-Haenzel approach was used for risk behavior variables measured at a nominal level (categorical data). The Mantel-Haenzel approach provides the opportunity to control for baseline differences. Analysis of variance with repeated measures was used for risk behavior variab!es measured at an interval level (ranked with equal intervals). As clear hypotheses had been formulated, i.e. reduction of risk behavior prevalence, one-tailed tests were used. Furthermore, univariate analysis of variance was used to analyze program effects as a function of 
program exposure. Discriminant analysis was used to assess determinants of program exposure.

Unless otherwise stated, the significance levels stated below were $p<0.05$. Only subjects who participated in all three surveys were included.

\section{Results}

Response to the baseline survey was $75.3 \%(N=1506 ; 775$ in the experimental and 731 in the control community). Attrition from T1 to T3 was $18.2 \%$ $(N=275$ in the total group). Both initial response and attrition did not differ significantly between the experimental and control groups. In both communities the dropouts did not differ from the subjects who participated in all measures in gender, education and risk behavior. However, in both communities the dropouts were less often married. Also, dropouts were more often in the lowest income category and less often in the middle income categories than the subjects in the final sample.

Overall, 1,231 respondents completed all three measures: 623 in the experimental and 608 in the control community.

There were no significant differences between the experimental and control group with respect to gender, education and income. The subjects in the control group were slightly older than the subjects in the experimental group (mean for control group 43.3; mean for experimental group 41.5; $\mathrm{t}(1229)=2.09$, $p<0.04)$ and less often married $175 \%$ in the control group, $81.2 \%$ in the experimental group; $\left.\mathrm{X}^{2}(1)=6.61 ; \mathrm{p}<0.02\right)$.

A significant baseline difference in risk behavior between the experimental and control group was only found for fat consumption (mean for experimental group 28.0 points, mean for control group 27.1 points; $t(1229)=2.88 ; p<0.005)$.

\section{Behavioral effects of the project}

Table 2 shows that in the experimental group fat consumption decreased from 28 points at $\mathrm{T} 1$ to 27.2 points at $\mathrm{T} 2$ and 26.8 points at $\mathrm{T} 3$. In the control group fat consumption decreased from 27.1 point at T1 to 26.8 points at T2 and T3. A significant main effect of time was found $(F(2,1228)=14.78 ; p<0.001)$, indicating that the joint mean scores of the experimental and control group decreased significantly in time. This main effect was accompanied by a significant interaction-effect of time by group $(F(2,1228)=6.30 ; p<0.003)$. In the experimental group fat consumption decreased significantly more than in the 
Table 2. Mean fat intake, mean estimated weekly consumption of alcohol (Alcohol I), percentage of smokers, percentage of respondents that drank six or more glasses of alcohol on a single day at least once during the last six months (Alcohol II), and percentage of respondents who used a solarium at least once during the last year, in experimental and control group (G) at TI, T2 and T3, the decrease or increase (D), $X^{2}$ and p-levels', and the number of subjects $(N)$

\begin{tabular}{|c|c|c|c|c|c|c|c|c|c|c|c|c|}
\hline Risk. behavior & G & T1 & T2 & $\mathrm{D}$ & & & T1 & T3 & D & & & $\mathbf{N}$ \\
\hline Fat: & exp & 28.0 & 27.2 & -0.8 & & & 28.0 & 26.8 & -1.2 & & & (623) \\
\hline consumption & con & 27.1 & 26.8 & -0.3 & & & 27.1 & 26.8 & -0.3 & & & $(608)^{\circ}$ \\
\hline \multirow[t]{2}{*}{ Alcohol I } & $\exp$ & 9.8 & 10.0 & 0.2 & & & 9.8 & 11.6 & 1.8 & & & $(612)$ \\
\hline & con & 11.0 & 9.9 & -1.1 & & & 11.0 & 11.5 & 0.5 & & & $(597)$ \\
\hline Risk behavior & G & $\mathrm{T} 1$ & T2 & D & $x^{2}$ & $p$ & $\mathrm{~T} 1$ & T3 & D & $x^{2}$ & p & $\mathbf{N}$ \\
\hline \multirow[t]{2}{*}{ Smoking } & $\exp$ & 35.9 & 31.8 & -4.1 & .79 & .19 & 35.9 & 32.6 & -3.3 & .77 & .19 & $(613)$ \\
\hline & con & 32.7 & 31.5 & -1.2 & & & 32.7 & 32.3 & .0 .4 & & & (594) \\
\hline \multirow[t]{2}{*}{ Alcohol II } & $\exp$ & 33.8 & 35.1 & 1.3 & 2.29 & .07 & 33.8 & 35.3 & 1.5 & .04 & .42 & $(623)$ \\
\hline & con & 35.5 & 39.5 & 4.0 & & & 35.5 & 34.8 & 0.7 & & & (608) \\
\hline \multirow[t]{2}{*}{ Sun } & $\exp$ & 18.1 & 17.3 & -0.8 & .93 & .17 & 18.1 & 19.3 & 1.2 & 2.29 & .07 & $(615)$ \\
\hline & $\operatorname{con}$ & 19.2 & 19.4 & 0.2 & & & 19.2 & 231.2 & 4,0 & & & $(600)$ \\
\hline
\end{tabular}

- only for variables measured at a nominal level

significant interaction effect of time by group $(p<0.003)$

control group. Closer examination of the results showed that most of the decrease occurred between pretest and first posttest $(F(1,1229)=11.20$; $p<0.002$ ).

Furthermore, in the experimental community, between $\mathrm{T} 1$ and $\mathrm{T} 2$, there was, in addition to an absolute increase in both communities, a trend towards a smaller increase in the percentage of respondents who drank six or more glasses of alcohol on a single day during the last six months. Table 2 also shows that, between T1 and T3, there was, in addition to an absolute increase in both communities, a trend towards a smaller increase in the percentage of respondents who used a solarium at least once during the last year.

No significant group differences were found for smoking, though the results were in the desired direction. 
Table 3. Change in mean fat intake and mean estimated weekly consumption of alcohol as well as percentage of smokers, respondents that drank six or more glasses of alcohol on a single day at least once during the last six months, and respondents who used a solarium at least once during the last year in the experimental group that stopped this risk bohavior, for different levels of exposure (G), between $T 1$ and $T 2$ and between $T_{1}$ and $T 3, X^{20}, F^{b}, p$-levels and the number of subjects $(N)$

\begin{tabular}{|c|c|c|c|c|c|c|c|c|c|c|c|}
\hline Risk behavior & $\mathrm{G}^{c}$ & $\mathrm{~T} 1-\mathrm{T} 2$ & $F$ & $p<$ & ก & $N$ & T1-T3 & $\mathrm{F}$ & $p<$ & $n$ & $N$ \\
\hline \multirow{5}{*}{$\begin{array}{l}\text { Change in } \\
\text { fat } \\
\text { consumption }\end{array}$} & 1 & 0.58 & 0.59 & 0.56 & $(98)$ & $(619)$ & -0.10 & 3.09 & 0.05 & (98) & (619) \\
\hline & 2 & 1.09 & & & (253) & & -1.36 & & & (253) & \\
\hline & 3 & 0.72 & & & (268) & & -1.45 & & & (268) & \\
\hline & 4 & -0.68 & 1.18 & 0.28 & $(386 i)$ & (623) & -0.89 & 3.96 & 0.05 & $(386)$ & (623) \\
\hline & 5 & -1.10 & & & (237) & & -1.68 & & & $(237)$ & \\
\hline \multirow{5}{*}{$\begin{array}{l}\text { Change in } \\
\text { alcohol } \\
\text { consumption }\end{array}$} & 1 & 0.32 & 0.16 & 0.99 & (93) & (608) & 1.79 & 0.17 & 0.85 & $(97)$ & $(618)$ \\
\hline & 2 & 0.11 & & & $(250)$ & & 1.30 & & & $(253)$ & \\
\hline & 3 & 0.07 & & & (265) & & 1.89 & & & $(268)$ & \\
\hline & 4 & -0.04 & 0.25 & 0.62 & (379) & $(612)$ & 1.44 & 0.47 & 0.50 & $(385)$ & (622) \\
\hline & 5 & 0.42 & & & (233) & & 2.17 & & & $(237)$ & \\
\hline Fisk behavior & G & T1-T2 & $x^{2}$ & $p<$ & $n$ & $\mathbf{N}$ & T1-T3 & $x^{2}$ & $p<$ & $n$ & $N$ \\
\hline \multirow[t]{5}{*}{ Smoking } & 1 & 13.3 & 1.83 & 0.41 & $(30)$ & (218) & 6.7 & 4.96 & 0.09 & (30) & (217) \\
\hline & 2 & 16.2 & & & (99) & & 14.1 & & & $\{99\}$ & \\
\hline & 3 & 22.5 & & & (89) & & 22.7 & & & $\{88\}$ & \\
\hline & 4 & 17.4 & 0.15 & 0.70 & (144) & $\{221\}$ & 16.1 & 0.02 & 0.88 & $(143)$ & (220) \\
\hline & 5 & 19.5 & & & $(77)$ & & 16.7 & & & $(77)$ & \\
\hline Alcohol & 1 & 27.3 & 0.66 & 0.72 & (33) & $(207)$ & 18.2 & 0.28 & 0.87 & (33) & (207) \\
\hline \multirow[t]{4}{*}{ consumption } & 2 & 27.8 & & & $(90)$ & & 21.1 & & & $\langle 90\rangle$ & \\
\hline & 3 & 22.6 & & & $(84)$ & & 22.6 & & & $\{84\}$ & \\
\hline & 4 & 24.8 & 0.09 & 0.77 & $(137)$ & (208) & 19.7 & 0.50 & 0.48 & $(137)$ & (208) \\
\hline & 5 & 26.8 & & & $(71)$ & & 23.9 & & & $\{71\rangle$ & \\
\hline \multirow[t]{5}{*}{ Solaria uso } & 1 & 31.6 & 0.15 & 0.93 & (19) & $(112)$ & 52.6 & 2.39 & 0.31 & (19) & (112) \\
\hline & 2 & 34.2 & & & (38) & & 39.5 & & & $\{38\rangle$ & \\
\hline & 3 & 36.4 & & & (55) & & 32.7 & & & $(55)$ & \\
\hline & 4 & 35.1 & 0.00 & 0.94 & (74) & (113) & 47.3 & 6.30 & 0.02 & $(74)$ & (113) \\
\hline & 5 & 35.9 & & & (39) & & 23.1 & & & (39) & \\
\hline
\end{tabular}

- for variables measured at a nominal level

- for variables measured at an interval level

c 1 = subjects who did not know the project

$2=$ subjects who recognized the name of the project

$3=$ subjects who could state the name of the project

$4=$ subjects who did not talk about the project with someone else

$5=$ subjects who did talk about the project with someone else 
Because of the significant differences between the experimental and control group with respect to age and marital status, some additional analyses were conducted which showed that these possible confounders did not influence the findings.

\section{Project effects and exposure to the project}

At T2, $84.2 \%$ of the respondents in the experimental group were familiar with the project: $40.9 \%$ could mention the name of the project and $43.3 \%$ could not mention the name, but recognized the name after the interviewer mentioned it. Almost $40 \%$ of the respondents in the experimental group said that they had discussed the project with someone else. Table 3 shows that respondents who recognized or mentioned the name of the project had a greater decrease in fat consumption (-1.36 and -1.45 respectively) than those who did not know the project $(-0,10)$. Also respondents who talked about the project showed a larger decrease in fat consumption $(-1.68)$ than those who did not $(-0.89)$. There was a trend towards a greater percentage of smokers who stopped from T1 to T3 being people who knew the project $(14.1 \%$ and $22.7 \%$ compared to $6.7 \%$ among those who did not know the project).

\section{Determinants of program exposure}

To assess variables that might determine program exposure a (direct) discriminant function analysis was conducted with 18 baseline variables as, predictors: 6 demographic variables, 2 community involvement variables, 5 disease-related variables and 5 risk behavior variables. Groups in the analysis were subjects who did not know the project (the non-exposed), subjects who recognized the name of the project (the somewhat exposed) and subjects who could state the name of the project (the exposed).

Two discriminant functions were calculated of which the first function was statistically significant $\left(X^{2}(36)=100.35, p<0.0001,83 \%\right.$ between-group variability). The group centroids in Table 4 show that this function maximally separated the non-exposed from the exposed, with the somewhat exposed falling between these two.

The loading matrix of correlations between predictors and discriminant functions (Table 4) suggests that the best predictors for distinguishing the nonexposed and the exposed were community involvement, education, marital status and gender. The exposed felt more involvement with their community than the non-exposed. Also, the exposed were more likely to be female and to 
GROUP:

Function I

- non-exposed

0.70

- somewhat exposed

0.16

- exposed

$-0.40$

\section{PREDICTORS:}

Demographic variables

- gender

0.30

- age

0.02

- marital status (married versus not married)

0.31

- number of household members

$-0.25$

- work status (job versus no job)

0.13

- education (lower versus middle or higher education)

$-0.32$

Community involvement variables

- feeling of involvement with the community

0.48

- number of contacts in the community $(10$ or less versus more than 10 )

$-0.28$

Disease-related variables

- perceived chance of getting cancer

0.25

= perceived chance of getting coronary heart disease

0.24

- betieved preventability of cancer

0.05

- believed preventability of coronary heart disease

0.22

- perceived health status

$-0.25$

Risk behavior variables

- smoking behavior (smoker versus non-smoker)

0.00

- fat consumption

0.23

- estimated weekly consumption of alcohol

0.13

- alcohol risk behavior (drank six or more glasses of alcohol on a single day

$-0.14$ during the last six months versus did not)

- solaria use (used a solarium during the last year versus did not)

0.06

- In the analysis 54 of the original 623 cases wera deleted due to missing data. Income was not added as a predictor because of 79 missing cases for this variable.

be married than the non-exposed. Furthermore, the exposed were more likely to have middle or higher education than the non-exposed. None of the diseaserelated and the risk behavior variables had high loadings.

Loadings less than .30 were not interpreted. 


\section{Discussion and conclusions}

The major goal of the Dutch community health project 'Healthy Bergeyk' was a reduction in cancer-related risk behavior prevalence, especially smoking and high fat consumption. Project development was based on community organization principles as well as a conceptual framework that combines the Stages of Change Model with a Model of Behavioral Change. A quasi-experimental design was used to study the effectiveness of the project. The results indicate a significant reduction in fat intake in the experimental community compared to the control community. This effect could be overestimated because of a floor effect in the control group, where the baseline mean fat intake was significantly lower than in the experimental community. However, the dose-response effect between project exposure and reduction in fat intake that was found in the experimental community, strengthens the possibility that the reduction in fat intake was caused by the project. Also, a floor effect in the control community is not obvious as mean fat intake is as high as 40 per cent of total energy intake in the Netherlands (Hulshof \& Van Staveren, 1991). At least a 12.5\% reduction in fat intake is recommended compared to current intake (from 40 to 30-35 per cent of total energy intake) (Dutch Nutrition Council, 1986b). This is not an unfeasible goal, as a simulation study using the data of the Dutch National Food Consumption Survey $1987 / 1988$ has shown that by substituting high fat products in four groups of products /cheese, milk and milk products, meat and meat products, butter, margarine and oils) by leaner alternatives, total fat intake could, in theory, be reduced to 28 per cent of total energy intake (Kistemaker, 1991). In our study, the mean fat intake in the experimental community decreased by 1.2 points. This means a $4.3 \%$ reduction compared to baseline fat intake.

No significant group differences were found for smoking, though results were in the expected direction. In addition to this, there was a trend towards a greater percentage of smokers who stopped between baseline and second posttest being people who knew the project.

Besides changes in smoking behavior and fat intake, the project aimed to reduce excessive alcohol use and exposure to artificial sunlight. However, far less priority was given to these risk behaviors and fewer activities aiming at these risk behaviors were employed by the local project group. Consistent with this, no significant effects were found. The smaller increase in the experimental community, between the baseline survey and the first follow-up, in the 
percentage of excessive alcohol consumers could probably be attributed to the fact that the baseline survey was conducted shortly before the carnival, which fell early that year, while the first posttest was conducted soon after the carnival. The way carnival is celebrated (alcohol habits included) varies among regions in the Netherlands. Also, this almost significant effect was not strengthened by a dose-response relationship in the experimental community. It should also be mentioned that from a study of Lemmens et al. (1992), in which several types of survey methods on alcohol consumption were compared, it can be derived that our instrument for measuring alcohol consumption might not have been a very reliable one and therefore not suitable for measuring changes in alcohol consumption, due to the time-variability of drinking and the fact that especially the people with a less regular drinking pattern seem to have trouble recalling the correct number of drinking occasions.

The dose-response effect between project exposure and reduction in solarium use is the reverse of what one would expect and also does not strengthen the almost significant difference in increased use between the experimental and control community. Solarium use seems to be a behavior that people try now and then, as high percentages of respondents stopped this risk behavior between the measurements, while the mean percentage of users remained quite stable. This natural instability of the risk behavior might explain the effects found.

It is difficult to compare these behavioral effects of the 'Healthy Bergeyk' project with those observed in other studies. In the Netherlands no results of comparable projects are as yet available. Comparison with foreign communitybased prevention projects, such as the Stanford Projects, the Minnesota Heart Health Project, the Community Health Improvement Project in Pennsylvania or the Finnish North Karelia Project is difficult as the target populations for these project were much larger and the projects lasted much longer. Also, effect measurements differed, especially for fat intake (Puska et al., 1985). In our study no physical measurements, such as blood pressure, were taken beyond self-reported behavior, which can be seen as a limitation of the study. Another study limitation was the nonfeasibility of a multiple communities design. Therefore, individuals were taken as the unit of analysis. This means that though the communities were randomized, the individuals within the communities were not and results might be biased due to factors that differ between the experimental and community group. However, several demographic 
variables were measured and the influence of those variables that differed significantly between the groups. was checked.

Time is considered to be the major limitation of the project. The implementation period was only one year due to financial constraints. Process evaluation showed, for instance, that as a result of this time limitation it was impossible for the project group to organize more smoking cessation group courses during the implementation period, although the community's interest in these courses was growing. With the project limitations in mind, the findings are encouraging. In a very short: time period the community was activated to actually implement. health promotion activities and a relevant reduction in fat intake was found one year after the first meeting of the project group. This reduction in fat intake was sustained at least for another half-year. Besides this, changes in the percentage of smokers were in the right direction.

It should also be kept in mind that the multiple risk factor approach might have reduced the potential effect on one risk behavior. For example, smokers might have chosen to reduce their fat intake instead of quitting smoking (see also Schwartz, 1987).

In our view the strength of the project is the workbook serving to integrate health education theory and methods with the community organizing model. This design ensured effective and integrated health promotion activities at short notice.

In addition to studying the behavioral effects of the project, special attention was given in this study to the determinants of program exposure. Attention for the project is the first phase in the behavioral change model and a prerequisite for further change. Results indicate that people exposed to the project were more involved with their community, and more likely to be female, married and with middle or higher education. However, the results of the process evaluation indicate that especially people with a low level of education participated in the health activities. Baseline risk behavior did not influence project exposure. These results can help to increase the community-level awareness of future projects. They should give special attention to and develop specific methods for those people who seem to be more difficult to reach. 



\title{
Chapter 5
}

\section{The process evaluation of a Dutch community health project $^{1}$}

\begin{abstract}
This article reports on the design and results of the process evaluation of the Dutch community project 'Healthy Bergeyk'. The major goal of this project was a reduction in cancer-related risk behavior prevalence, especially smoking and high fat consumption. The project was designed to integrate health education theory and methods with community organization principles. An intersectoral local project group was formed for project implementation. The main objectives of the process evaluation were to assess what was done and how this was evaluated by participants and leaders of activities, project group members and the community in general. Data were gathered using minutes of meetings, registration forms, prestructured telephone interviews, written questionnaires, and semi-structured interviews. Community members were involved in the data collection. The results indicated that the project group organized many health activities in their community in a short time period. Positive elements of the project concerned the intersectoral co-operation and the workbook supplied to the project group. Time pressure and limited possibilities for community initiatives were the main negative aspects of the project. The implications of the findings for both the community health project and the process evaluation are discussed.
\end{abstract}

1 Submitted for publication as: Van Assema, P., Steenbakkers “, M., Eriksen, M., \& Kok, G.. The process evaluation of a Dutch community health project: What was done and how was this evaluated by participants and leaders of activities, project group members and the community in general. 


\section{Introduction}

The literature on health promotion projects stresses the importance of process evaluation (Green \& Lewis, 1986; Glanz et al., 1990). However, this part of evaluation is rarely reported in detail. While there are many publications on impact evaluation, only a few examples of process evaluation can be found in the health promotion literature (e.g. Finnegan et al, 1989; Norman et al. 1990). As a result, replication of successful aspects of projects in other settings is difficult as this relies on extensive documentation of projects as they were actually carried out and on information about how successful the different elements of the project were (Altman, 1986; Norman et al., 1990). Also, due to the lack of exchange of experiences between researchers with respect to this kind of evaluation, there is not much information available on exactly how to conduct the process evaluation of health promotion projects.

This article reports on the process evaluation of the community project 'Healthy Bergeyk'. The project began in the municipality of Bergeyk, a Dutch community of 10,000 inhabitants, in 1990. The major goal of the project was a reduction in four cancer-related risk behaviors: smoking, high fat consumption, excessive alcohol consumption and use of solaria, in the adult population. The project was designed to integrate health education theory and methods with community organization principles. During a one-year period a project group, representing eleven sectors in the community, prepared and organized several carefully selected health activities. The project group was guided by a part-time local co-ordinator.

An extensive evaluation was conducted to assess the projects' success. In the effect evaluation the intervention community was compared with a control community on three occasions with respect to changes in risk behavior. The results indicated a significant reduction in fat intake in the experimental community compared to the control community. Further analysis among respondents in the experimental condition showed that those exposed to the project had a greater decrease in fat consumption between baseline survey and second posttest than those who were not. Also, the percentage of smokers who quit was greater among those who knew about the project. No other behavioral effects were found (Van Assema et al., submitted).

The process evaluation aimed at extensive documentation of what actually occurred in the community. Also, it was studied how the different elements of the project were evaluated by participants and leaders of activities, project 
group members and/or the community in general. The purpose of the process evaluation was not only to assess whether the project was conducted and worked out as planned, but also to give rapid feedback to those involved in the planning and organization of the project. In the process evaluation a distinction was made between the 'design' and 'output' level of the project. The design level included all design or organizational elements of the project that led to the actual health activities as organized by the project group, i.e. the output level. The main research questions of the process evaluation were:

\section{Design level}

(1) What actually occurred at the design level of the project?

(2) What was the opinion of the project group members about the project?

Output level

(3) Which health activities were organized, how often, how many people participated, and what were the characteristics of the participants?

(4) What was the level of satisfaction of the participants and the leaders with the activities, and what were the effects of the activities?

Both levels

(5) How many inhabitants of the community were familiar with the project, and what was their opinion about the project?

Theoretical background of the project, intervention components, and organization of the project

The development of the intervention and the planning of the implementation of the intervention were based on two different theoretical approaches:

(1) A conceptual framework that combined two theoretical (health education) models, i.e. the Transtheoretical Model of Stages of Change and the Model of Behavioral Change

(2) Community organization principles.

The conceptual framework was used for the development of a package of local health activities aiming at behavioral change in the community. The Transtheoretical Model of Stages of Change (Prochaska \& DiClemente, 1984) proposes that people may be at different stages of change: precontemplation, contemplation, action, and maintenance. Precontemplators are subjects who have not considered changing their behavior in the desired way. Contemplators have considered this action but have not made a commitment and have not 
taken action yet. Actors are those subjects who are actually changing their behavior, and maintainers have continued their behavior change over an extended period of time. The Model of Behavioral Change (McGuire, 1985; Kok \& de Vries, 1989) suggests the phases that lead to a continued change in behavior as a result of health communication: attention to and comprehension of the message, changes in the determinants of behavior lattitudes, social influence and self-efficacy), a change in behavior, and maintenance of the behavior change. The behavioral change phases may vary in importance for people at different stages of change. For example, precontemplators especially need an attitude change, while contemplators especially need a change in selfefficacy (Van Assema et al., 1993; Prochaska \& DiClemente, 1992).

The framework served as a checklist for the developers of the intervention to ensure that the intervention included activities for subjects in each stage of change and to cover whatever phase of behavioral change these people are in. Thirty-two activities were carefully selected or developed. The activities were divided into five program components: a mass media component, a group and self-help program component, an information center component, a social network component, and a structural component that aimed at changes in the physical environment. Most activities aimed at smoking cessation and fat reduction, with only a few on reduction of alcohol consumption and solarium use. All the activities were directed at adults.

The conceptual framework was generic for all four types of risk behavior. However, an additional 'awareness' phase was added to the Model of Behavioral Change in relation to changing fat consumption, because most Dutch people are not aware of how high or low in fat their diets are (Van Assema et al., 1993). In other words, many people do not even know that they eat too fat, i.e. that they perform the risk behavior. In this aspect, fat consumption differs from the other risk behaviors, where performance of the behavior is obvious, e.g. smoking cigarettes.

Community organization principles were mainly used to plan the implementation of the intervention in a community, i.e. to plan the overall organization of the project. In addition, community organization principles were also applied as much as possible in the activities that were part of the intervention. This strategy was based on the notion that the success of population-based interventions depends in large part on the effective application of these principles (Bracht, 1990). The community organization principles included community participation, link up with the current situation, social 
network approach (i.e., spreading information from network members to other network members), target at individuals as well as the environment they live in, and intersectoral co-operation. Community participation in the planning and implementation of a health project is important in order to fit the project to. local needs, habits, possibilities and barriers. Also, it can develop a sense of community ownership of the project: and transfer capacities to the community. which will facilitate long-term continuation of the project by the community itself (Orlandi et al., 1990). Linking up with pre-existing activities and using local expertise and facilities can also facilitate permanence of the project (Bracht, 1990). The social network approach refers to the explicit use of tho community's interpersonal communication channels. By using interpersonai communication alongside a mass mecia approach, the information can reach more people in the community, including people with lower social economic status (Rogers, 1983; Weenig, 1991). Moreover, projects using interpersonal communication are more successful in achieving behavioral change due to social influence processes (Festinger, 1954; Moscovici, 1985; Bandura, 1986; Weenig, 1991). An environmental strategy alongside an individual strategy is important because people's behavior is largely affected by environmental factors (Simons-Morton et al., 1988). Finally, intersectoral co-operation is needed because risk behavior is determined by multiple factors. Different sectors in the community may have the power to influence these factors. Also, intersectoral co-operation can channel and co-ordinate resources (De Leeuw, 1989).

The community organization principles were given concrete form by organizing the project similar to the five-stage community organizing model of Bracht \& Kingsbury (1990); community analysis, design-initiation, implementation, maintenance-consolidation, and dissemination-reassessment.

To help a local project group implement the intervention and to ensure that effective and integrated health activities would be the result of the community organizing process a workbook was developed. The workbook described the thirty-two health education and health promotion interventions. In addition, the workbook included background information on the relationship between health and behavior, the determinants of behavior and how behavioral change can be achieved. The workbook also included guidelines. The project group was recommended to move through three steps.

(1) The first step was to organize themseives as a group. The workbook gave instructions for making a meeting schedule, developing a recognizable logo and ordering note-paper and envelopes with this logo. Also, instructions 
were given to make regulations to record agreements about, for instance, the decision making process, goals, roles and responsibilities.

(2) The second step was to choose activities. The project group was encouraged to organize activities from each program component. However, to increase involvement and ownership they were also free to develop their own activities. For each of the thirty-two activities in the workbook, the target, target group and importance of the activity was described. A timeline for the implementation of the activity was also provided. Forms were included that could help the group to make considered decisions.

(3) The third step was to prepare and implement the activities. The workbook included general recommendations as well as so-called work schedules for the systematic set up of the different activities. Examples of materials, such as possible press releases, were also part of the workbook. The project group was recommended to split up in small work groups, which would each be responsible for the preparation and implementation of certain activities. Also, they were recommended to link up with pre-existing activities in the community.

The project was initially started and financed for one year, but the initiators aimed at continuation of the project by the project group itself. Health activities in the community were expected to take place during the last six months of this period. The budget which was available to finance the project and the process evaluation was quite limited. The main costs were related to the appointment of the part time local co-ordinator, whose main tasks were to co-ordinate the project, to stimulate and support the project group members and to prepare and chair the meetings.

\section{Method}

\section{Data collection}

Data collection took place throughout the implementation period of the project (March 1990 until February 1991). A mix of data collection methods was used and community members were involved in the data collection.

Minutes were made of all meetings by one of the group members, the local coordinator or one of the researchers. In addition to this, one of the researchers made process reports of all project group meetings, in which a detailed report of the meeting was given as well as a personal impression of the meeting. 
One-page registration forms were used by volunteers working in the information center of the project to record name, address and demographic data of those who called or visited the center. Also, the reason for calling or visiting was registered. One-page registration forms were also completed by those in charge of group activities. The content and duration of the activity, the number of participants, and the names and addresses of participants were registered.

Screening of local and regional media for information regarding the project was. done by one of the project group members. University staff recorded reports regarding the project in national media.

Short written questionnaires were used to evaluate group activities and were provided to participants at the end of the activity. Participants were asked to indicate their satisfaction with (certain aspects of) the activity and the perceived effects of the activity on the different phases of behavioral change lawareness, attitude, etc.). Also, demographic data were collected. A one-page written questionnaire was also completed by those in charge of group activities. They were asked to give their personal impression about some aspects of the activity.

Prestructured short telephone interviews were used to evaluate self-help materials. All those who applied for materials at the information center or took materials home after visiting a group activity were called about 6 weeks later by one of the volunteers working in the information center. The interview included questions about the use of and satisfaction with the materials, and the perceived effects of the materials on the different phases of behavioral change.

Telephone interviews were also used to collect data among the general population. The first posttest of the effect evaluation, which was completed by 665 inhabitants directly after the implementation period, included sixteen additional questions to measure the community's familiarity with the project and the activities and their opinion about the project.

Finally, at the end of the implementation period, semi-structured face-to-face interviews were conducted by an independent researcher with all project group members and the local co-ordinator separately. In these interviews the project group members were asked how they experienced participating in the project group and what their opinion was about the project in general and some specific elements of the project, such as the workbook, the local co-ordinator, etc. The average time for conducting these interviews was, 70 minutes. 


\section{Data analyses}

The data that were collected with the registration and evaluation forms were analyzed using the SPSS-X statistical computer package (SPSS Inc., 1988). Registration forms provided information to mark the location of participants' houses on a street map of the municipality. The semi-structured interviews were recorded on audiotape from which they were transcribed. The reports of the interviews and the reports of the project group meetings were reorganized by topic and summarized.

\section{Results}

\section{Design level: What actually occurred at the design level of the project?}

The project was initiated by university staff. First, the mayor of Bergeyk was asked for permission to conduct the experimental health project in his community. Next, a community analysis was conducted to introduce the project in the community, to achieve early community involvement and to answer some important implementation questions such as which community sectors should be asked to participate in the project group. Written materials on the community were collected, key figures in the community were interviewed and short street interviews were conducted. A report with the results of the community analysis was sent to all key figures in the community. Next, a part-time local coordinator who lived in the community was hired. In January 1990, the local coordinator invited all the sectors mentioned during the community analysis to participate in a project group. All sectors agreed, resulting in a project group with eleven representatives from local government, the women's association, the health sector, the National Cross Association, an environmental organization, the cultural sector, the association for the elderly, the organization for industry and shops, and three neighborhood associations. March 1990, a meeting was organized for project group members, the local co-ordinator, university staff, the mayor and aldermen, and the press. During this meeting, which was the official start of the project, the project group was offered the workbook.

The project group took about three months to organize themselves and decide about the activities. They chose to organize the greater part of the activities in the workbook and some of their own activities. Then, four small work groups were formed, although the whole project group also continued to meet regularly, especially to keep each other informed about the progress and results 
of the activities. One of the small work groups took responsibility for the intended mass media activities. Another work group focussed on setting up a local information center where inhabitants could enroll in activities, request materials and get information about the project. The other two groups took responsibility for group and structural activities respectively. The local coordinator sat on all work groups. The work groups worked together with other people, inside or outside the community, to realize the activities. For instance, five dieticians were asked to participate in the project. They were asked to prepare and organize the nutrition activities the project group had decided on. Sixteen other community members were recruited to work as volunteers in the information center. Twice, a meeting with the owners of local food shops was organized to discuss possible co-operation.

During the implementation period the project group met 13 times. In addition to this, each work group had about 8 meetings. The university research team had bi-weekly meetings with the local co-ordinator. During these staff meetings the process reports and minutes of meetings were used to discuss the progress of the project and to decide on future strategies. The dieticians assembled 8 times as a group. They used the information in the workbook to plan and organize nutrition activities. As soon as the activities started, they regularly considered retrospectively the activities that they were involved in by using the questionnaires collected, and made changes if necessary. Six meetings were organized for the volunteers of the information center. During the first three meetings they were trained for their job by university staff. During the other three meetings experiences were exchanged and the work group responsible for the information center gave feedback to the volunteers about the progress of the project using the registration forms that they processed on an ongoing basis.

In general, all meetings passed off satisfactorily. However, during two of the project group meetings there was serious discord. The first discord concerned the project group's decision not to organize structural activities. These activities were perceived to be difficult to achieve. Shops, restaurants, cafetarias and workplaces were expected to be unwilling to participate. They were also afraid that shops, restaurants and cafetarias might take their own advantage of the activities. The project group did not want to be viewed as people that poke one's nose into everything. They did not want to force other people to a specific behavior. In their opinion, people and organizations should ask for these activities themselves. The university was afraid that this would seriously 
influence the project's effects and decided to give additional information to the project group about the importance of these kinds of activities and to ask them to reconsider their decision. The project group decided to form a work group for structural activities, after they listened to the arguments of the researchers. However, the project group members were irritated and disappointed because the university did not keep its promise that the project group would be free to choose the activities. The second discord concerned the continuation of the project. Although the university had said from the beginning that they aimed at continuation of the project after the initial one-year period, continuation was not discussed in the project group until November 1990 due to time constraints. There was a discord between the members whether the project should be continued or not. For most members it was not clear how the project could be continued without specific guidelines from the university and without the local co-ordinator. In any case, they did not want to invest as much time in the project as they had during the previous year. The prospect of continuing alone made most members very insecure. During this meeting it turned out that, until then, most members had perceived the project as a project of the university and not as their own project. Finally, the project group decided to form a work group that would study the possibilities for continuation. In this work group three project group members, the local co-ordinator and one of the researchers were represented. The work group assembled twice and advised the project group to try to get grants from provincial and local government for continuing the project and the appointment of the local co-ordinator for another experimental period of two years. After these two years the project should have to become a structural part of local health policy. The project group agreed and after a few months' break (March 1991-August 1991) the project has been continued by the project group with grants from local and provincial government. The project group has become the board of an official 'Healthy Bergeyk' Foundation. All sectors, except local government, are still represented in this board. In the new structure, the board defines the policy of the Foundation. Other community members are recruited for task groups which prepare and organize activities in the community. The project does not only focus on the four risk behaviors, but also at other risk behaviors or health problems. The researchers are represented on the project advisory committee now. 
Design level: What was the opinion of the project group members about the project

All project group members indicated that they decided to participate in the project group because they were asked to by their sector and because health is an important and interesting topic. Overall, everybody was satisfied about the way the group functioned. In general, the decision-making process was clear, although not everyone agreed with all the decisions the group had taken. Some members indicated that the group was too big and therefore the meetings were quite long. Others indicated that it was good to have so many members, especially because it was consequently possible to work in several small work groups. All agreed that the composition of the group was good, although some suggestions for other possible members were given. All members indicated that they invested a lot of time in the project and that the time investment was larger than expected. Better information about what was to be expected should have been given before the start of the project. Everyone indicated that participation was worth the time investment.

All members were very positive about the intersectoral co-operation, which gave a surplus value to the project. Communication between the sectors has been improved. All sectors contributed to the project and because of the intersectoral co-operation more was achieved than if the organizations would have worked separately. Activities could be mutually attuned and because of the intersectoral co-operation the project had more status in the community.

The importance of environmental changes was recognized by the project group members. However, one had the opinion that structural changes are very difficult to achieve, though not impossible.

Opinions were divided about the actual possibilities to participate in the planning of the project. Some felt that they had a lot of influence, especially in the work groups. Others felt that it was only possible to have influence within the framework set up by the university. Most members thought it too restricted in that the university defined that the project should focus especially on smoking and nutrition. Also, many members would have preferred to aim the project at all people in the community and not only at adults. The overall participation of inhabitants in the planning and organization of the project was perceived to be limited to the project group members and therefore very minor. For other inhabitants only indirect influence was possible via the project group members. 
All agreed that the project linked up with the current situation in the community. Not much had been organized in the health field yet, although there was a lot of interest in the topic.

All members indicated they felt involved with the topic and the project. They indicated that they would do everything to make the project a success. All said they had spread information about the project to other people. All members indicated that the goal of the project was also endorsed by the sector they represented, though not always explicitly. The communication with their own sector was good but could be better according to some. All members indicated that one way or the other they enlisted people from their own sector in organizing project activities.

Everybody thought it important that the project should be continued. One year was much too short for some of the activities and it is important to repeat the message. Most members thought that all sectors should stay represented in the project group. Almost all agreed that the project should be structurally financed by the municipality and/or the province.

Everybody indicated that the workbook was an important element of the project and was used a lot, especially in the beginning. It gave the necessary background information and gave direction to the project.

According to most members, the university gave important support to the project and was stimulating. Some members thought the university was too directive.

Some members thought the project was negatively influenced by the process evaluation. According to them, registration of participants was not appreciated by the inhabitants. Also, the telephone interviews were a lot of work for the volunteers and the information center might have functioned better without this task. People who participated in more than one activity where confused as they were also approached for the research more than once. On the other hand, most members indicated that the research gave the project more status.

All members said that the local co-ordinator was an indispensable element of the project. She stimulated and co-ordinated the project. Because so much work had to be done, it was not possible to do it with volunteers only. 
Output level: Which health activities were organized, how often, how many people participated, and what were the characteristics of the participants?

Health activities were organized in Bergeyk from September 1990 until February 1991. An overview of activities conducted, organized by risk behavior, is given in Table 1.

Overall, 89 articles were published about the project in newspapers. The articles focused on one of the risk behaviors or on the project in general. The articles, for instance, announced the start of a group activity, reproduced an interview with a participant of an activity or gave information about the advantages and disadvantages of a certain risk behavior.

Smoking activities comprised of 4 smoking cessation group courses given b' an experienced course leader. These courses consisted of 8 group meetings and a follow-up meeting. A self-help smoking cessation manual was available for those smokers who preferred to stop on their own. Furthermore, a questionnaire was sent to 230 workplaces and 45 associations to find out which rules they had on smoking and alcohol use. Based on the results of this questionnaire the project group sent letters to the workplaces and associations with suggestions for a smoking and alcohol policy. Another alcohol activity was a letter that was sent to local government with a request for an alcohol reduction policy in the community. Letters were also sent to 14 cafes and discotheques with the request to enlarge their assortment of alcohol-free drinks and to promote these among their clients.

Nutrition activities comprised of 13 living room nutrition sessions guided by a dietician. Inhabitants could apply at the information center for a session in their own home and invite about 8 other people (family, friends, neighbors). At the request of associations, 6 lectures about nutrition were given for members. Furthermore, a fat reduction program was available to use at home. This program could be hung in the kitchen and consisted of 4 steps. Each step focused on a different group of food products. In each step advice was given about how the amount of fat consumed by eating these products could be reduced. Users were advised to take one week for each step. At the end of the program the user could do a test. In the local newspaper 10 large advertisement appeared with healthy recipes. These advertisements were paid for by the local food shops, while the dieticians made the healthy recipes. Furthermore, a cooking course was organized, which consisted of 4 sessions. Finally, 2 local cafetarias sold a sandwich 'Healthy Bergeyk' and one of the 5 local workplace cafetarias that received a letter with this option invited a dietician to 


\section{Smoking}

newspaper article

small group course

15

self-help manual

questionnaire on smoking policies

letter to workplaces and associations

\section{Nutrition}

newspaper article

cooking course

living room session

lecture

self-help fat reduction program

newspaper advertisement

with healthy recipes

sandwich 'Healthy Bergeyk'

advice to workplece cafetarias

recipes to cafetarias and restaurants

\section{Alcohol}

nowspaper articlo

questionnaire on alcohol policies

letter to workplaces and associations

letter to local government

letter to cafes and discotheques

Solarium

newspeper article

\section{General}

newspaper article

information market

posters and pamphlets

information center

radio interview

discuss the food offer in their cafetaria. Several recipes for healthy sandwiches were sent to local employers. 
Posters and pamphlets were used to announce the project activities. Pamphlets were circulated house to house. Posters were put up in public places. In addition, there were exhibitions and an information market to gain attention for the project in general. Also, the project information center was started, which had a key role in the organization of the activities and the dissemination of materials.

Except for the smoking cessation course and the cooking course all activities were free of charge.

The separate evaluation showed that especially women participated in the group activities and requested self-help materials. More than $90 \%$ of those who participated in the nutrition activities (living room session, lecture, cooking course or fat reduction program) and about $70 \%$ of those who participated in the smoking activities (course or self-help manual) were female. Especially people in the age group 30-69 years participated in the nutrition activities. People who participated in the smoking activities were slightly younger and mainly from the age group 30.49 years. About $70 \%$ of those who participated in the nutrition activities and about $50 \%$ of those who participated in the smoking activities had a low levell of education.

The street map registration showed that participants were mainly concentrated around the shopping center of the community. In some other neighborhoods participation was very low.

Output level: What was the level of satisfaction of the participants and the leaders with the activities, and what were the effects of the activities?

In general, participant's level of satisfaction with (the various elements of) the group activities and self-help materials was high. Negative aspects of group activities, as stated by participants or those in charge, were changed in the next activity whenever possible. The dieticians were not always satisfied about the nutrition living-room sessions. Some living-rooms were very small and not really suited and therefore it was not always possible to give the session a structured course. However, in these sessions some of the people who participated were not very interested in the topic yet, but came because they were invited. According to the dieticians, these people would not have been reached with other methods.

Most participants in the nutrition activities reported that they started to eat less fat as a result of the activity. Of the smokers who used the self-help manual $25 \%$ were still abstaining from smoking six weeks after they got the 
manual. During the follow-up session to the smoking cessation course lone month after the last group session) $67.5 \%$ of the 40 participants were not smoking.

How many inhabitants of the community were familiar with the project, and what was their opinion about the project?

Directly after the implementation period $82.4 \%$ of the 665 respondents who completed the first posttest of the effect evaluation were familiar with the project: $42.4 \%$ could mention the name of the project and $40 \%$ could not mention the name, but recognized the name after the interviewer mentioned it. Of all respondents $80.3 \%$ had read something about the project in newspapers. The information center was farniliar to $42 \%$ of all respondents. Almost $37 \%$ of all respondents said they had discussed the project with someone else.

Of those who were familiar with the project $67.2 \%$ indicated they had a positive opinion about the project. About $16 \%$ were somewhat positive, $2.5 \%$ had a negative or somewhat negative opinion and the other $14.2 \%$ did not know. Almost $84 \%$ reported that they thought it important to have a project like 'Healthy Bergeyk' in their community, $10 \%$ did not think it important and almost $7 \%$ had no opinion about this. Almost $77 \%$ thought it important for the project to continue and $15 \%$ of these people (i.e. $10 \%$ of all respondents) said that they would be willing to contribute to the project if the project were to continue. Finally, almost $80 \%$ of all respondents who were familiar with the project indicated that they had confidence that the project spread correct information. Slightly more than $9 \%$ had a bit confidence, $1.3 \%$ had no confidence and the other $10.6 \%$ did not know.

\section{Discussion and conclusions}

The major goal of the Dutch community project 'Healthy Bergeyk' was a reduction in cancer-related risk behavior prevalence, especially smoking and high fat consumption. The project tried to integrate health education theory and methods with community organization principles by offering a local project group a workbook which described thirty-two possible health education and health promotion interventions. Process evaluation was conducted to document what actually occurred in the community. Also, it was studied how the different elements of the project were evaluated by participants and leaders of activities, 
project group members and/or the community in general. The implications of the study findings for both the process evaluation and the project will be discussed.

\section{Implications for the process evaluation}

In the process evaluation a mixture of data collection methods was used and inhabitants were involved in the data collection. A distinction was made between research questions on the design and output level of the project.

The study findings show that due to the process evaluation the project was documented extensively and that successful and less successful elements of the project were assessed. The evaluation also produced enough information to explain the (lack of) behavioral effects of the project (see section 'implications for the project'). The data of the process evaluation were used to give fast feedback to the staff as well as the community members involved. This feedback was stimulating and made it possible to make adaptations when necessary and to decide about furure activities.

One of the main dilemmas in the planning of the process evaluation was whether each activity, i.e., each mass media message, had to be evaluated separately and to what extent. Some of the activities only had the purpose to gain attention for the project in general. It was decided that all activities would be recorded, but that only the group and self-help activities that were expected to achieve behavioral change were evaluated separately. Questionnaires wero kept as short as possible and only posttests were conducted. Lack of pretests can been seen as one of the lirnitations in the evaluation of the group and self help materials. Pretests would have made it possible to assess changes in (determinants of) risk behaviors. However, this would not only have given organizational problems, but also would not have been acceptable to the project group. They were afraid of overloading people with questionnaires. Similarly they were against interviewing twice people that participated in two activities.

One of the advantages of involving community members in the data collection was that they received direct feedback on their efforts, Also, the data collection was too time consuming to be executed by the researchers alone. Anotheif very important reason for community involvement in the data collection was that if the project would be continued by the community itself, some sort of process evaluation should also be part of the project and be executed by the community itself. However, one of the disadvantages was; that the interviews were not always conducted properly. Sometimes questions were skipped because the interviewers did not perceive them to be important. Alsc, privacy problems 
appeared, especially regarding the telephone interviews. Interviewer and interviewee lived in the same community and often knew each other. The interviewers had especially problems asking the interviewee about level of education.

In retrospect it would have been better to involve leaders of activities, project group members and the volunteers in the information center in the questionnaire development also. It would have given them the opportunity to add questions they wanted to be answered and the evaluation would have been more 'for' instead of 'on' the community. It would have made the process evaluation part of the project and not only something the university wanted. Their involvement would probably also have given them more insight in the importance of some of the questions in the interviews and of the process evaluation in general.

Finally, some of the key concepts that were applied in the project could have been studied more extensively, for instance the concept of intersectoral cooperation. Based on the experiences of other community projects, to facilitate the intersectoral co-operation, instructions were given to the project group to make regulations to record agreements about for instance the decision-making process, goals, roles and responsibilities. However, as part of the process evaluation, a study into the actual intersectoral co-operation and the determinants of the co-operation might have produced very useful information.

\section{Implications for the project}

The findings show that the project group achieved many health activities in their community in a short time period. Most of the activities focused on fat consumption. Several activities focused on smoking cessation and just a few activities were directed at the reduction of alcohol consumption and the use of solaria. This explains the results of the effect evaluation, where no significant effects of the project on alcohol consumption and solarium use were found (Van Assema et al., submitted).

The project group had problems organizing structural activities. The activities that they finally realized, i.e. letters to several organizations, were offers without engagement and therefore probably not very effective in achieving environmental changes. It seems that the project group should have been given more support and more information about possible structural activities.

The number of inhabitants that participated in group activities or requested self-help materials was not large. In some cases this was due to enrollment limits. For instance, as so much work had to be done, it was impossible for the 
project group to organize more than four smoking cessation courses. It seems that if the implementation period had been longer, participation rates would have been higher.

The group activities and self-help materials seem to have reached women especially and specific parts of the community. Furthermore, many of the participants had a low level of education. This, however, was closely connected to the high participation of women in a specific age group. As many participants reported they had talked about the activity with other people, there might have been a spin-off effect. In particular, this refers to the nutrition activities where most participants prepared the family meals. Nevertheless, more effort should be put into reaching other groups in the community.

In general, participants in group or self-help activities were positive about the activity. However, these results should be interpreted carefully, as satisfaction is a difficult concept to measure. High levels of satisfaction with activities are found in most programs (Pirie, 1990). Although the self-reports on behavioral change should also be interpreted carefully, the activities seem to have been quite effective in achieving their goals.

Familiarity with the project in the community was high. Mass media seem to have been an important source of information. Also, many people talked about the project with someone else. Therefore, the social network approach seems to have been successful. The general opinion in the community about the project was positive and supportive of the continuation of the project.

The main positive elements of the project concerned the workbook and the intersectoral co-operation. The workbook was positively evaluated by the proiect group members and used a lot. However, the workbook could be improved if it were extended by including activities for inhabitants under 18 alsa and by giving more information about structural interventions. Due to the workbook a rapid start of the project was pessible. As the project group decicled to organize the greater part of the workbook activities, a package of activities was organized that was based on health education theory and methods. The workbook was also helpful for the dieticians.

The intersectoral composition of the project group was positively evaluateci by all participants. Due to the co-operation, more was achieved than if the organizations would have worked separately and communication between the sectors has been improved.

A very negative aspect of the project was the short implementation period, due to the fact that the research had to be finished within a certain time period. 
There was a lot of time pressure on the project and the project group members were overburdened. Better information about time investments should have been given to the project group members at the beginning of the project. A possible solution might also have been to ask other community members to participate in the work groups. This would also have increased the number of people participating in the planning of the project, which was now mainly limited to the project group members. However, this would have made the total project organization more complex. Also, many members of the project group enjoyed primarily the practical jobs. One of the most negative consequences of the time pressure was that there was no time to carry over knowledge and skills to the community. The local co-ordinator spent a lot of time on practical jobs just to make sure that intended health activities could take place, instead of creating conditions for the continuation of the project. This resulted in a lack of expertise in those involved in the project and therefore the university had to interfere during the project in order to ensure that the group would organize effective activities. This was not appreciated by the project group and did not improve ownership of the project. As a consequence, and also because the discussion about the continuation of the project started too late, the continuation of the project did not proceed easily. The aim to continue the project without the local co-ordinator after the one-year period was not realized.

Another problem was that the risk behaviors the project should focus on had already been defined by the university and invariable due to grant conditions. More freedom in defining the project's objectives might have improved community involvement and ownership.

In conclusion, the most difficult dilemma in the project was to combine quality and effectiveness of health education and health promotion interventions with community ownership of the project and long-term project continuation. To some extent, successful outcomes were at the cost of community ownership. Nevertheless, the behavioral results of the project were promising and an intersectoral network for health promotion which functioned well was created in the community. 


\section{References}

Ajzen, I., \& Fishbein, M. (1980). Understanding attitudes and predicting social' behavior. Englewood Cliffs, NJ: Prentice Hall.

Ajzen, I., \& Madden, T.J. (1986). Prediction of goal-directed behavior: Attitudes, intentions, and perceived behavioral control. Journal of Experimental Social Psychology, 22, 453-474.

Albright, C.L., Flora, J.A., \& Fortmann, S.P. (1990). Restaurants menu labeling: Impact of nutrition information on entree sales and patron attitudes. Health Education Quarterly, 17, 157-167.

Altman, D.G. (1986). A frarnework for evaluating community-based heart disease prevention programs. Social Science and Medicine, 22, 479-487.

Anderson, J., \& Haas, M.H. (1990). Impact of a nutrition education program on food sales in restaurants. Journal of Nutrition Education, 22, 232-238.

Arnstein, S.R. (1969). A ladder of citizen participation. Journal of the American Institute of Planners, 35, 216-224.

Bandura, A. (1986). Social foundations of thought and action: A social cognitive theory. Englewood Cliffs, NJ: Prentice Hall.

Basch, C.E. (1987). Focus group interview: An underutilized research technique for improving theory and practice in health education. Health Education Quarterly, 14, 411-448.

Becel (1989). Becel Voedingsprogramma, een professioneel programma voor de personal computer (Becel Nutrition Program, a professional program for the personal computerl. Rotterdam, the Netherlands: Becel Voedingsdienst.

Bingham, S.A., Nelson, M., Paul, A.A., Haraldsdottir, J., Loken, E.B., \& Van Staveren, W.A. (1988). Methods for data collection at an inclividual level. In M.E. Cameron, \& W.A. Van Staveren (Eds.), Manual on methodology for food consumption studies (pp. 53-106). Oxford: Oxford University Press.

Block, G. (1982). A review of validations of dietary assessment methods. American Journal of Epidemiology, 115, 492 505.

Block, G., Clifford, C., Naughton, M.D., Henderson, M., \& McAdams, M. (1989). A brief dietary screen for high fat intake. Journal of Nutrition Education, 21, 199-207. 
Block, G., Patterson, B., \& Subar, A. (1992). Fruit, vegetables, and cancer prevention: A review of the epidemiological evidence. Nutrition and Cancer, 18, 1-29.

Bracht, N. (1990). Introduction. In N. Bracht (Ed.), Health promotion at the community level (pp. 19-25). Newbury Park, CA: Sage.

Bracht, N., \& Gleason, J. (1990). Strategies and structures for citizen partnerships. In N. Bracht (Ed.), Health promotion at the community level (pp. 109-124). Newbury Park, CA: Sage.

Bracht, N., \& Kingsbury, L. (1990). Community organization principles in health promotion: A five-stage model. In N. Bracht (Ed.), Health promotion at the community level (pp. 66-88). Newbury Park, CA: Sage.

Brink, S.G., Simons-Morton, D., Parcel, G., \& Tierman, K. (1988). Community interventions handbooks for comprehensive health promotion programming. Family and Community Health, 11, 28-35.

Burema, J., Van Staveren, W.A., \& Van den Brandt, P.A. (1988). Validity and reproducibility. In M.E. Cameron, \& W.A. Van Staveren (Eds.), Manual on methodology for food consumption studies (pp. 171-181). Oxford: Oxford University Press.

Calnan, M. (1985). Patterns in preventive behavior: A study of women in middle age. Social Science and Medicine, 20, 263-268.

Calnan, M., \& Rutter, D.R. (1986). Preventive health practices and their relationship with socio-demographic characteristics. Health Education Research, 1, 247-253.

Cameron, M.E., \& Van Staveren, W.A. (Eds.) (1988). Manual on methodology for food consumption studies. Oxford: Oxford University Press.

CBS (1987). Bevolking der gemeenten van Nederland op 1 januari 1987 (Population of the municipalities of the Netherlands at January 1, 1987). 's Gravenhage, the Netherlands: Staatsuitgeverij.

Charlton, A. (1977). Cancer: Opinions of some secondary school pupils in Northern England. International Journal of Health Education, 20, 112119.

Chavis, D., Stucky, P., \& Wandersman, A. (1983). Returning basic research to the community: A relationship between scientist and citizen. American Psychologist, 38, 424-434.

Cobb, R.W., \& Elder, C.D. (1983). Participation in American politics: The dynamics of agenda-building. Baltimore, MD: The John Hopkins University Press. 
Coebergh, J.W.W. (1989). Algemene introductie (General introduction). In D.E. Grobbee, \& A. Hofman (Eds.), Epidemiologie van ziekten in Nederland (Epidemiology of diseases in the Netherlands) (pp. 56-76). Utrecht, the Netherlands: Bunge.

Cohen, S., \& Syme, S.L. (Eds.) (1985). Social support and health. Orlando, FL: Academic Press.

Colsher, P.L., \& Wallace, R.B. (1989). Is modest alcohol consumption better than none at all? An epidemiological assessment. Annual Review of Public Health, 10, 203-219.

Commission of the European Communities (1987). Survey: Europeans and the prevention of cancer. Working document of the services of the European Commission, Brussels.

Cook, T.D., \& Campbell, D.T. (1979). Quasi-experimentation: Design and analysis issues in field settings. Boston, MA: Houghton Mifflin.

Damoiseaux, V. (1991). Listen, lusten and lasten van massamediale voorlichting: De planning van publieksgerichte inrerventies ITricks, joys and burdens of mass media education: The planning of public oriented interventions). Assen/Maastricht, the Netherlands: Van Gorcum.

De Bruijn, F. (1993). Agendabouw-theorie: een aanzet om de kloof tussen theorie en praktijk te slechten (Agenda-building theory: an attempt to bridge the gap between theory and practice). In E. de Leeuw, \& J. ton Dam (Eds.), Gezonde steden en onderzoek, reikwijdte, methoden. toepassingen (Healthy cities and research, range, methods and applications) (pp. 42-51). Assen/Maastricht, the Netherlands: Van Gorcum.

De Leeuw, E.J.J. (1989). The sane revolution, health promotion: Backgrounds, scope, prospects. Assen/Maastricht, the Netherlands: Van Gorcum.

De Leeuw, E. (1991). Gezondheidsbeleid en lokale gezondheidsbevordering (Health policy and local health promotion). In E. De Leeuw (Ed.), Gezonde steden, lokale gezondheidsbevordering in politiek, theorie en praktijk (Healthy cities, local health promotion in policy, theory and practice) (pp. 11-35). Assen/Maastricht, the Netherlands: Van Gorcum.

Den Boer, D-J., Kok, G.J., Hospers, H.J., Gerards, F.M., \& Strecher, V.J. (1991). Health education strategies for attributional retraining and selfefficacy improvement. Health Education Research, 6, 239-248. 
De Vries, H., Dijkstra, M., \& Kuhlman, P. (1988). Self-efficacy: The third factor besides attitude and subjective norm as a predictor of behavioral intentions. Health Education Research, 3, 273-282.

De Walle-Sevenster, J., Beucken, L.R.J., Röling, N.G. (1986). Voorlichting aan achterstandsgroepen (Education of arrear groups). 's Gravenhage, the Netherlands: Vuga.

DiClemente, C.C., Prochaska, J.O., \& Gilbertini, M. (1985). Self-efficacy and the stages of self-change of smokıng. Cognitive Therapy Research, 9, $181-200$.

Doll, R. (1989). The prevention of cancer: Opportunities and challenges. Keynote address. The prevention of cancers: Spreading the message. A European Colloquium of Cancer and Health Promotion Experts. Lisbon, February.

Doll, R., \& Peto, R. (1981). The causes of cancer: Quantitative estimate of avoidable risks of cancer in the United States today. Journal of the National Cancer Institute, 66, 1191-1308.

Dufly, S.W., \& Sharples, L.D. (1992). Alcohol and cancer risk. In J. Duffy (Ed.), Alcohol and illness, the epidemiological viewpoint (pp. 64-127). Edinburgh: University Press.

Dutch Nutrition Council (Voedingsraad) (1982). Voeding in relatie tot coronaire hartziekten (Nutrition in relation to coronary heart diseases). 's Gravenhage, the Netherlands: Voedingsraad.

Dutch Nutrition Council (Voedingsraad) (1986a). Factoren in de voeding en het ontstaan van kanker (Dietary factors and the development of cancer). 's Gravenhage, the Netherlands: Voedingsraad.

Dutch Nutrition Council (Voedingsraad) (1986b). Advies Richtlijnen Goede Voeding (Advice Guidelines Healthy Nutrition). 's Gravenhage, the Netherlands: Voedingsraad.

Dutch Nutrition Council (Voedingsraad) (1989). Notitie voeding in relatie tot coronaire hartziekten (Notice nutrition in relation to coronary heart diseases). 's Gravenhage, the Netherlands: Voedingsraad.

Dutch Nutrition Council (Voedingsraad) (1991). Nader advies inzake de richtlijn m.b.t. de vetconsumptie uit het Advies Richtlijnen Goede Voeding 1986 (Further advice regarding the recommendations with relation to the fat consumption in the Advice Guidelines Healthy Nutrition 1986). 's Gravenhage, the Netherlands: Voedingsraad. 
Farquhar, J.W., Fortmann, S.P., Maccoby, N., Wood, P.D., Haskell, W.L., Taylor, C.B., Flora, J.A., Solomon, D.S. Rogers, T., Adler, E., Breitrose, P., \& Weiner, L. (1984). The Stanford Five City Project: An overview, in J.D. Matarazzo, S.M. Weiss, J.A. Herd, N.E. Miller, \& S.M. Weiss (Eds.), Behavioral health: $\boldsymbol{A}$ handbook of health enhancement and disease prevention (pp. 1154-1165). New York: John Wiley.

Festinger, L. (1954). A theory of comparison processes. Human Relations, 7. 117-140.

Finnegan, J.R., Murray, D.M., Kurth, C., \& McCarthy, P. (1989). Measuring and tracking education program implementation: The Minnesota Heart Health Program experience. Health Education Quarterly, 16, 77-90.

Flay, B.R. (1987). Mass media and smoking cessation: A critical review. American Journal of Public Health, 77, 153-160.

Flay, B.R., \& Cook, T.D. (1981). The evaluation of media-based prevention campaigns. In R. Rice, \& W. Paisley (Eds.), Public communication campaigns (pp. 239-264). Beverly Hills, CA: Sage.

Flegal, K.M., \& Larkin, F.A. (1990). Partitioning macronutrient intake estimates from a food frequency questionnaire. American Journal of Epidemiology. 131, 1046-1058.

Fleiss, J. (1981). Statistical methods for rates and proportions. New York: John Wiley.

Glanz, K. (1985). Nutrition education for risk factor reduction and patient education: A review. Preventive Medicine, 14, 721-752.

Glanz, K., Lewis, F.M., \& Rimer, B.K. (1990). Moving forward: Research and evaluation methods for health behavior and health education. In K. Glanz, F.M. Lewis, \& B.K. Rimer (Eds.), Health behavior and health education: Theory, research, and practice (pp. 428-435). San Francisco, CA: Jossey-Bass.

Glanz, K., \& Mullis, R.M. (1988). Environmental interventions to promote healthy eating: A review of models, programs and evidence. Health Education Quarterly, 15, 395-415.

Glanz, K., \& Seewald-Klein, T. (1986). Nutrition at the worksite: An overview. Journal of Nutrition Education, 18, S1-S12.

Green, L.W. (1986). The theory of participation: A qualitative analysis of its expression in national and international health policies. Advances in Health Education and Promotion, 1, 211-236. 
Green, L.W., \& Kreuter, M.W. (1991). Health promotion planning: An educational and environmental approach. Mountain View, CA: Mayfield.

Green, L.W., Kreuter, S.G., Deeds, S.G., \& Partridge, K.B. (1980). Health education planning, a diagnostic approach. Palo Alto, CA: Mayfield.

Green, L.W., \& Lewis, F.M. (1986). Measurement and evaluation in health education and health promotion. Palo Alto, CA: Mayfield.

Harris, D.M., \& Guten, S. 11979). Health-protective behavior: An exploratory study. Journal of Health and Social Behavior, 20, 17-29.

Hochbaum, G.M. (1983). The Health Belief Model revisited. Paper presented at the Annual Meetings of the APHA, Dallas, TX. November 14.

Hueben, F., De Leeuw, E. (1991). Intersectorale samenwerking: de theorie en de praktijk (Intersectoral co-operation: Theory and practice). In E. De Leeuw (Ed.), Gezonde steden, lokale gezondheidsbevordering in politiek, theorie en praktijk (Healthy cities, local health promotion in policy, theory and practice) (pp. 87-108). Assen/Maastricht, the Netherlands: Van Gorcum.

Hulshof, K.F.A.M. (1993). Assessment of variety, clustering and adequacy of eating patterns, Dutch National Food Consumption Survey. Thesis, University of Limburg, Maastricht, the Netherlands.

Hulshof, K.F.A.M., \& Van Staveren, W.A. (1991). The Dutch National Food Consumption Survey: Design, methods and first results. Food Policy, 16, $257-260$.

International Agency for Research on Cancer (1988). Alcohol drinking (monograph no. 44). Lyon: IARC/WHO.

Jackson, A., \& Laking, A. (1985). Formative research and its implementation in the making of the BBC television series 'Can you avoid cancer?'. In D.S. Leather, G.B. Hastings, K.M. O'Reilly, \& J.K. Davies (Eds.), Health education and the media (pp. 101-108). Proceedings of the Second International Conference, Edinburgh, 25-29 March. Oxford: Pergamon Press.

Jain, M., Howe, G.R., Johnson, K.C., \& Miller, A.B. (1980). Evaluation of a diet history questionnaire for epidemiologic studies. American Journal of Epidemiology, 111, 212-219.

Janz, N.K., \& Becker, M.H. (1984). The health belief model: A decade later. Health Education Quarterly, 11, 1-47.

Kistemaker, C. (1991). Simulatiestudie aangaande de invloed op de vetconsumptie van vervanging van vetrijke produkten door magere 
alternatieven, bij 22-49 jarigen (Simulation study concerning the influence on fat consumption of substituting high fat products by lean alternatives, in 2.49 age group). Report V91.360. Zeist, the Netherlands: TNOvoeding.

Knopf. A. (1976). Changes in women's opinions about cancer. Social Science and Medicine, 10, 191-195.

Kok, G., \& De Vries, H. (1989). Primary prevention of cancers: The need for health education and intersectoral health promotion. In T. Heller, B. Davey, \& L. Bailey (Eds.), Reducing the risk of cancers (pp. 99-111). London: Hodder and Stoughton.

Kok, G., De Vries, H., Mudde, A., \& Strecher, V.J. (1991). Planned health education and the role of self-efficacy: Dutch research. Health Education Research, 6, 231.238.

Koopmanschap, M.A., Van Roijen, L. \& Bonneux, L. (1991). Kosten van ziekten in Nederland (Costs of diseases in the Netherlands). Rotterdam, the Netheriands: Instituut Maatschappelijke Gezondheidszorg.

Kristal, A.R., Shattuck, A.L., Henry, H.J., \& Fowler, A.S. (1990). Rapid assessment of dietary intake of fat, fiber, and saturated fat: Validity of an instrument suitable for community intervention research and nutritional surveillance. American Journal of Health Promotion, 4, 288-295.

Krueger, R.A. (1988). Focus groups: A practical guide for applied research. Beverly Hills, CA: Sage Publications.

Lalonde, M. (1974). A new perspective on the health of Canadians - a working document. Ottawa: Government of Canada.

Lefebvre, R.C. (1990). Strategies to maintain and institutionalize successful programs: A marketing framework. In N. Bracht (Ed.), Health promotion at the community level (pp. 209-228). Newbury Park, CA: Sage.

Lemmens, P., Tan, E.S., \& Knibbe, R.A. (1992). Measuring quantity and frequency of drinking in a general population survey: $A$ comparison of five indices. Journal of Studies on Alcohol, 53, 476-486.

Liedekerken, P.C., Jonkers, R., De Haes, W.F.M., Kok, G.J., \& Saan, J.A.M. (1988). The effectiveness of health education. Rijswijk, the Notherlands: Uitgeverij voor Gezondheidsbevordering.

Luther, S.L., Price, J.H., \& Rose, C.A. (1982). The public's knowledge about cancer. Cancer Nursing, 6, 109-116.

Maccoby, N., Farquhar, J.W., Wood, P.D., \& Alexander, J.K. (1977). Reducing the risk of cardiovascular disease: Effects of a community-based 
campaign on knowledge and behavior. Journal of Community Health, 3. 100-114.

Marr, J.W., \& Heady, J.A. (1986). Within- and between-person variation in dietary surveys: Number of days needed to classify individuals. Human Nutrition: Applied Nutrition, 40A, 347-364.

McGuire, W.J. (1984). Public communication as a strategy for inducing healthpromoting behavioral change. Preventive Medicine, 13, 299-319.

McGuire, W.J. (1985). Attitudes and attitude change. In G. Lindzey, \& E. Aronson (Eds.). The handbook of social psychology (Vol. 2) (pp. 233346). New York: Random House.

Mechanic, D., \& Cleary, P.D. (1980). Factors associated with the maintenance of positive health behavior. Preventive Medicine, 9, 805-814.

Medlin, C., \& Skinner, J.D. (1988). Individual dietary intake methodology: A 50year review of progress. Journal of the American Dietetic Association, $88,1250-1257$.

Milio, N. (1986). Multisectoral policy and health promotion: Where to begin. Health Promotion - An International Journal, 1, 129-132.

Ministerie van Welzijn, Volksgezondheid en Cultuur (1989a). Discussienota doelgericht veranderen, ontwerp-Kerndocument Gezondheidsbeleid voor de jaren 1990-1995 (Discussion document Core Document Health Policy for the years 1990-1995). Rijswijk, the Netherlands: Ministerie van WVC.

Ministerie van Welzijn, Volksgezondheid en Cultuur (1989b). Discussienota kankerbestrijding (Discussion document cancer control). Rijswijk, the Netherlands: Ministerie van WVC.

Minkler, M. (1990). Improving health through community organization. In $\mathrm{K}$. Glanz, F.M. Lewis, \& B.K. Rimer (Eds.), Health behavior and health education (pp. 257-287). San Francisco, CA: Jossey-Bass.

Mittelmark, M.B., Luepker, R.V., Jacobs, D.R., Bracht, N.F., Carlaw, R.W., Crow, R.S., Finnegan, J., Grimm, R.H., Jeffery, R.W., Kline, F.G., Mullis, R.M., Murray, D.M., Pechacek, T.F., Perry, C.L., Pirie, P.L., \& Blackburn, H. (1986). Community-wide prevention of cardiovascular disease: Education strategies of the Minnesota Heart Health Program. Preventive Medicine, 15, 1-17.

Morgan, D.L. (1988). Focus groups as qualitative research. Sage University paper Series on Qualitative Research Methods, Vol. 16. Beverly Hill, CA: Sage Publications. 
Moscovici, S. (1985). Social influence and conformity. In G. Lindzey, \& E. Aronson (Eds.). Handbook of social psychology (Vol. 2) (pp. 347.412). New York: Random House.

National Cancer Institute (1983). Cancer prevention: An editorial. The Cancer Bulletin, 32, 127.

Nelson, M., Black, A.E., Morris, J.A., \& Cole, T.J. (1989). Between- and withinsubject variation in nutrient intake from infancy to old age: Estimating the number of days required to rank dietary intakes with desired precision. American Journal of Clinical Nutrition, 50, 155-167.

NEVO (1989). NEVO tabel, Nederlands voedingsstoffenbestand 1989/1990 (The Dutch food composition table 1989/1990). Stichting Nevo. Zeist/'s Gravenhage, the Netherlands: Voorlichtingsbureau voor de Voeding.

Norman, S.A., Greenberg, R., Marconi, K., Novelli, W., Felix, M., Schechter, C., Stolley, P., \& Stunkard, A. (1990). A process evaluation of a two-year community cardiovascular risk reduction program: what was done and who knew about it?. Health Education Research, 5, 87-97.

Orlandi, M.A., Landers, C., Weston, R., \& Haley, N. (1990). Diffusion of health promotion innovations. In K. Glanz, F.M. Lewis, \& B.K. Rimer (Eds.), Health behavior and health education: Theory, research, and practice (pp. 288-313). San Francisco, CA: Jossey-Bass.

Peto, R. (1985). The preventability of cancer. In M.P. Vessey, \& M. Gray (Eds.), Cancer risks and prevention (pp. 1-14). Oxford: Oxford University Press

Pirie, P.L. (1990). Evaluating health promotion programs: Basic questions and approaches. In N. Bracht (Ed.), Health promotion at the community level (pp. 201-208). Newbury Park, CA: Sage.

Preston, M.A., Baranowski, T., \& Higginbotham, J.C. (1988). Orchestrating the points of community intervention: Enhancing the diffusion process. International Quarterly of Community Health Education, 9, 11-34.

Prochaska, J.O., \& DiClemente, C.C. (1984). A transtheoretical approach: Crossing traditional boundaries of therapy. Homewood, III: Dow JonesIrwin.

Prochaska, J.O., \& DiClemente, C.C. (1992). Stages of change in the modification of problem behaviors. Progress in Behavior Modification, 28, 184-218.

Puska, P. (1984). Community-based prevention of cardiovascuiar disease: The North Karelia project. In J.D. Matarazzo, S.M. Weiss, J.A. Herd, N.E. Miller, \& S.M. Weiss (Eds.), Behavioral health: A handbook of health 
enhancement and disease prevention (pp. 1140-1147). New York: John Wiley.

Puska, P., Nissinen, A., Tuomilehto, J., Salonen, J.T., Koskela, K., McAlister, A., Kottke, T.E., Maccoby, N., \& Farquhar, J.W. (1985). The communitybased strategy to prevent coronary heart disease: Conclusions from the ten years of the North Karelia Project. Annual Review of Public Health, 6 , 147.193.

Rogers, E.M. (1983). Diffusion of innovations. New York: The Free Press.

Samuels, S.E. (1990). Project LEAN: A national campaign to reduce dietary fat consumption. American Journal of Health Promotion, 4, 435-440.

Scenario Commission Cancer (Scenariocommissie Kanker) (1987). Kanker in Nederland (Cancer in the Netherlands), deel 1. Utrecht, the Netherlands: Bohn, Scheltema \& Holkema.

Schrameijer, F., \& Brunenberg, W. (1992). Psychosociale zorg bij kanker. patiënten en hulpverleners over problemen en hulpaanbod (Psycho-social care in cancer, patients and care providers about problems and care supply). Utrecht, the Netherlands: Nederlands Centrum Geestelijke Volksgezondheid.

Schwartz, J.L. (1987). Review and evaluation of smoking cessation methods:

The United States and Canada, 1978-1985. NIH Publication no.87-2940. Washington, DC: Government Printing Office.

Simons-Morton, D.G., Simons-Morton, B.G., Parcel, G.S., \& Bunker, J.F. (1988). Influencing personal and environmental conditions for community health: A multi-level intervention model. Family and Community Health, 11, 25-35.

SPSS inc. (1988). SPSS-X user's guide. Chicago, III: SPSS inc.

Steenbakkers, M., Van Assema, P., \& Kok, G.J. (1992). Voedingsinformatiepakket 'Gezonder en minder vet eten' (Nutrition information package 'Eating more healthy and less fat'. Tijdschrift Gezondheidsvoorlichting, 9, 14-16.

Steenbakkers, M., Van Assema, P., Kok, G., \& Gabriëls-Stensen, D. (1991). Project Gezond Bergeyk, de ontwikkeling en implementatie van een lokaal gezondheidsproject (Project Healthy Bergeyk, the development and implementation of a local health project). In E. De Leeuw (Ed.), Gezonde steden, lokale gezondheidsbevordering in politiek, theorie en praktijk (Healthy cities, local health promotion in policy, theory and practice) (pp. 225-248). Assen/Maastricht, the Netherlands: Van Gorcum. 
Suls, J. (1982). Social support, interpersonal relations and health: Benefits and liabilities. In G.S. Sanders, \& J. Suls (Eds.). Social psychology of health and illness (pp. 255-277). Hillsdale, NJ: Lawrence Erlbaum Associates.

Suls, J.M., \& Miller, R.L. (Eds.) (1977). Social comparison processes: Theoretical and empirical perspectives. Washington, DC: Hemisphere.

Tweede Kamer (1986). Nota 2000. Gezondheid als uitgangspunt (Noto 2000. Health as the basis), vergaderjaar 1985-1986, kamerstuk 19500, nrs 1 2-3. 's Gravenhage, the Netherlands.

U.S. Department of Health and Human Services (1982). The health consequences of smoking: Cancer. A report of the Surgeon General. Washington, DC: U.S. Government Printing Office.

U.S. Department of Health and Human Services (1983). The health consequences of smoking: Cardiovascular disease. A report of the Surgeon General. Washington, DC: U.S. Government Printing Office.

U.S. Department of Health and Human Services (1984). The health consequences of smoking: Chronic obstructive lung disease. A report of the Surgeon General. Washington, DC: U.S. Government Printing Office.

U.S. Department of Heaith and Hurnan Services (1985). Cancer rates and risks. NIH Publication no.85-691. Washington, DC: Government Printing Office.

U.S. Department of Health and Human Services (1986). Integration of risk factor interventions. Monograph series, Office of Disease Prevention and Health Promotion. Washington, DC: Government Printing Office.

Van Assema, P. (1989). Bergeyk, een veldverkenning voor het opzetten van een gezondheidsproject (Bergeyk, a field orientation for the organization of a health project). Maastricht, the Netherlands: Vakgroep GVO, Rijksuniversiteit Limburg.

Van Assema, P., Brug, J., Kok, G., \& Brants, H. (1992c). The reliability and validity of a dutch questionnaire on fat consumption as a means to rank subjects according to individual fat intake. European Journal of Cancer Prevention, 1, 375-380.

Van Assema, P., Damoiseaux, V.M.G., \& Kok, G.J. (1987). Diffusie en cognitieve effecten van een publieksvoorlichtingsbrochure over kanker (Diffusion and cognitive effects of a public education brochure about cancer). GVO/Preventie, 8, 27-34. 
Van Assema, P., De Vries, H., \& Kok, G.J. (1992b). Kanker-preventieanderzoek met focus-groepinterviews (Cancer prevention research with focus group interviews). Gedrag en Gezondheid, 20, 10-22.

Van Assema, P., De Vries, H., Pieterse, M., \& Kok, G.J. (1990a). Kennis en opvattingen van de Nederlandse bevolking over de preventiemogelijkheden van kanker (Knowledge and views of the Dutch population about the prevention possibilities of cancer). Tijdschrift Sociale Gezondheidszorg, 68, 306-311.

Van Assema, P., Krijnen-Swinkels, I., \& Holdinga, Y. (1992d). De diëtiste aan huis: Tupperware-methode succesvol bij voedingsvoorlichting (The dietician at home: Tupperware-method successful in nutrition education). Tijdschrift Gezondheidsvoorlichting, 9, 10-12.

Van Assema, P., Mesters, I., \& Kok, G. (1992a). Het focusgroep-interview: een stappenplan (The focus group interview: Stepwise guidelines). Tijdschrift Sociale Gezondheidszorg, 70, 431-437.

Van Assema, P., Pieterse, M., Kok, G., Eriksen, E., \& De Vries, H. (1993). The determinants of four cancer-related risk behaviors. Accepted for publication in Health Education Research, 8.

Van Assema, P., \& Steenbakkers, M. (1990). Werkboek gezondheidsproject voor de gemeente Bergeyk (Workbook health project for the municipality of Bergeyk). Maastricht, the Netherlands: Vakgroep GVO, Rijksuniversiteit Limburg.

Van Assema, P., Steenbakkers, M., \& Vasse, R. (1990b). Stap voor stap minder vet, een voedingsinformatieprogramma (Step by step less fat, a nutrition information programl. Maastricht, the Netherlands: Vakgroep GVO, Rijksuniversiteit Limburg.

Van Assema, P., Steenbakkers, M., Kok, G., \& Eriksen, M. (submitted). The process evaluation of a Dutch community health project: What was done and how was this evaluated by participants and leaders of activities, project group members and the community in general. Maastricht, the Netherlands: Vakgroep GVO, Rijksuniversiteit Limburg.

Van Assema, P., Steenbakkers, M., Kok, G., Eriksen, M., \& De Vries, H. (submitted). Results of the Dutch community project 'Healthy Bergeyk'. Maastricht, the Netherlands: Vakgroep GVO, Rijksuniversiteit Limburg.

Van Assema, P., \& Willemsen, M. (1993). Community projecten (community projects). In V. Damoiseaux, H.T. van der Molen, \& G.J. Kok. (Eds.), 
Gezondheidsvoorlichting en gedragsverandering (Health education and changing behavior). Assen/Maastricht, the Netherlands: Van Gorcum.

Van den Brandt, P.A., Van de Crommert, S., Mordant-Dols, A. (1991). De bijdrage van voedingsmiddelen aan de consumptie van een aantal voedingsstoffen door de Nederlandse bevolking (The contribution of food products to the consumption of some nutrients by the Dutch population). Tijdschrift voor Sociale Gezondheidszorg, 69, 357-364.

Vartiainen, E., Puska, P. . Koskela, K., Nissinen, A., \& Toumilehto, J. (1986). Ten-year results of a community-based anti-smoking program (as part of the North Karelia Project in Finland). Health Education Research, 1, 175184.

Weenig, W.H. (1991). Information diffusion and persuasion in communication networks: The strength of weak and strong ties. Thesis, Leiden, the Netherlands.

Willett, W.C., Sampson, L., Stampler, M.J., Rosner, B., Bain, C., Witschi, J.. Hennekes, C.H., \& Speizer, F.E. (1985). Reproducibility and validity of a semiquantative food frequency questionnaire. American Journal of Epidemiology, 122, 51-65. 



\section{Summary}

Cancer is the second most frequent cause of death in the Netherlands. In the last few decades it has become clear that primary prevention of cancer is possible by reducing risk behavior in the general population.

This thesis describes the development, implementation and evaluation of a local cancer prevention intervention. The goal of the intervention was a reduction in the prevalence of four types of cancer-related risk behavior in the adult population: smoking, high fat consumption, excessive alcohol consumption and solarium use. The intervention was designed to integrate health education theory and methods with community organization principies, i.e. community participation, intersectoral co-operation, a social network approach, an environmental strategy, a multi-media and multi-method strategy and link up with the current situation in the community. The intervention was implemented in Bergeyk, a Dutch municipality in the province of Noord-Brabant with about 10,000 inhabitants. After a community analysis conducted by university staff, a local project group with representatives from eleven different sectors was formed. During a six-month period the project group organized several health activities in the community, such as stop smoking group courses, living room nutrition sessions, newspaper articles, an information center and a sandwich 'Healthy Bergeyk', which was sold in local cafetarias. The intersectoral project group was supported by a part-time local co-ordinator and used a workbook that included background information and guidelines and described about thirty possible health activities. Both an effect and a process evaluation of the community project were conducted. After the research period the project has been continued by the project group with a grant from local and provincial government.

Chapter 1 of this thesis provides an overview of the entire research project. First of all a summary of the present knowledge concerning the relationship between cancer and individual risk behavior is given. Subsequently, a broad outline of the different phases of the research project is provided and the main results are discussed. Finally, general conclusions of the research conducted are formulated and some methodological aspects are discussed. Several recommendations are given for those who intend to start a community health project and for the development of community projects in the Netherlands in general. 
In chapter 2 the results of a telephone survey conducted among a random sample of 1600 adults preceding the development of the intervention are reported. This survey was conducted to assess the determinants of the four cancer-related risk behaviors. The study also addressed the question whether the four risk behaviors were interrelated. The theoretical model that was used in this study was the 'Attitude - Social influence - Efficacy model' (ASE model). To operationalize the theoretical concept in this model, a pilot study was conducted using focus group interviews. For all four risk behaviors, subjects who performed the risk behavior were compared with subjects who did not with respect to attitudes, social influence and self-efficacy beliefs. Also, subjects who intended to change their risk behavior were compared with those who did not. The results indicated that, apart from small correlations between smoking and heavy alcohol consumption and between high fat consumption and heavy alcohol consumption, there were no significant relationships between the four risk behaviors. Therefore, no attempts were undertaken to study the determinants of a combination of risk factors. Furthermore, the results showed that the four types of risk behavior were determined by several factors: the perceived behavior of the social environment, individual attitudes towards the risk behavior, and self-efficacy perceptions on changing the risk behavior. High fat consumption differed from the other risk behaviors, in that people generally were not aware of their high fat consumption. Comparison between those who intended to change their risk behavior and those who did not, showed that the different determinants may vary in importance for people at different 'stages of change'. Based on the study findings, it was determined for each risk behavior which changes in determinants the intervention should emphasize. In addition, possible strategies to achieve these changes were devised.

In chapter 3 a short questionnaire on fat consumption is presented and on the basis of two studies of 52 and 639 men and women its relative validity regarding a 7-day diet record and its reproducibility are discussed. The questionnaire consists of 25 items covering 12 (groups of) food products. The questionnaire was designed to rank individuals according to dietary intake of fat and was specifically developed for measuring fat intake in the survey and in the effect evaluation of the local health project. A Pearson correlation of 0.59 was observed between fat intake estimated by 7-day diet records and fat score derived from the short questionnaire. Gross misclassification, defined as disagreement between the two fat consumption assessments beyond an adjacent tertile, was $15.4 \%$. A Pearson correlation of 0.71 was calculated by a 
test-retest procedure. It was concluded that the Dutch short questionnaire on fat consumption is a rapid, simple and inexpensive method that can very well be used in nutrition education research to rank individuals according to their dietary fat intake.

Chapter 4 reports the design and results of the effect evaluation of the project. In the effect evaluation the experimental community was compared with a control community with respect to changes in risk behavior. Data were collected from both communities among cohort research samples on three occasions using telephone interviews. The results indicated a significant reduction in fat intake in the experimental community. No other significant behavioral effects were found. Further analysis among respondents in the experimental condition showed that those personally exposed to the project as indicated by familiarity with and discussion about the project, had a greater decrease in fat consumption between baseline survey and second posttest than those who were not. Also, the percentage of smokers who quit between baseline survey and second posttest was greater among those who knew about the project than among those who did not. Finally, discriminant analysis was used to furthor examine the determinants of project exposure. Community involvement, marital status, education, and gender were related to project exposure.

Chapter 5 reports the design and results of the process evaluation of the project. The main objectives of the process evaluation were to assess what was done and how this was evaluated by participants and leaders of activities, project group members and the community in general. Data were gathered using minutes of meetings, registration forms, prestructured telephone interviews, written questionnaires, and semi-structured interviews. Community members were involved in the data collection. The results indicated that the project group organized many health activities in their community in a short time period. Familiarity with the project in the community was high. Positive elements of the project concerned the intersectoral co-operation and the workbook supplied to the project group. Time pressure and limited possibilities for community initiatives were the main negative aspects of the project. The implications of the findings for both the community health project and the process evaluation are discussed.

The main conclusion of this thesis is that with the limitations of the project in mind the results of the community project are encouraging. Although the project was only partially successful in reaching its behavioral objectives, the project led to effective, appreciated and integrated health promotive activities in the 
community at short notice and achieved high community awareness. Based on the findings it is recommended to develop similar projects in other Dutch communities. 


\section{Samenvatting}

Kanker is in Nederland de op één na meest voorkomende doodsoorzaak. In de laatste decennia is duidelijk geworden dat primaire preventie van kanker mogelijk is door het reduceren van risicogedrag bij de algemene bevolking.

Dit proefschrift beschrijft de ontwikkeling, implementatie en evaluatie van een kankerpreventie-interventie op lokạal niveau. Het doel van deze interventie was een reductie van de prevalentie van vier, aan kanker gerelateerde, risicogediagingen bij de volwassen bevolking: roken, hoge vetconsumptie, excessief alcoholgebruik en het gebruik van solaria. De interventie was ontworpen om theorieën en methoden, die bij de ontwikkeling van GVO-interventies vaak worden gebruikt, te integreren met zogenaamde 'community organisatie' principes, te weten bevolkingsparticipatie, intersectorale samenwerking, een sociale netwerk benadering, een omgevingsgerichte strategie, hot gebruik van meerdere media en meerdere methoden en het aansluiten bij de bestaande lokale situatie. De interventie werd geïmplementeerd in Bergeyk, een gemeente in do provincie Noord-Brabant met ongeveer 10.000 inwoners. Naar aanleiding van een analyse van de gemeente werd een lokale projectgroep geformeerd met daarin vertegenwoordigers van elf verschillende sectoren. Deze projectgroep organiseerde gedurende zes maanden diverse gezondheidsactiviteiten in Bergeyk, zoals stoppen-met-roken cursussen, voedingsvoorlichtingsavonden bij inwoners thuis, publikatie van berichten in plaatselijke media, de opzet van een informatiecentrum en het aanbod van een broodje 'Gezond Bergeyk' door enkele lokale cafetaria's. De intersectorale projectgroep werd ondersteund door een lokale coördinator. Daarnaast gebruikte de projectgroep een werkboek waarin achtergrondinformatie en richtlijnen voor de te volgen werkwijze stonden on waarin ongeveer dertig mogelijke gezondheidsactiviteiten werden beschreven. Het lokale project werd zowel op effect als op proces geèvalueerd. $\mathrm{Na}$ de onderzoeksperiode kreeg de projectgroep subsidie van de gemeente Bergeyk en de provincie Noord-Brabant waardoor het project door de projectgroep kon worden gecontinueerd.

In hoofdstuk 1 van dit proefschrift wordt een overzicht gegevon van het gehele onderzoeksproject. Er wordt een globale schets van de opzet van de verschillende fasen van het onderzoeksproject gegeven en de belangrijkste. resultaten worden besproken. Vervolgens worden de conclusies van het onderzoek geformuleerd en komt een aantal methodologische beperkingen van het 
onderzoek aan de orde. Tenslotte worden enkele aanbevelingen gegeven voor het opzetten van een lokaal gezondheidsproject en voor de ontwikkeling van lokale gezondheidsbevordering in het algemeen.

In hoofdstuk 2 worden de opzet en resultaten van een gedragsdeterminantenonderzoek gerapporteerd. Dit onderzoek vond plaats voorafgaande aan de ontwikkeling van de interventie. Het onderzoek werd verricht om de determinanten van de vier aan kanker gerelateerde risicogedragingen te bepalen. Het onderzoek richtte zich ook op de vraag of, en in welke mate, de vier risicogedragingen aan elkaar waren gerelateerd. Het theoretische model dat aan dit onderzoek ten grondslag lag was het 'Attitude-Sociale invloed-Eigen effectiviteit' model (ASE model). Focusgroepinterviews werden gebruikt om de concepten van dit theoretische model te operationaliseren. Door middel van telefonische interviows werden gegevens verzameld bij een steekproef van 1600 volwassen uit de Nederlandse bevolking. Voor alle vier de risicogedragingen werden respondenten die het risicogedrag vertoonden, vergeleken met respondenten die het risicogedrag niet vertoonden met betrekking tot attitude, sociale invloed en eigen effectiviteit. Ook werden respondenten die de intentie hadden hun risicogedrag te veranderen, vergeleken met respondenten die deze intentie niet hadden. De resultaten toonden aan dat - afgezien van kleine correlaties tussen excessief alcoholgebruik en respectievelijk roken en hoge vetconsumptie - er geen significante relaties waren tussen de vier genoemde risicogedragingen. Om deze reden werden pogingen om de determinanten van een combinatie van risicofactoren te bestuderen niet ondernomen. Voorts bleek dat de vier risicogedragingen werden bepaald door verschillende factoren: het waargenomen gedrag van de sociale omgeving, individuele attitudes ten aanzien van het gedrag en eigen-effectiviteitspercepties ten aanzien van het veranderen van het risicogedrag. Het belang van deze factoren varieerde afhankelijk van de fase van gedragsverandering waarin de respondenten zich bevonden. Het risicogedrag 'hoge vetconsumptie' verschilde van de andere risicogedragingen, in die zin dat de respondenten zich over het algemeen niet bewust waren dat ze dit risicogedrag vertoonden. Op basis van de onderzoeksgegevens werd voor ieder risicogedrag bepaald op welke determinanten de interventie zich met name zou moeten richten. Ook mogelijke strategieën om deze veranderingen te realiseren, werden bedacht.

In hoofdstuk 3 wordt een korte vragenlijst beschreven die werd ontworpen om individuen te rangschikken naar vetconsumptie. Deze vragenlijst werd specifiek ontwikkeld om te worden gebruikt in het gedragsdeterminantenonderzoek en de 
effectevaluatie van het lokale gezondheidsproject. De vragenlijst bestond uit 25 vragen over 12 (groepen) voedingsmiddelen. Op basis van twee studies onder respectievelijk 639 en. 52 volwassenen, wordt de reproduceerbaarheid en de relatieve validiteit van dit meetinstrument in vergelijking met een zevendaagse dagboekmethode besproken. Een Pearson correlatie van 0.59 werd gevonden tussen vetconsumptie als geschat door de zevendaagse dagboekmethode en de vetscore ontleend aan de korte vragenlijst. Bij $15.4 \%$ van de respondenten was er sprake van een groot verschil tussen de vitkomst van de dagboekmethode en de uitkomst van de korte vragenlijst. Een Pearson correlatie van 0.71 werd gevonden bij een test-hertest procedure. Geconcludeerd werd dat de korte vragenlijst een snelle, eenvoudige en goedkope methode is die goed kan worden gebruikt in voedingsvoorlichtingsonderzoek om individuen te rangschikken naar vetconsumptie.

In Hoofdstuk 4 worden de opzet en resultaten van de effectevaluatie van het lokale gezondheidsproject beschreven. In de effectevaluatie werd de experimen. tele gemeente vergeleken met een controle gemeente met betrekking tot veranderingen in de vier genoemde risicogedragingen. In beide gemeenten werden op drie momenten, door middel van telefonische enquêtes, gegevens verzameld bij een cohort onderzoeksgroep van enkele honderden volwassen inwoners. De resultaten lieten een significante daling van de vetconsumptie in de experimentele gemeente zien. Andere gedragseffecten werden niet gevon. den. Uit nadere analyses onder de respondenten uit de experimentele gemeente bleek dat degenen die waren blootgesteld aan het project een grotere reductie in vetconsumptie tussen de voormeting en de tweede nameting hadden dan degenen die niet waren blootgesteld. Verder was het percentage rokers dat stopte tussen de voormeting en de tweede nameting groter onder de groep rokers die het project kende, dan onder de groep rokers die het project niet kende. Tenslotte werden met behulp van een discriminantanalyse de determinanten van bekendheid met het project bestudeerd. Burgelijke staat, opleidingsniveau, mate van betrokkenheid bij het plaatselijk gebeuren en geslacht waren gerelateerd aan het al dan niet kennen van het project.

In Hoofdstuk 5 worden de opzet en resultaten van de procesevaluatie van het project beschreven. De belangrijkste doelstelling van de procesevaluatie was na te gaan hoe het project verliep en hoe dit werd geëvalueerd door deelnemers en leiders van activiteiten, projectgroepleden en de inwoners van Bergeyk in het algemeen. De gegevens werden verzameld met behulp van registratieformulieren, voorgestructureerde telefonische enquêtes, schriftelijke vragenlijsten, 
notulen van vergaderingen en semi-gestructureerde interviews. Inwoners van Bergeyk waren betrokken bij de gegevensverzameling. Uit de resultaten bleek dat de projectgroep in korte tijd veel gezondheidsactiviteiten organiseerde. De bekendheid van het project in de gemeente was hoog. Positief gewaardeerde elementen van het project waren de intersectorale samenwerking en het werkboek dat aan de projectgroep werd verstrekt. Gebrek aan tijd en de beperkte mogelijkheden voor initiatieven van inwoners waren de belangrijkste negatieve aspecten van het project. De implicaties van de resultaten voor zowel het lokale gezondheidsproject als de procesevaluatie worden besproken.

De belangrijkste conclusie van dit proefschrift is dat, rekening houdend met de beperkingen van het project, de resultaten van het lokale project bemoedigend zijn. Het project was slechts gedeeltelijk succesvol in het realiseren van de gedragsveranderingsdoelen. In korte tijd werden echter effectieve, gewaardeerde en geïntegreerde gezondheidsbevorderende activiteiten in de gemeente bewerkstelligd en de bekendheid van het project was groot. Op basis van de resultaten wordt aanbevolen gelijksoortige projecten te ontwikkelen in andere gemeenschappen. 


\section{Annex 1}

Examples of questions on behavioral determinants:

- Indirect attitude.

For example "do you think that smoking helps to keep your weight down?" or "do you think smoke smells good or bad?".

Items were measured either on a unipolar three-point scale $(-2,0$ or 0,2$)$, i.e. helps to keep down, helps slightly to keep down, does not help to keep down/don't know, or a bipolar five-point scale $(-2,2)$, i.e. smells good, smells slightly good, neutral/don't know, smells slightly bad, smells bad.

- Direct attitude.

For example: "do you think smoking is good or bad?" and "do you think smoking is pleasant or unpleasant?".

Items were measured on a bipolar five-point scale $(-2,2)$, i.e. good, slightly good, neutral/don't know, slightly bad, bad.

- Behavior of the social environment.

For example: "are there many or a few people in your social environment who smoke?".

Items were measured on a bipolar five-point scale $(-2,2)$, i.e. many, rather many, neutral/don't know, rather few, few.

- Indirect subjective norm.

For example: 1. "as far as smoking is concerned, to whom do you give in to?" and 2. "Does (your partner, your daughter, your colleague, etc.) think you should smoke or not smoke?".

The second question was only stated if the respondent indicated to give in to one or more people. The second question was measured on a bipolar fivepoint scale $(-2,2)$, i.e. thinks I should certainly smoke, thinks I should smoke, neutral/don't know, thinks I should not smoke, thinks I should certainly not smoke.

- Self-efficacy.

For example: "is it difficult or easy for you not to smoke while you are at a party?".

Items were measured on a bipolar five-point scale $(-2,2)$, i.e. difficult, slightly difficult, don't know/neutral, slightly easy, easy. 
Before asking the questions, the risk behaviors were formulated to the respondent as "smoking cigarettes", "regularly drinking six or more glasses of alcohol a day" and "regularly using a solarium". For the questions on fat consumption a description was given first of a high-fat eating pattern and a lowfat eating pattern. All the questions were subsequently formulated on the highfat eating pattern. 


\section{Curriculum vitae}

Patricia van Assema was born on December 23, 1962 in Haarlem. In 1981 she received her VWO diploma at the Veluws College in Apeldoorn. In that same year she started studying Health Sciences at the University of Limburg. In 1985 she graduated, specializing in Health Education. During the first haif-year after graduating she worked at the Department of Health Education of the University of Limburg on the evaluation of a pamphlet of the Dutch Cancer Society (Nederlandse Kankerbestrijding/KWF). In 1986 and 1987 she was a social oncology fellow of the Dutch Cancer Society, specializing in public education on primary prevention of cancer. From 1988 to 1991 she was employed as research associate at the Department of Health Education. In this period she conducted the study described in this thesis. In 1992 a temporary position as university teacher followed at the Department of Health Education. Since January 1993 she has been working as a post-doc at the Department of Health Education by means of a centrum grant for stimulating social scientific nutrition research, which is financed by the Dutch Heart Foundation INederlandse Hartstichting) and adjudged by the Dutch Organization for Scientific Research (NWO). 
